\title{
VILLE \\ Containment Data Report
}

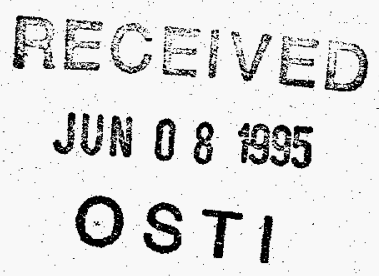

T. Stubbs

R. Heinle

March 1995

This is an informal report intended primarily for internal or limited external distribution. The op inions and conclusions stated are those of the author and may or may not be those of the Laboratory.

Work performed under the auspices of the Department of Energy by the Lawrence Livermore National Laboratory under Contract W-7405-Eng-48.

\author{
R. Heinle
}

March 1995

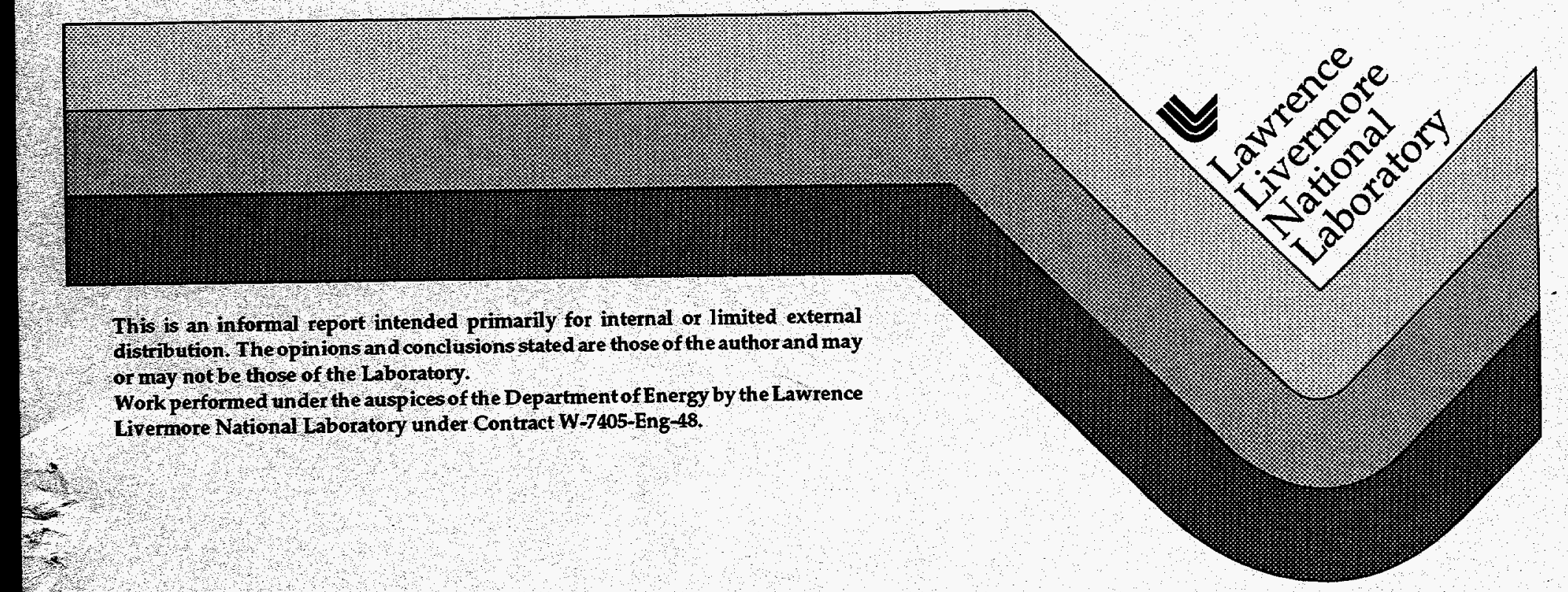




\section{DISCLAIMER}

This report was prepared as an account of work sponsored by an agency of the United States Government. Neither the United States Government nor any agency thereof, nor any of their employees, make any warranty, express or implied, or assumes any legal liability or responsibility for the accuracy, completeness, or usefulness of any information, apparatus, product, or process disclosed, or represents that its use would not infringe privately owned rights. Reference herein to any specific commercial product, process, or service by trade name, trademark, manufacturer, or otherwise does not necessarily constitute or imply its endorsement, recommendation, or favoring by the United States Government or any agency thereof. The views and opinions of authors expressed herein do not necessarily state or reflect those of the United States Government or any agency thereof. 


\section{DISCLAIMER}

Portions of this document may be illegible in electronic image products. Images are produced from the best available original document. 
VILLE Instrumentation Summary

\begin{tabular}{|c|c|c|c|}
\hline Instrumentation & $\begin{array}{l}\text { Fielded on } \\
\text { this Event }\end{array}$ & $\begin{array}{c}\text { Data } \\
\text { Return }\end{array}$ & $\begin{array}{l}\text { Present in } \\
\text { this Report }\end{array}$ \\
\hline Plug Emplacement & yes & yes & yes \\
\hline Radiation & yes & yes & yes \\
\hline Pressure & & & \\
\hline Stemming & yes & yes & yes \\
\hline Challenge & yes & yes & yes \\
\hline Cavity & no & - & - \\
\hline Atmospheric & no & - & - \\
\hline Motion & & & \\
\hline Free Field & no & - & - \\
\hline Surface & yes & yes & yes \\
\hline Plug & yes & yes & yes \\
\hline Stemming & yes & yes & yes \\
\hline Surface Casing & yes & yes & yes \\
\hline Emplacement Pipe & yes & yes & yes \\
\hline Hydrovield (a) & yes & yes & no \\
\hline Collapse (b) & yes & yes & yes \\
\hline Stress & yes & yes & yes \\
\hline Strain $(c)$ & yes & yes & $?$ \\
\hline Other Measurements (d) & yes & yes & ? \\
\hline
\end{tabular}

(a) CORTEX or SLIFER in emplacement hole.

(b) EXCOR or CLIPER in emplacement hole.

(c) Emplacement pipe.

(d) Gas temperature.

\section{Event Personnel}

\section{Containment Pmusics}
B. Hudson
LLNL
V. Wheeler
LLNL
J. Kalinowski
EG\&G/AVO
T. Stubbs

Instumentation

$\begin{array}{ll}\text { C. Cordill } & \text { LLNL } \\ \text { R. Salazar } & \text { EG\&G/AVO } \\ \text { A. Moeller } & \text { EG\&G/NVO } \\ \text { W. Webb } & \text { EG\&G/NVO }\end{array}$




\section{Contents}

1. Event Description

1.1 Site

1.2 Instrumentation

2. Emplacement

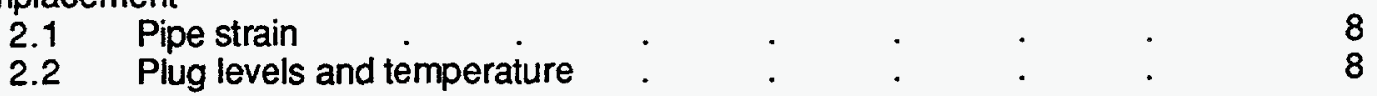

3. Stemming Pertormance

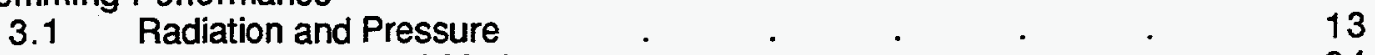

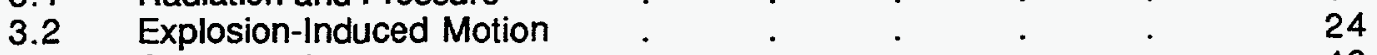

3.3 Collapse phenomena . . . . . . . . . 42

4. Other Measurements $4.1 \quad$ Gas temperature in the challenge pressure hose $\quad$. $\quad . \quad 59$

4.2 Stress and strain in the deepest plugs. $\quad . \quad . \quad . \quad 59$

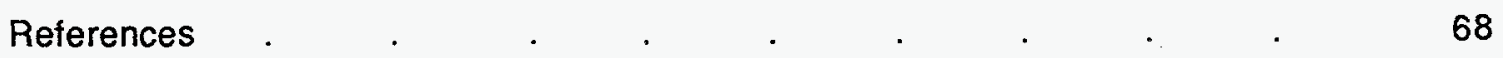




\section{Event Description}

\subsection{Site}

The VILLE event was detonated in hole U4am of the Nevada Test Site as indicated in Fig. 1.1. A plan view map of the local region around hole U4am indicating the inferred faults and drill holes is shown in figure 1.2. The device had a depth-of-burial of $293 \mathrm{~m}$ in the alluvium of Area 4, about $240 \mathrm{~m}$ above the standing water level (SWL), as shown in Figure $1.3^{(1)}$. Stemming of the $2.44 \mathrm{~m}$ diameter emplacement hole followed the plan shown in Fig. 1.4. A $\log$ of the stemming operations was maintained by Holmes \& Narver (2).

Detonation time was 08:15 PDT on June 13,1985 and about 28 minutes later the chimney collapsed to the surface leaving a crater with a mean radius of $59.7 \mathrm{~m}$ and a maximum depth of $17.3 \mathrm{~m}$.

No radiation arrivals were detected in the emplacement hole and the VILLE containment was considered successful.

\subsection{Instrumentation}

Figure 1.5 is a schematic layout of the instrumentation designed to monitor the emplacement procedures and stemming performance of the VILLE event.

Three of the five stemming plugs (the first, fourth and fifth) were composed of coarse gypsum aggregate in a gypsum cement slumy. Each of these three gypsum-filled-aggregate (GFA) plugs was monitored during emplacement with arrays of conductivity probes and thermistors. The remaining two plugs were soft, coal tar aggregate (CT/A) gas seal membranes having a thickness of about $1.5 \mathrm{~m}$ sandwiched between layers of fines material. $A$ layer of CT/A was poured on the top of each of the top two GFA plugs.

The coarse stemming beneath every plug except the third was instrumented with pressure and radiation stations. Included in this were three stations designed to monitor the pressure and radiation challenging the bottom plug (plug 1). Station 32 was mounted about $25 \mathrm{~m}$ above the top of plug 1 and connected to the environment below the plug through a section of gas sample hose (about $45 \mathrm{~m}$ long). Station 31 was connected to the same hose, 
but mounted in the plug near its bottom surface. A second section of gas sample hose extended below the plug from a location near the plug center where station 88 was located. This hose was pre-pressurized to about 60 psi before the event. The deepest soft CT/A plug was instrumented below, within and above for pressure, radiation and vertical motion. Similar stations containing pressure, radiation and vertical motion sensors were fielded below the top two GFA plugs and in the stemming between the bottom plug and the deepest CT/A plug.

Vertical motion was monitored in plugs 4 , and 5 , on the surface casing, on the top of the emplacement pipe, and at $0.61 \mathrm{~m}$ depth in the ground surface, $15.24 \mathrm{~m}$ from SGZ. Displacement between the surface casing and the top plug was monitored by an array of proximity switches located in the plug at the bottom of the surface casing.

Stress and strain of the bottom two plugs (both the GFA and CT/A elements) was monitored at four stations.

Data from each of the above transducers were transmitted to the recording trailer by an analog system and recorded on magnetic tape.

Two CLIPER/CORRTEX sensors were emplaced, as indicated in figure 1.5 , to measure the hydrodynamic yield of the device and to monitor cavity collapse and chimney formation. Results of the yield measurements are reported elsewhere $(3)$.

A history of the fielding operations of the instrumentation, including the emplacement pipe strain measurements, is outlined in reference 4. Details of the instrumentation are given in reference 5. 


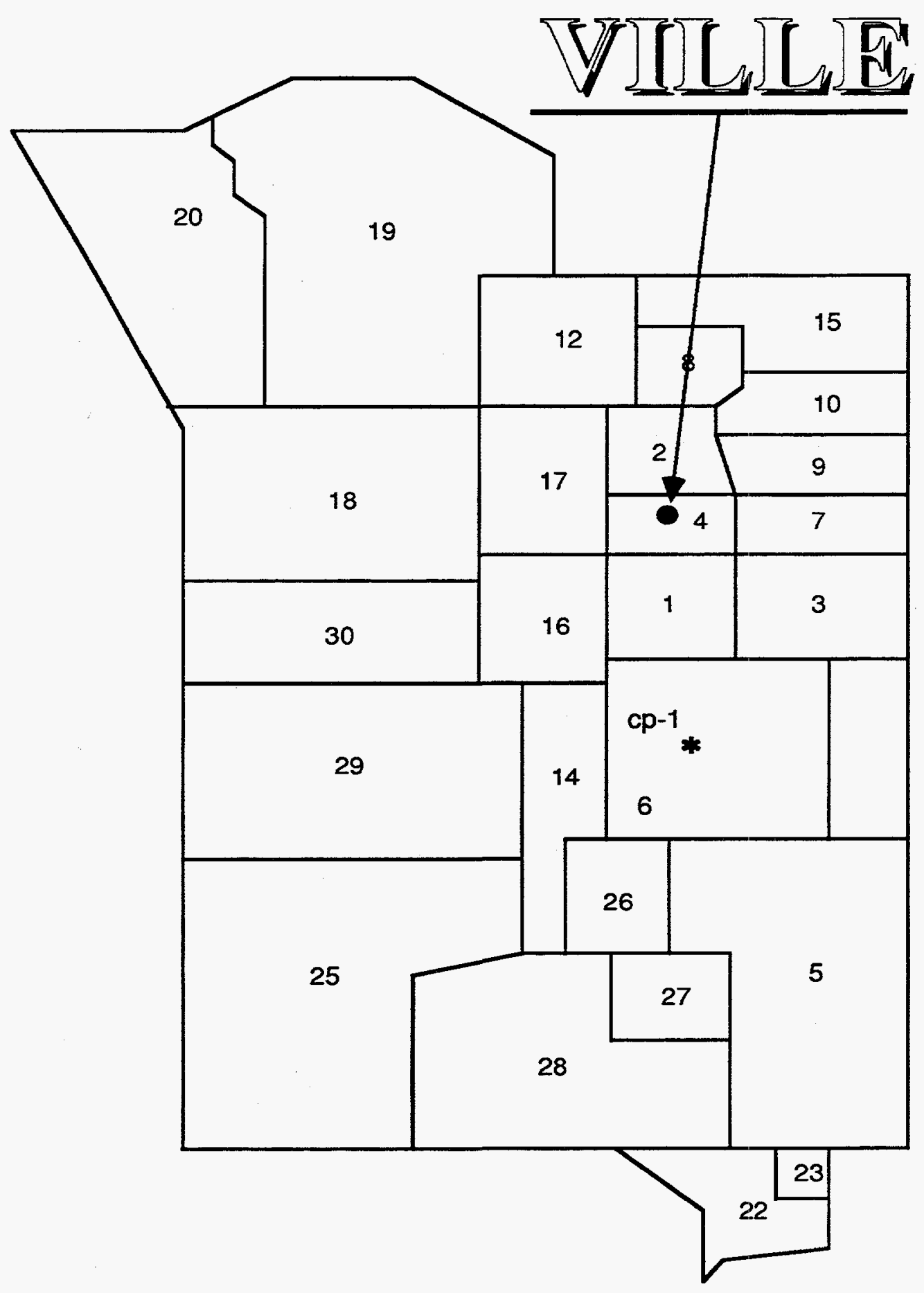

Figure 1.1 Map of the Nevada Test Site indicating the location of hole U4am. 


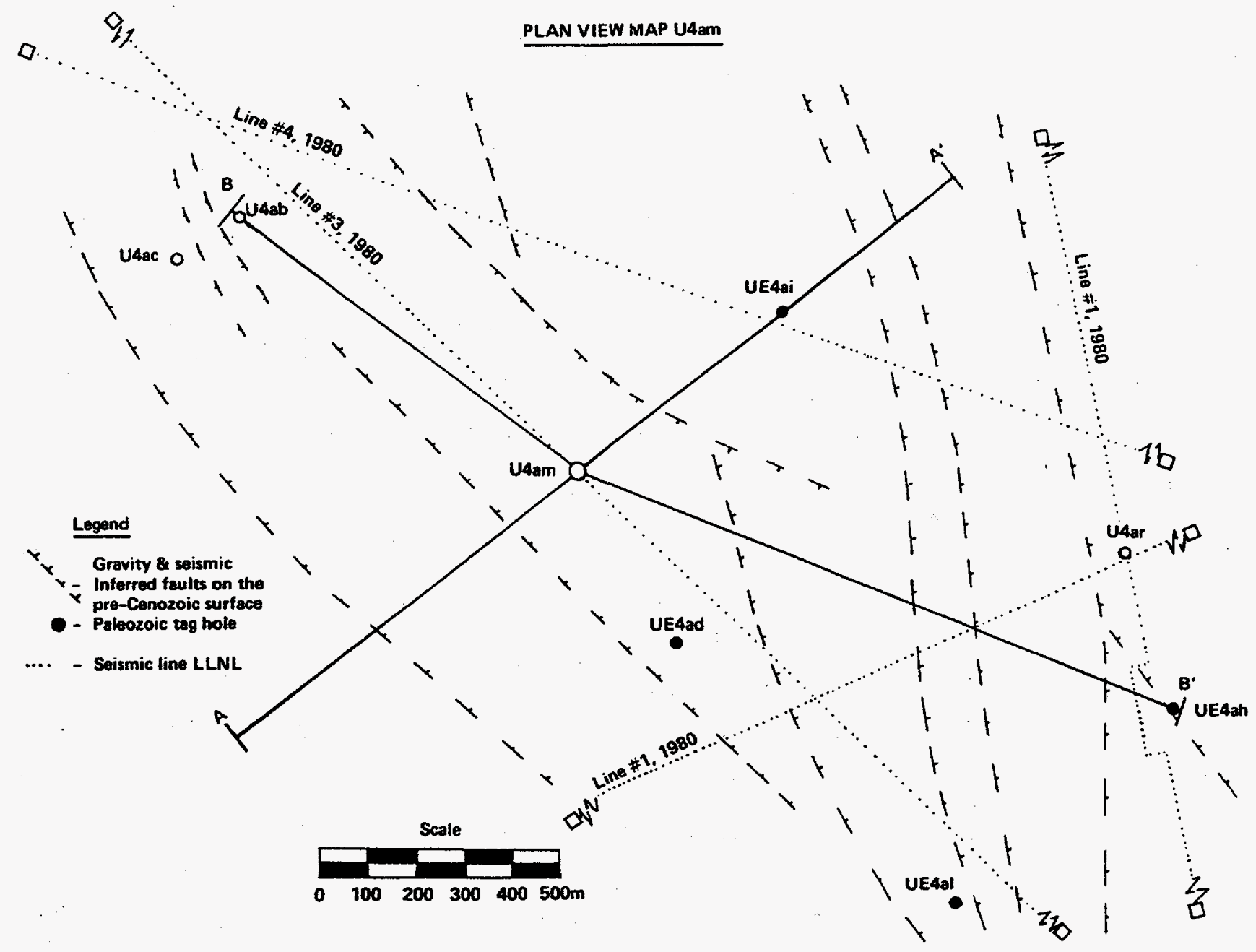

Figure 1.2 Plan view map of the U4am site. 

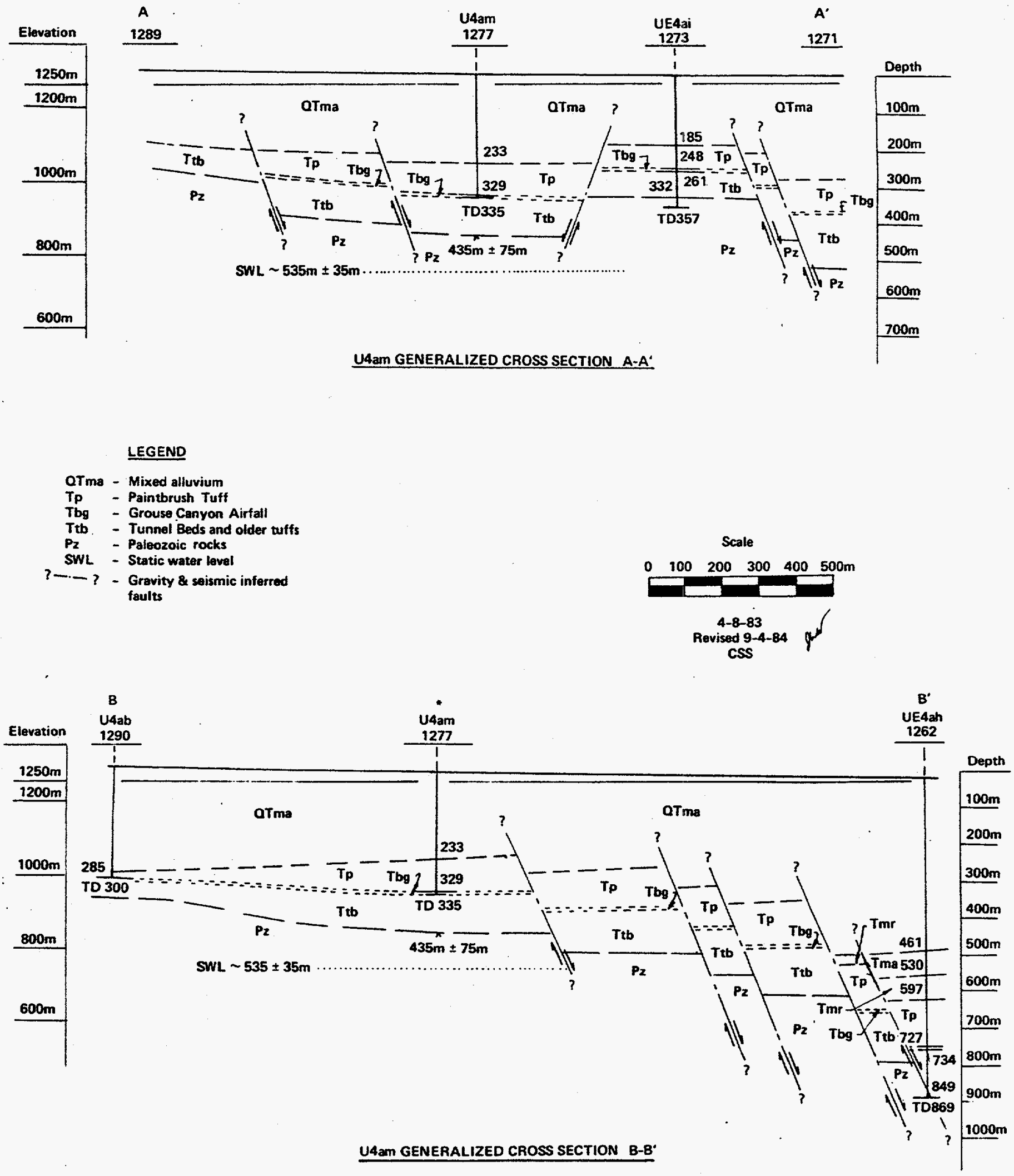

Figure 1.3 Geologic cross sections through hole U4am. 


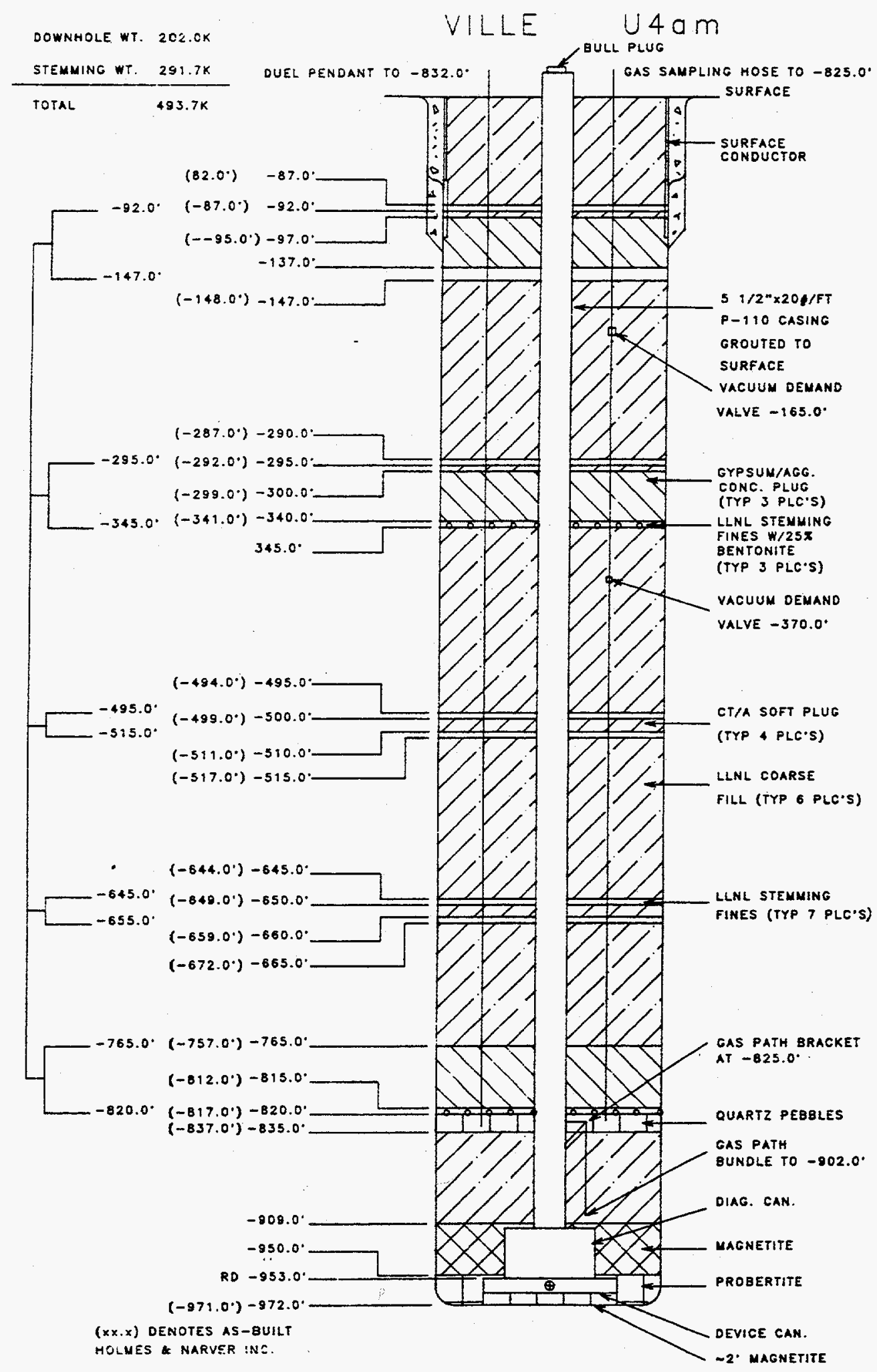

Figure 1.4 As-built stemming plan for the event VILLE in Hole U4am. 


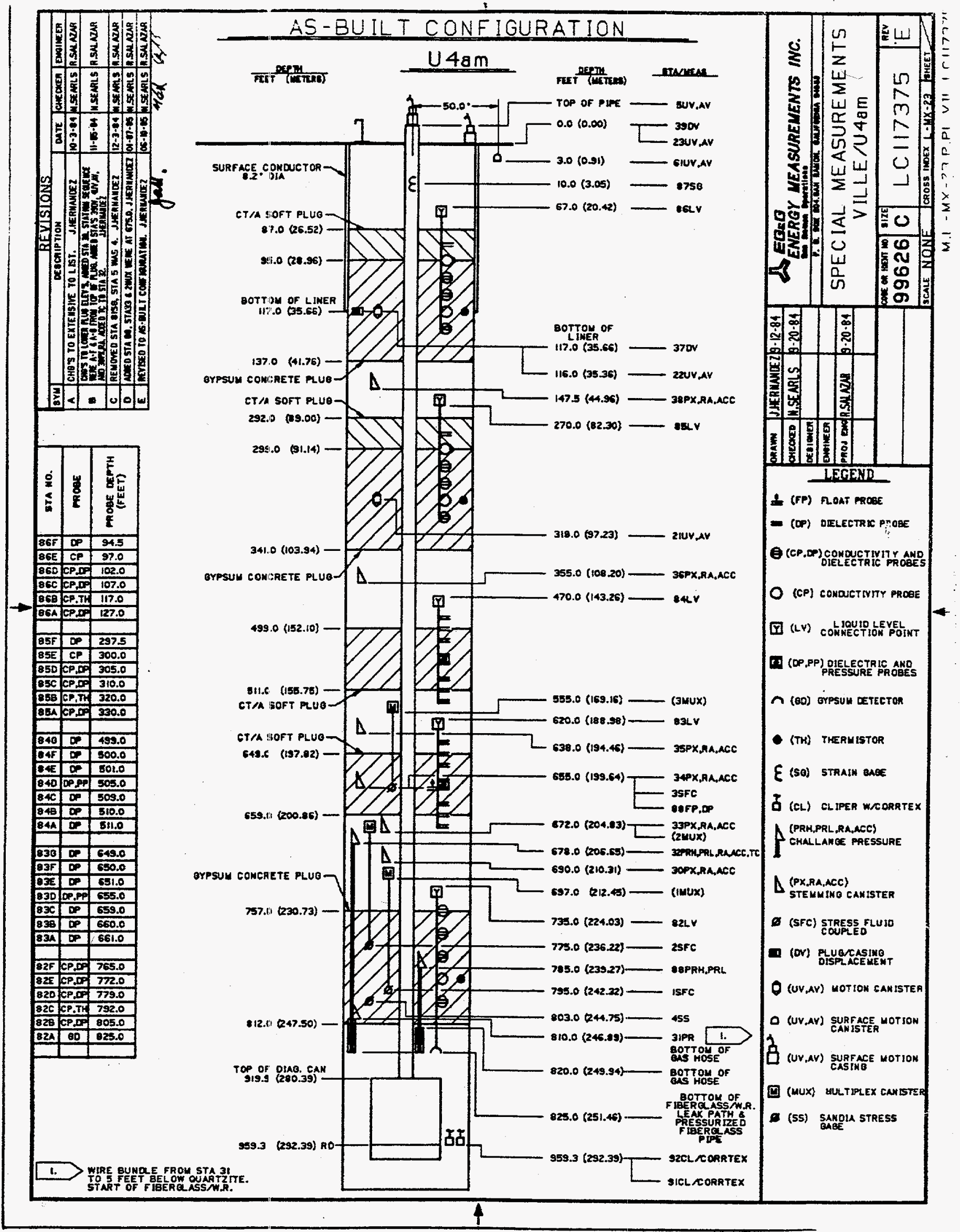

Figure 1.5 As-built containment instrumentation plan for the VILLE event. 


\section{Emplacement}

\subsection{Pipe strain}

Figure 2.1 is the strain history measured on the emplacement pipe during stemming of the VILLE experiment. The emplacement pipe was instrumented with a strain gage station on the final pipe section just below the load collar (Station 87).

\subsection{Plug levels and temperature}

The emplacement of each of the three gypsum concrete plugs was monitored with an array of dielectric and conductivity probes and thermistors. The locations of the probes are tabulated in figure 1.5. The upper and lower boundary positions of the plugs were determined by tag lines. Figures 2.2 through 2.4 contain plots of the arrival times of the GFA slurry as a function of depth (as determined from the conductivity probes and tag lines) and GFA temperature histories. A temperature sensor was located at the approximate mean depth of each concrete plug. These data indicate that all plugs were emplaced as planned. 

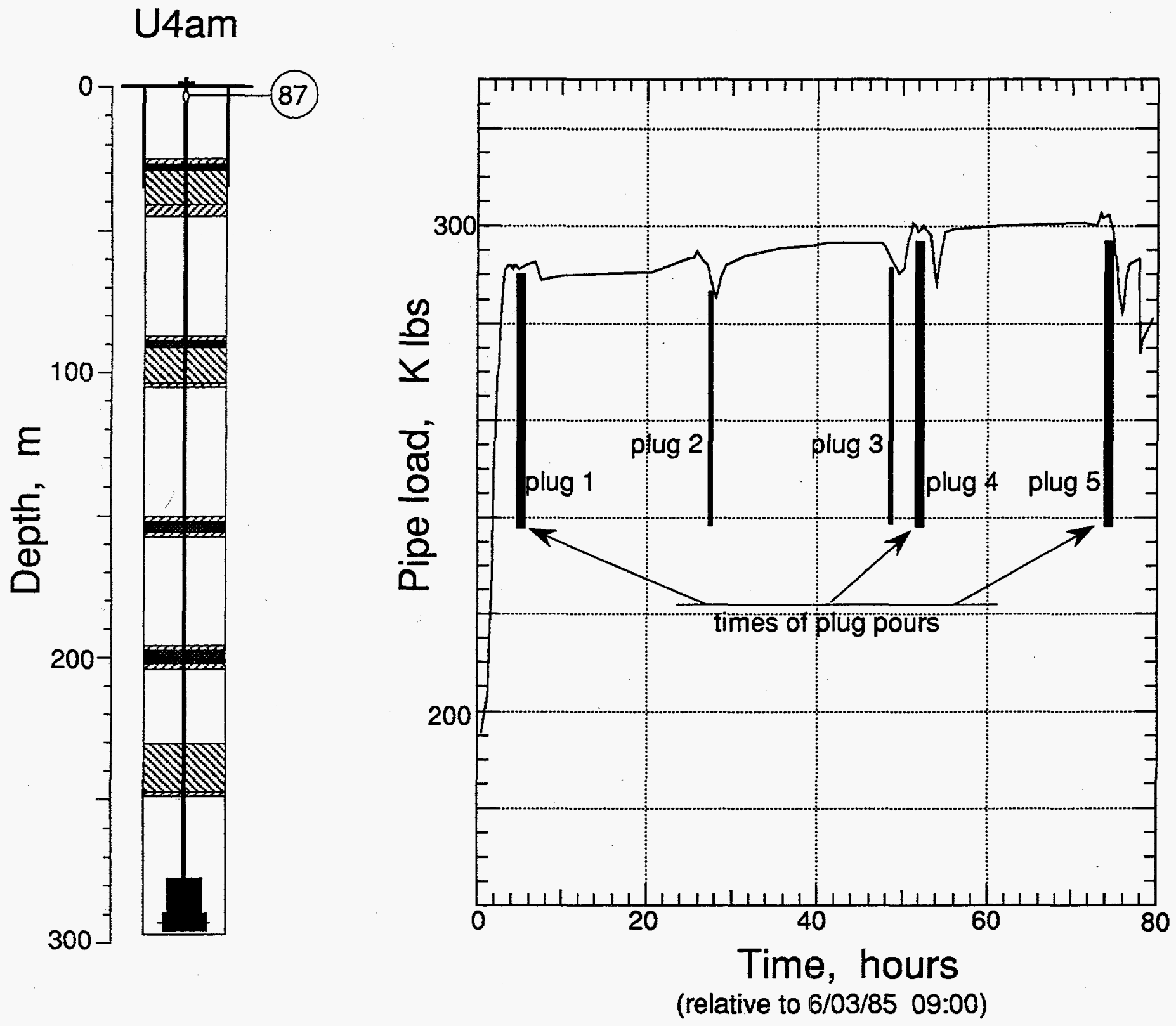

Figure 2.1 Strain measurements during the stemming at stations 87 (near the top of the pipe). 


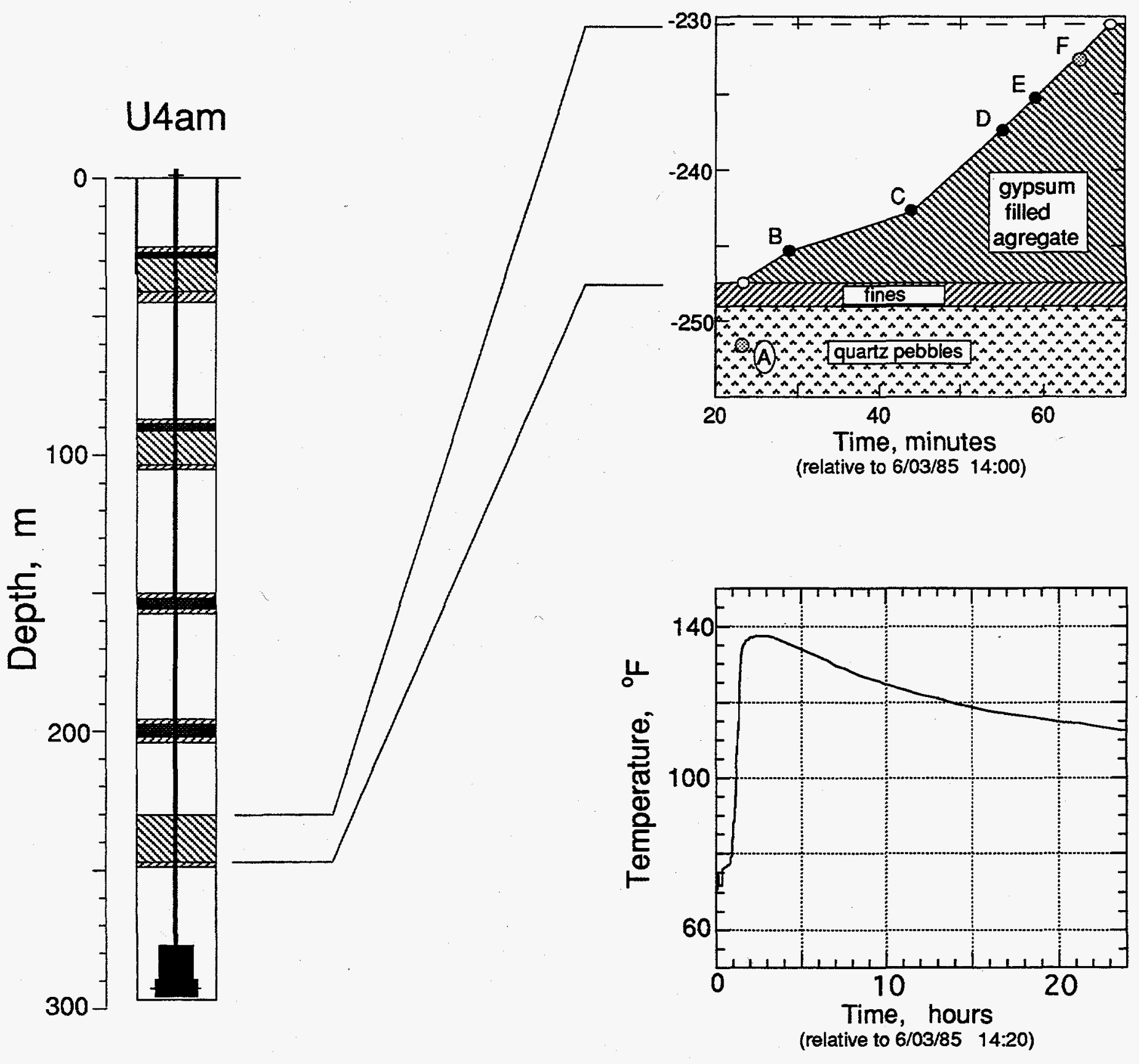

Figure 2.2. Emplacement diagnostics data at GFA plug 1. The upper and lower boundaries of the plug were determined with a tag line. Solid symbols indicate the elevation of the probes, shaded symbols indicate only the elevations of probes that were not contacted (the contact times are fictional), and the open symbols are at the tag depths. A temperature sensor was located at probe " $\mathrm{C}$ ". 

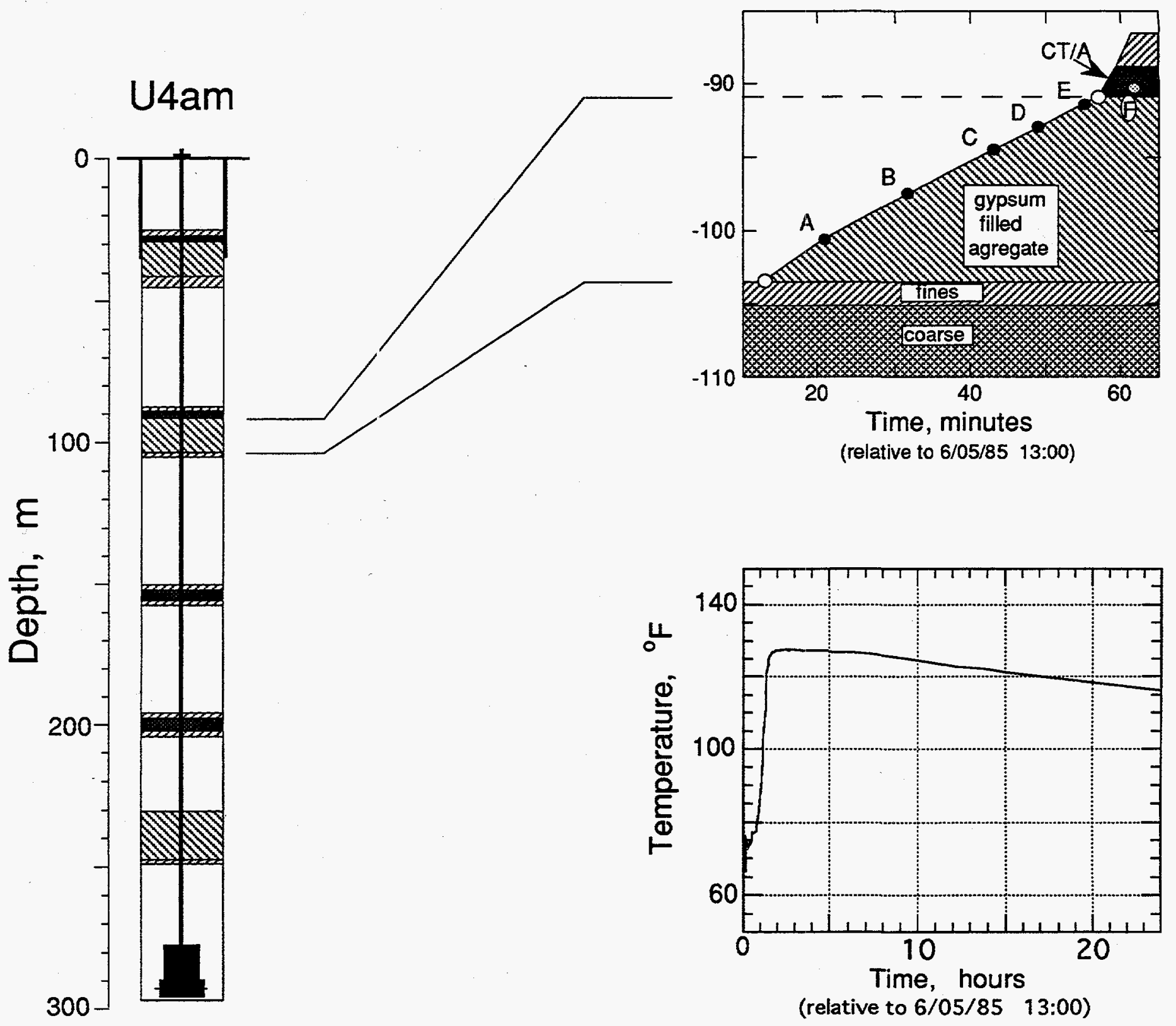

Figure 2.3. Emplacement diagnostics data at GFA plug 4. The upper and lower boundaries of the plug were determined with a tag line. Solid symbols indicate the elevation of the probes, shaded symbols indicate only the elevations of probes that were not contacted (the contact times are fictional), and the open symbols are at the tag depths. A temperature sensor was located at probe "B". 


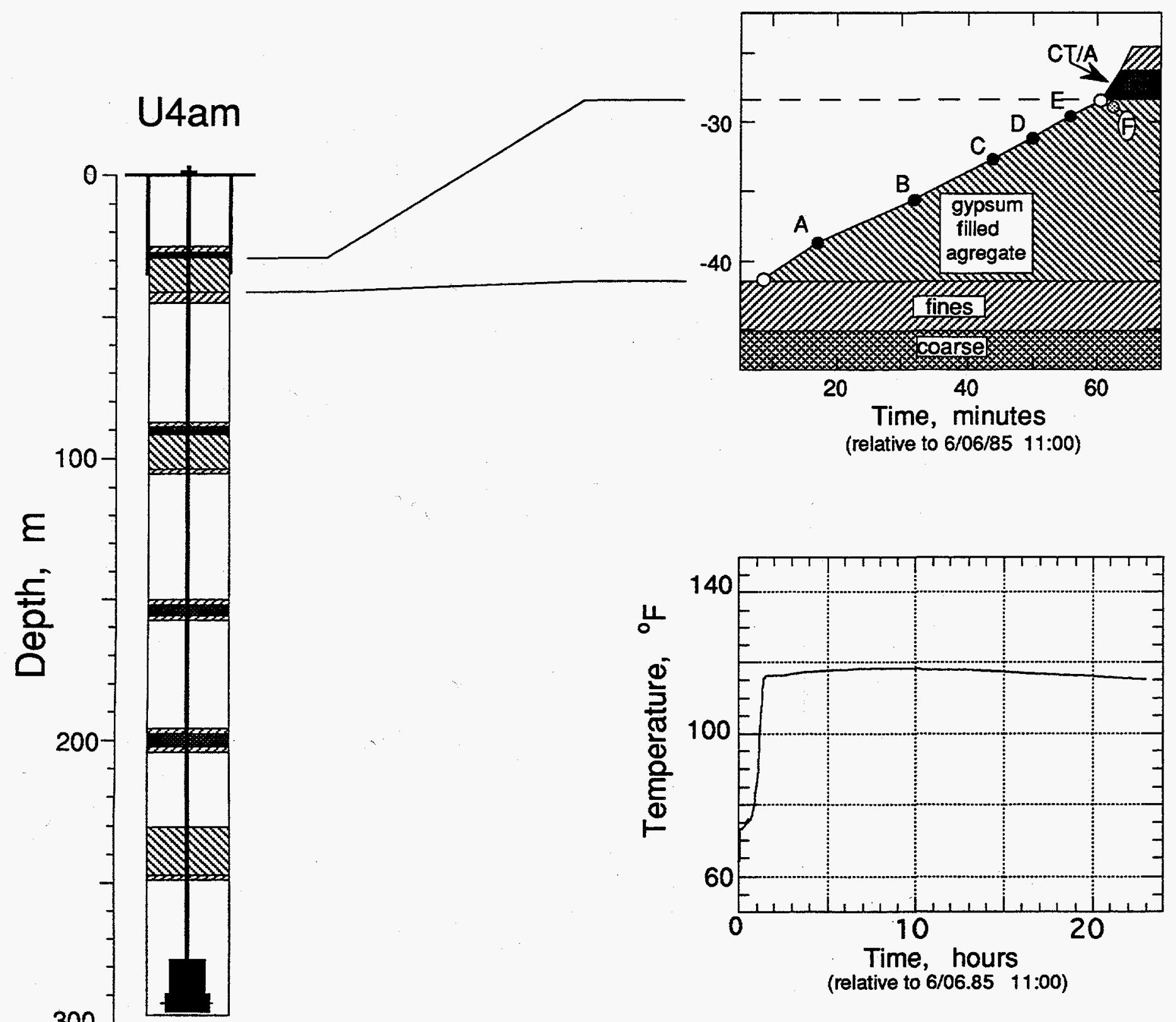

Figure 2.4. Emplacement diagnostics data at GFA plug 5. The upper and lower boundaries of the plug were determined with a tag line. Solid symbols indicate the elevation of the probes, shaded symbols indicate only the elevations of probes that were not contacted (the contact times are fictional), and the open symbols are at the tag depths. A temperature sensor was located at probe " $\mathrm{B}$ ". 


\section{Stemming Performance}

\subsection{Radiation and Pressure}

As seen in figure 1.5, the region near each GFA plug (except the deepest) was monitored by pressure and radiation stations. The signals were transmitted to the recording trailer in analog form and recorded on magnetic tape for later processing.

Pressure and radiation histories from a few seconds before detonation until loss of signal at cavity collapse (about 28 minutes later) are shown in figures 3.1-3.9.

Challenge pressure was monitored at three stations $(88,31$ and 32 ; figures $3.1,3.3$ and 3.4 , respectively). A direct comparison of the wave forms from stations 88 and 32 is shown in figure 3.10 wherein it is indicated that the two sensors register a difference of about 3 psi over the entire time span (after the initial pressurization of station 88 is eliminated). This pressure difference may be due the different mounting conditions of the stations: both were at the end of sections of gas sample hoses with the hose of station 32 being $32.6 \mathrm{~m}$ longer than that of station 88 , including $24 \mathrm{~m}$ in the coarse stemming. No explanation is made for the wave form seen at station 31 (monitoring the same gas sample hose as station 32), which was expected to resemble those of stations 88 and 32 .

Pressure measured in the coarse stemming on either side of the deepest CT/A gas seal plug (stations 33 and 35; figures 3.5 and 3.7, respectively) indicate that a pressure differential of about 3 psi was maintained across the plug. The pressure within the soft CT/A plug 2 was monitored by station 34 (figure 3.6). Essentially no pressure was registered at this station.

No radiation above ambient was observed at any station in the emplacement hole.

All pressure and radiation data are consistent with satisfactory containment. 

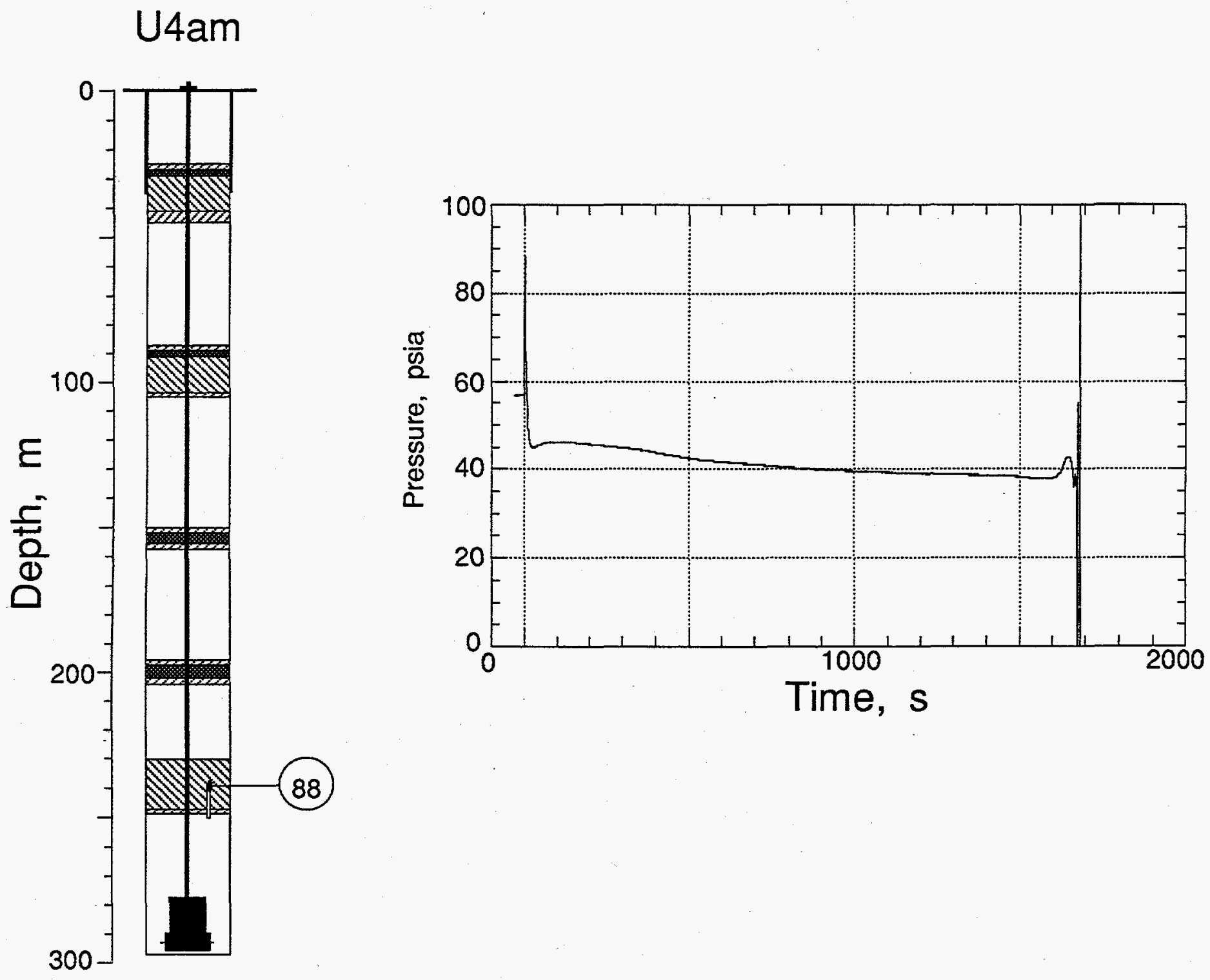

Figure 3.1 Pressure challenging the deepest plug (station 88 ) at a depth of $246.9 \mathrm{~m}$. Gas pressure was sensed through a section of wire rope (gas sample hose) that was pre-pressurized to about 57 psi. Sensor was emplaced within the GFA plug at a depth of $239.3 \mathrm{~m}$. Signals were lost at collapse time (1675 s). 

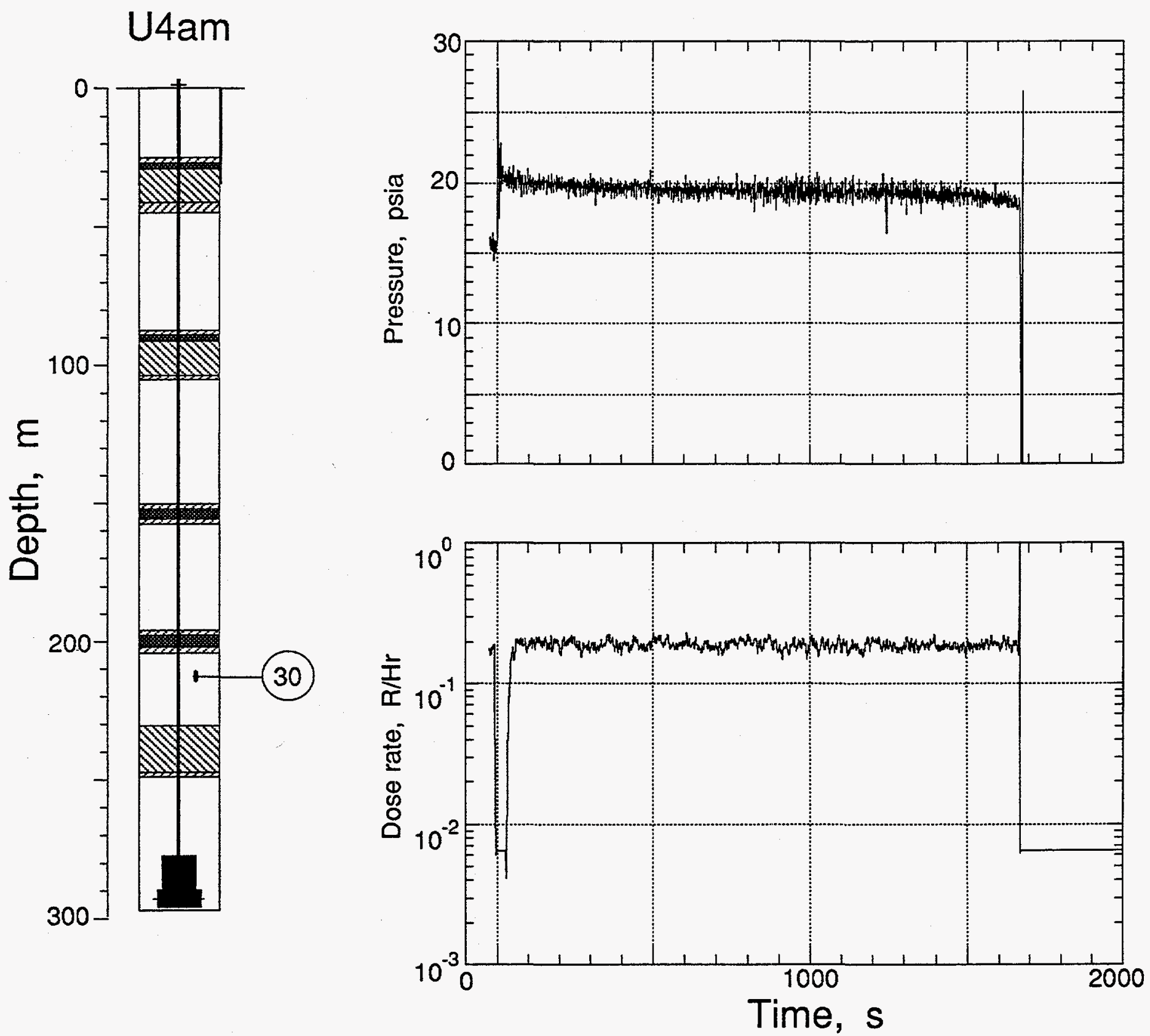

Figure 3.2 Pressure and radiation measured in the coarse stemming between the deepest GFA plug 1 and the gas seal plug 2 (Station 30 at $210.3 \mathrm{~m}$ depth). Signals were lost at collapse time (1675 s). 


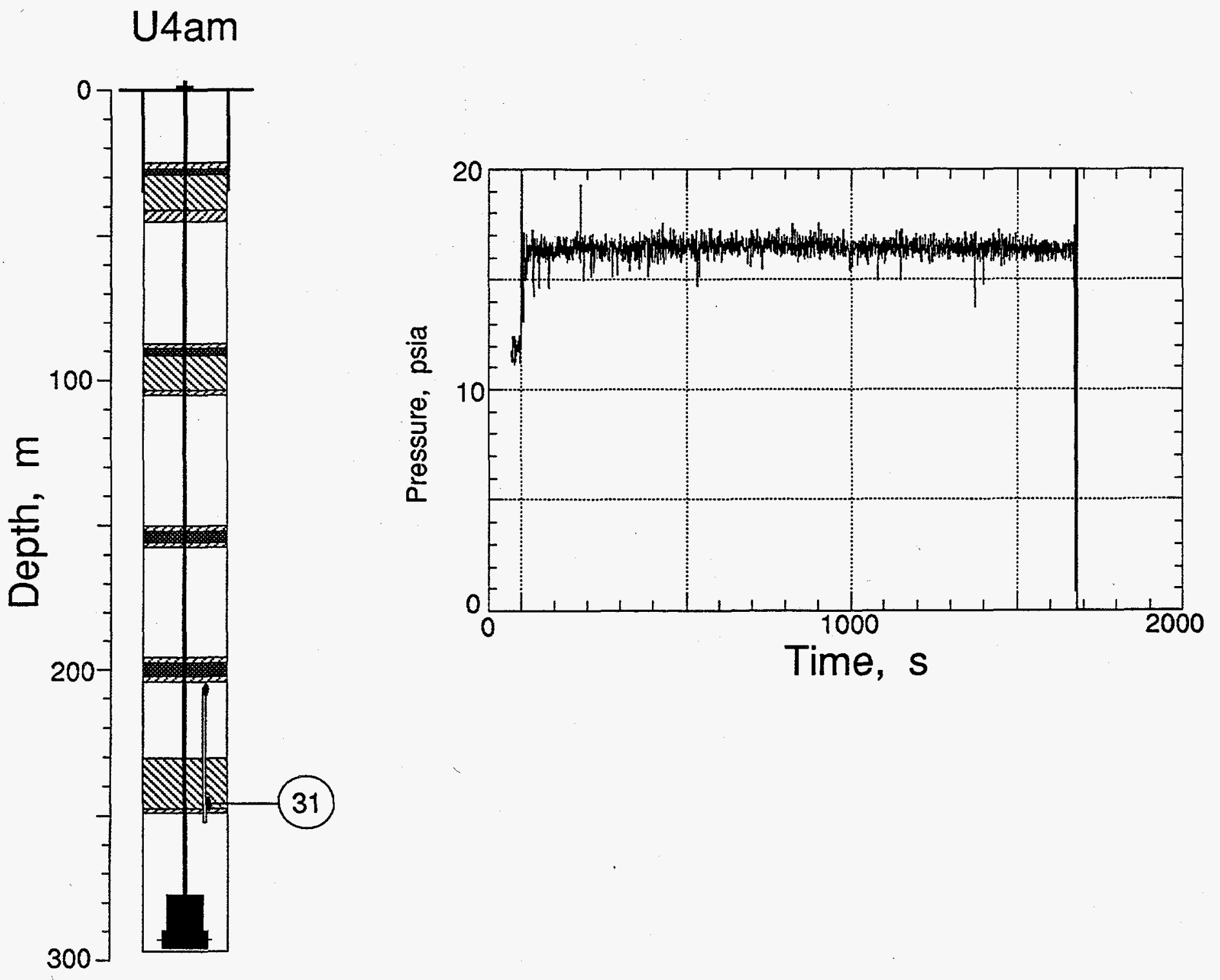

Figure 3.3 Pressure challenging the deepest plug (station 31) at a depth of $246.9 \mathrm{~m}$. Gas pressure was sensed through a section of wire rope (gas sample hose). Sensor was emplaced within the GFA plug at a depth of $244.8 \mathrm{~m}$ and on the same hose that accommodated station 32 . Signals were lost at collapse time (1675 s). 

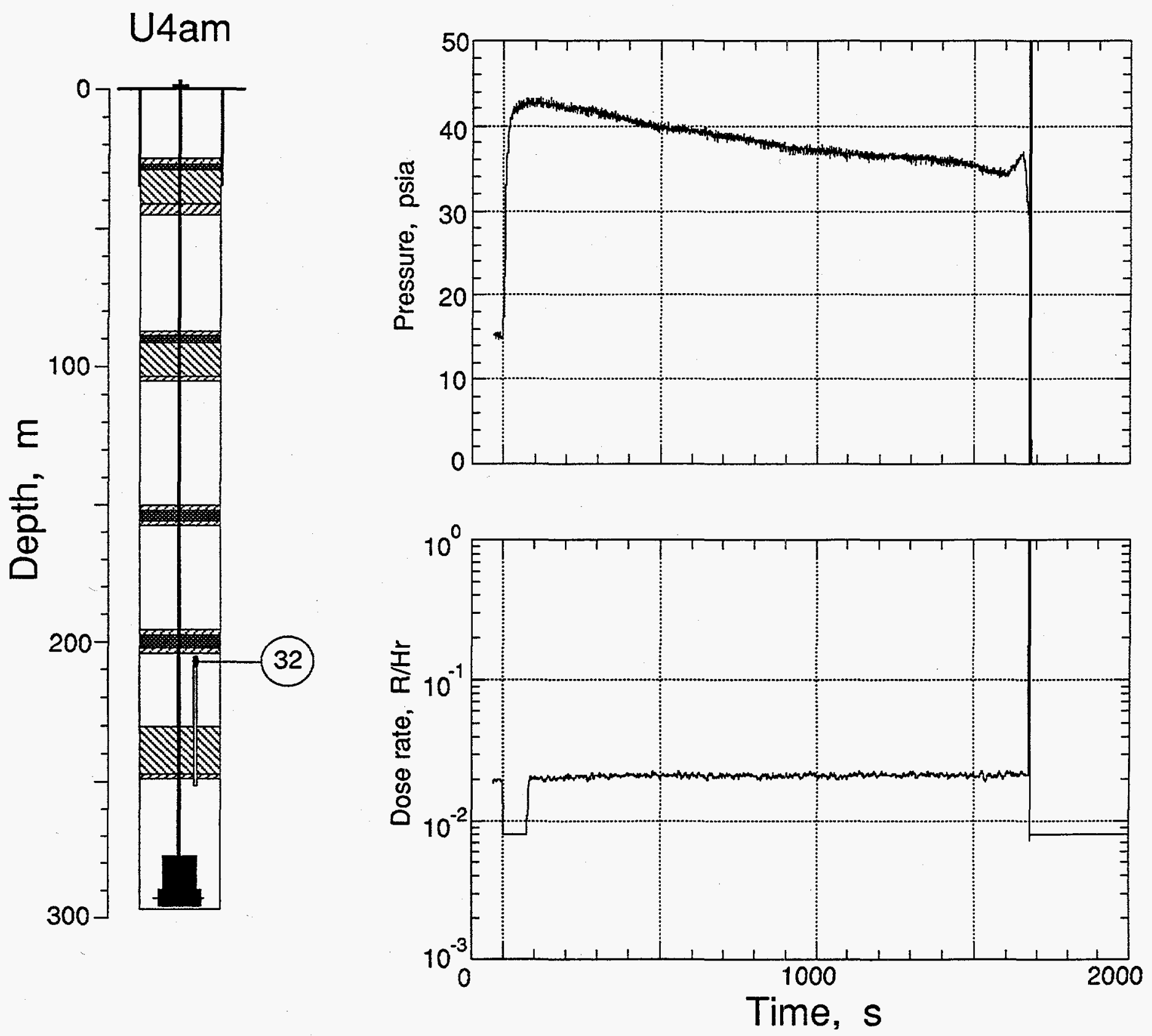

Figure 3.4 Pressure and radiation challenging the deepest plug (station 32) at a depth of $246.9 \mathrm{~m}$. Gas pressure was sensed through a section of wire rope (gas sample hose). Sensor was emplaced within the coarse stemming above the deepest GFA plug at a clepth of $206.7 \mathrm{~m}$ and on the same hose that accommodated station 31 . Signals were lost at collapse time (1675 s). 

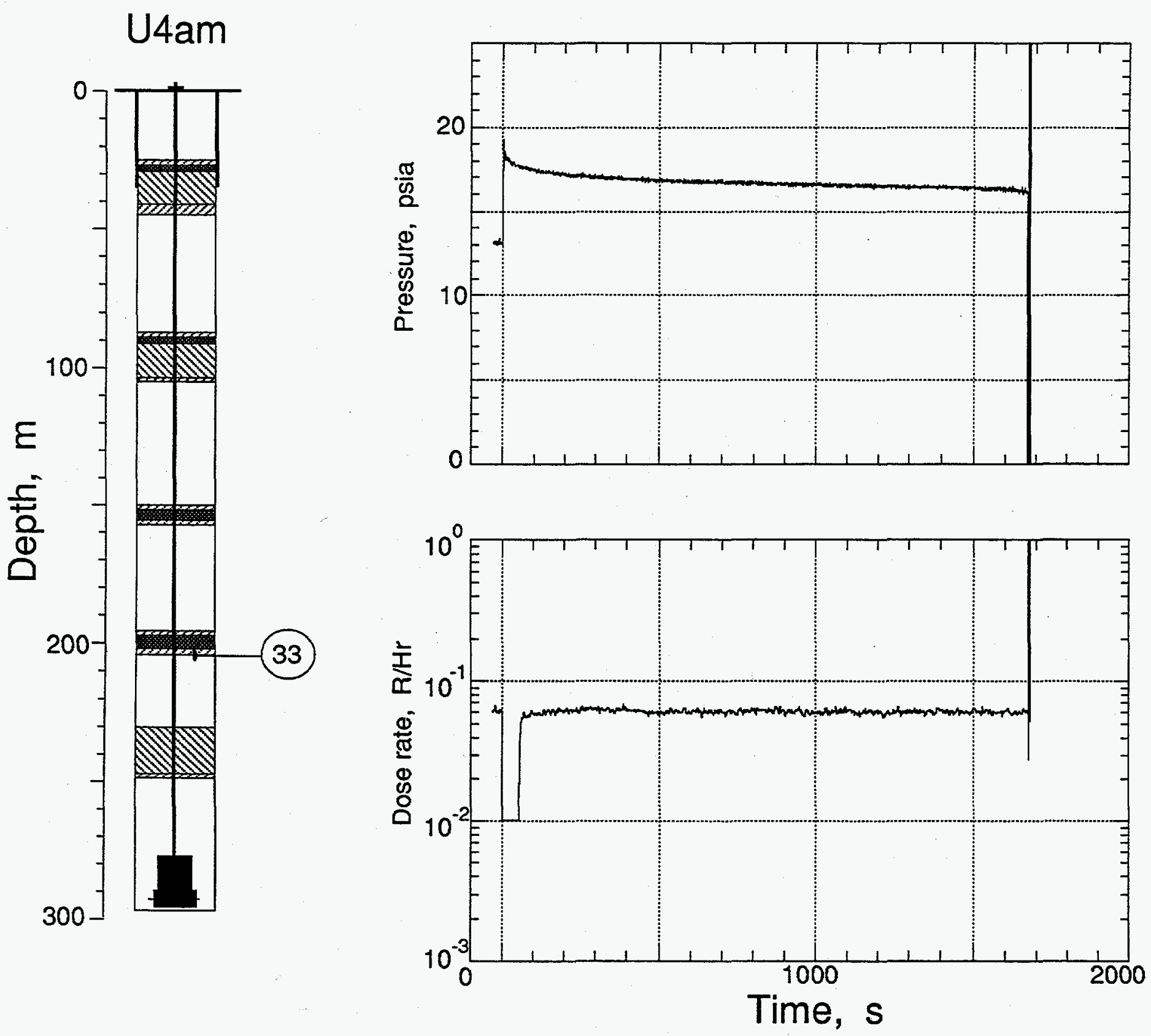

Figure 3.5 Pressure and radiation in the coarse stemming below gas seal plug 2 at a depth of $204.8 \mathrm{~m}$ (station 33). Signals were lost at collapse time (1675 s). 

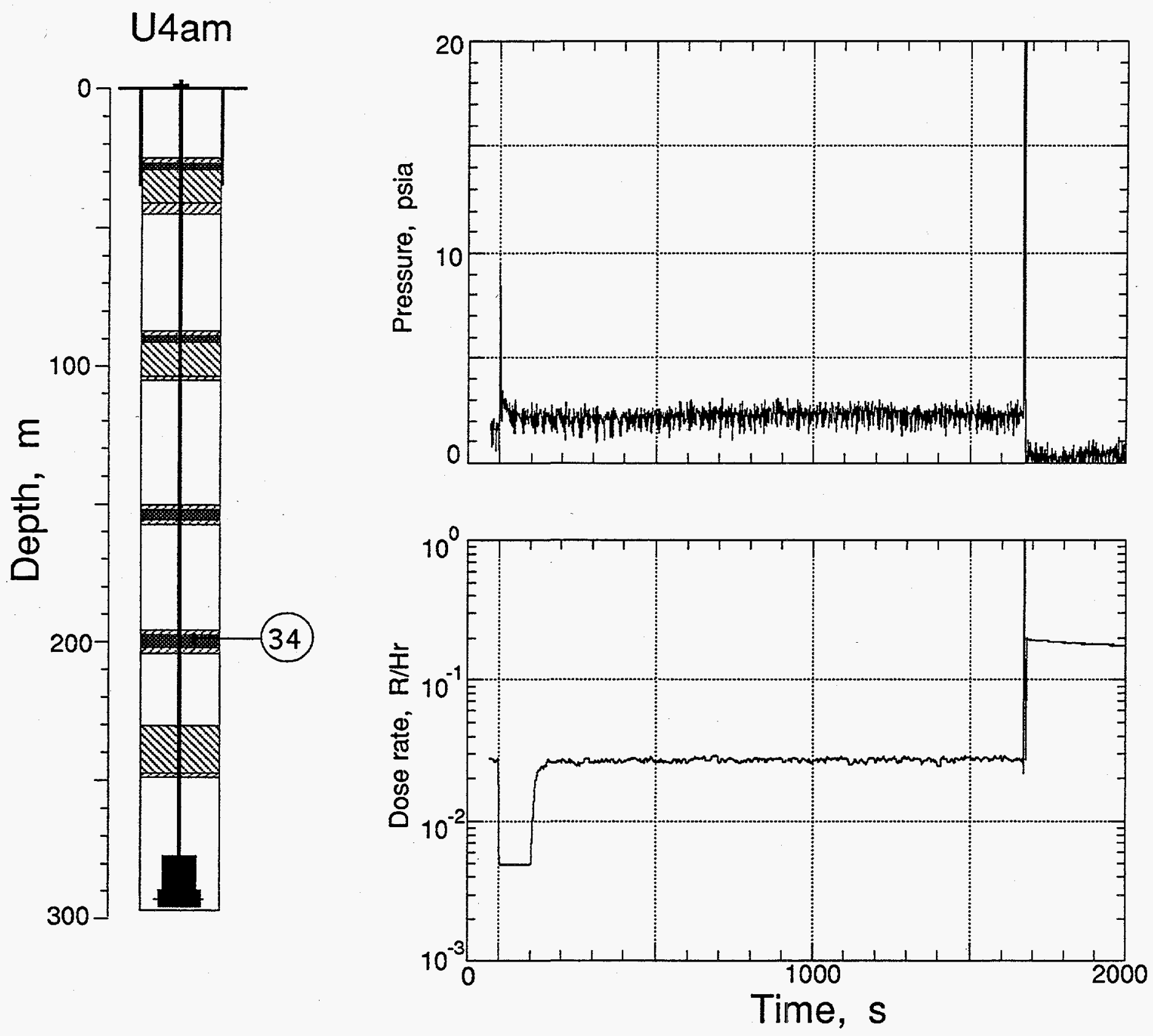

Figure 3.6 Pressure and radiation measured in gas seal plug 2 at a depth of $199.6 \mathrm{~m}$ (station 34). Signals were lost at collapse time (1675 s). The low level of pressure obtained from within the soft plug is questionable. 

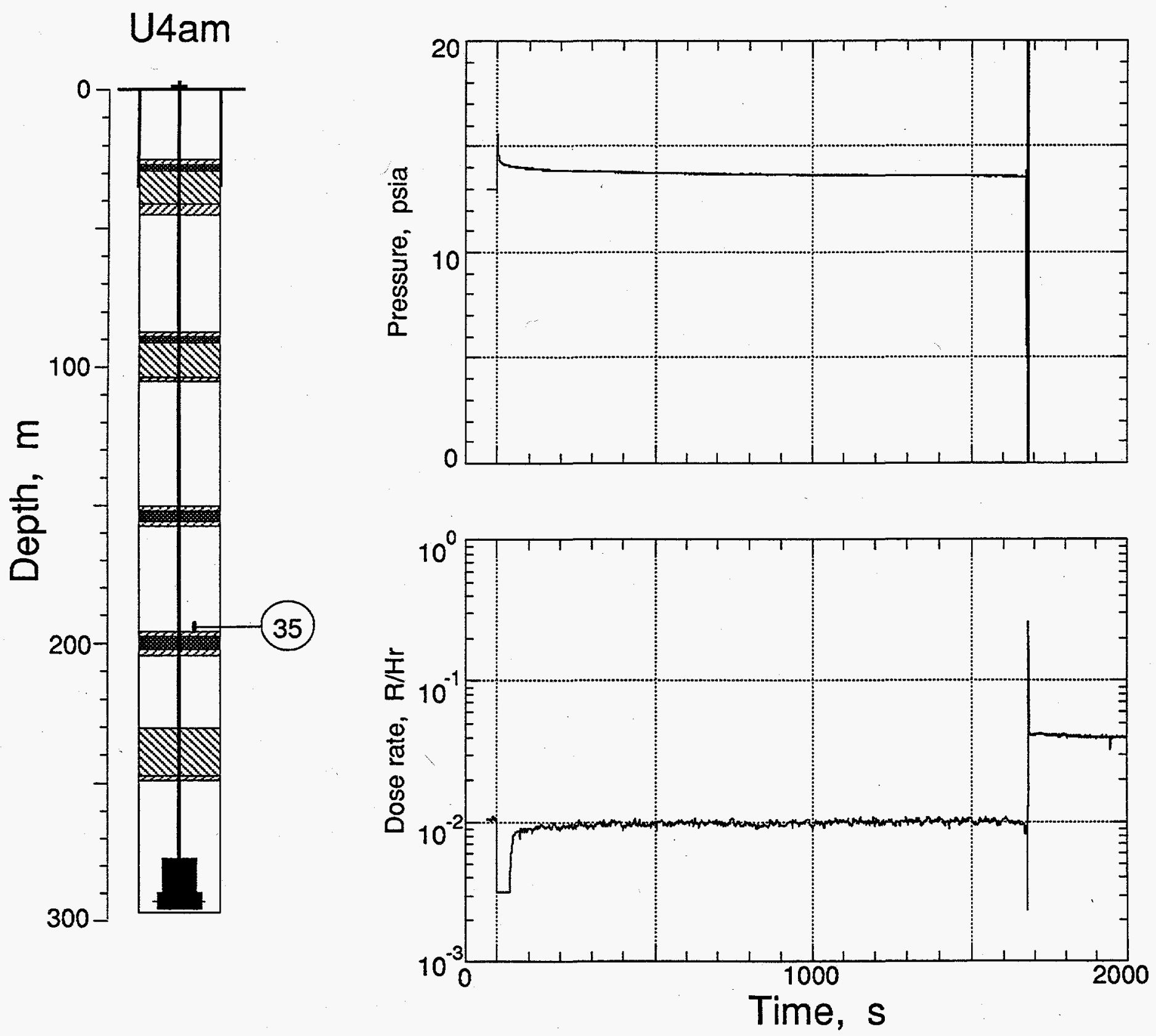

Figure 3.7 Pressure and radiation measured in the coarse stemming above gas seal plug 2 at a depth of $194.5 \mathrm{~m}$ (station 35). Signals were lost at collapse time (1675. s). 


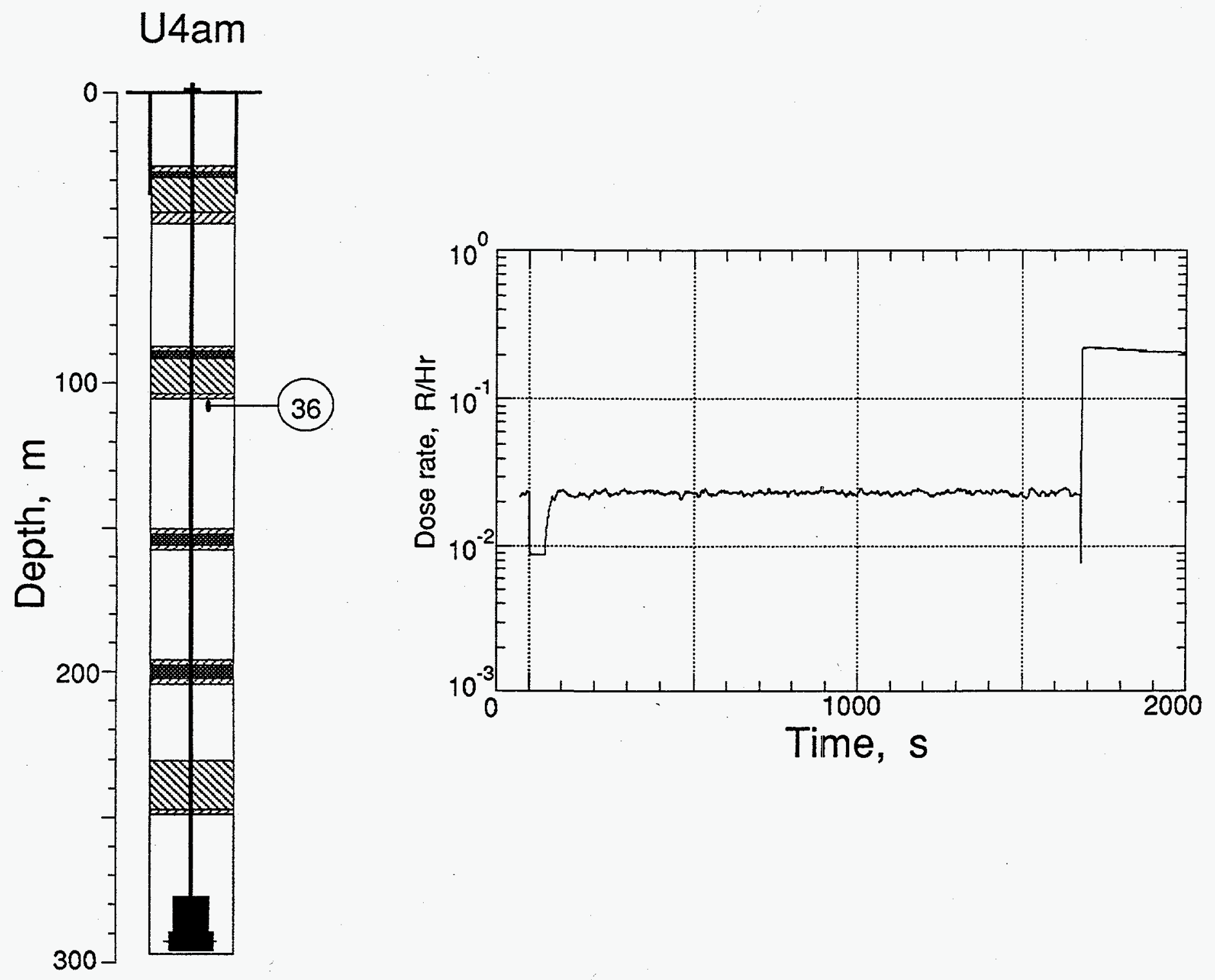

Figure 3.8 Radiation measured in the coarse stemming below GFA plug 4 at a depth of $108.2 \mathrm{~m}$ (station 36). The pressure transducer was off-line pre-shot. Signal was lost at collapse time (1679 s). 

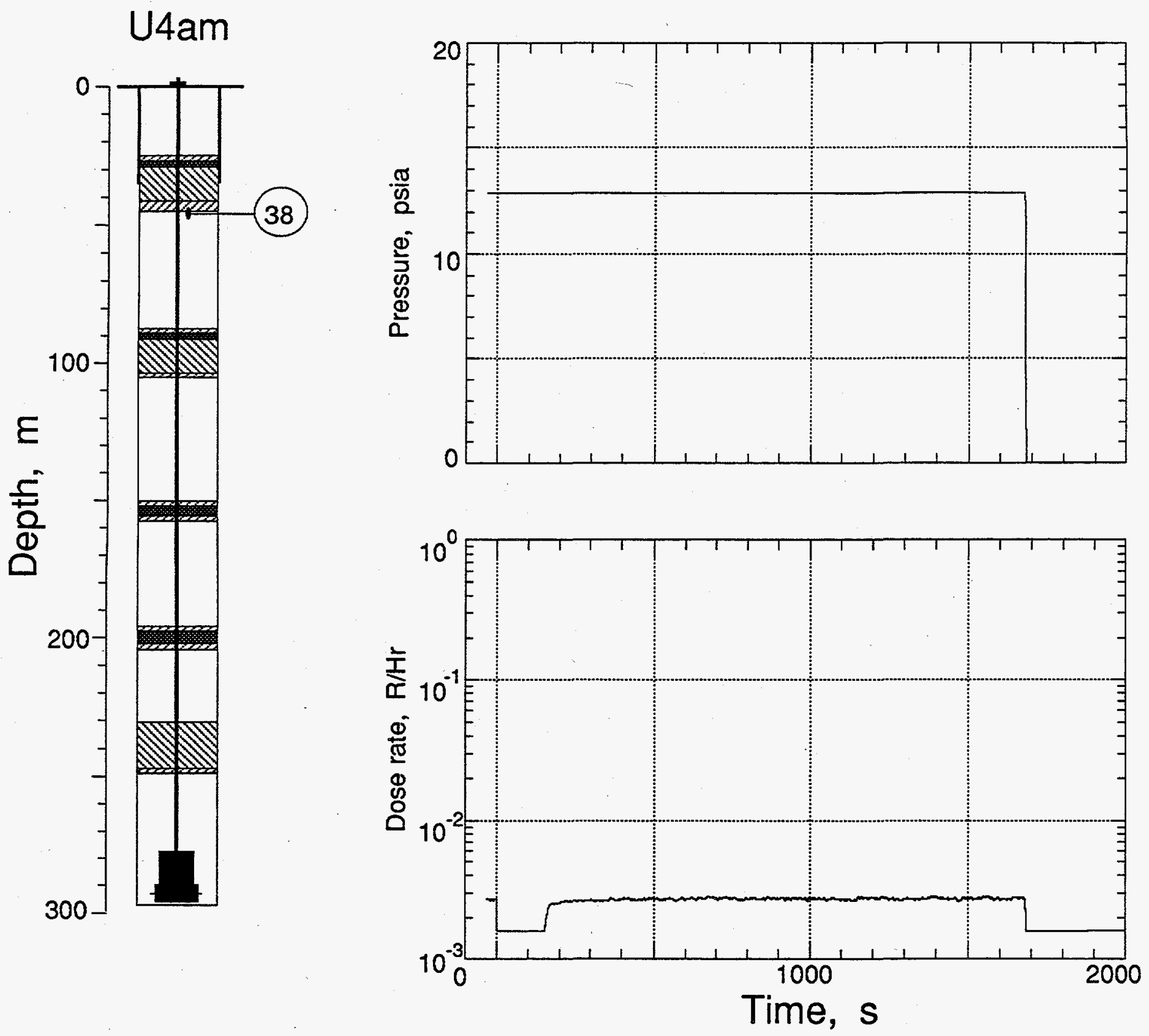

Figure 3.9 Pressure and radiation measured in the coarse stemming below the top GFA plug at a depth of $45.0 \mathrm{~m}$ (station 38 ). Signals were lost at collapse time (1681 s). 


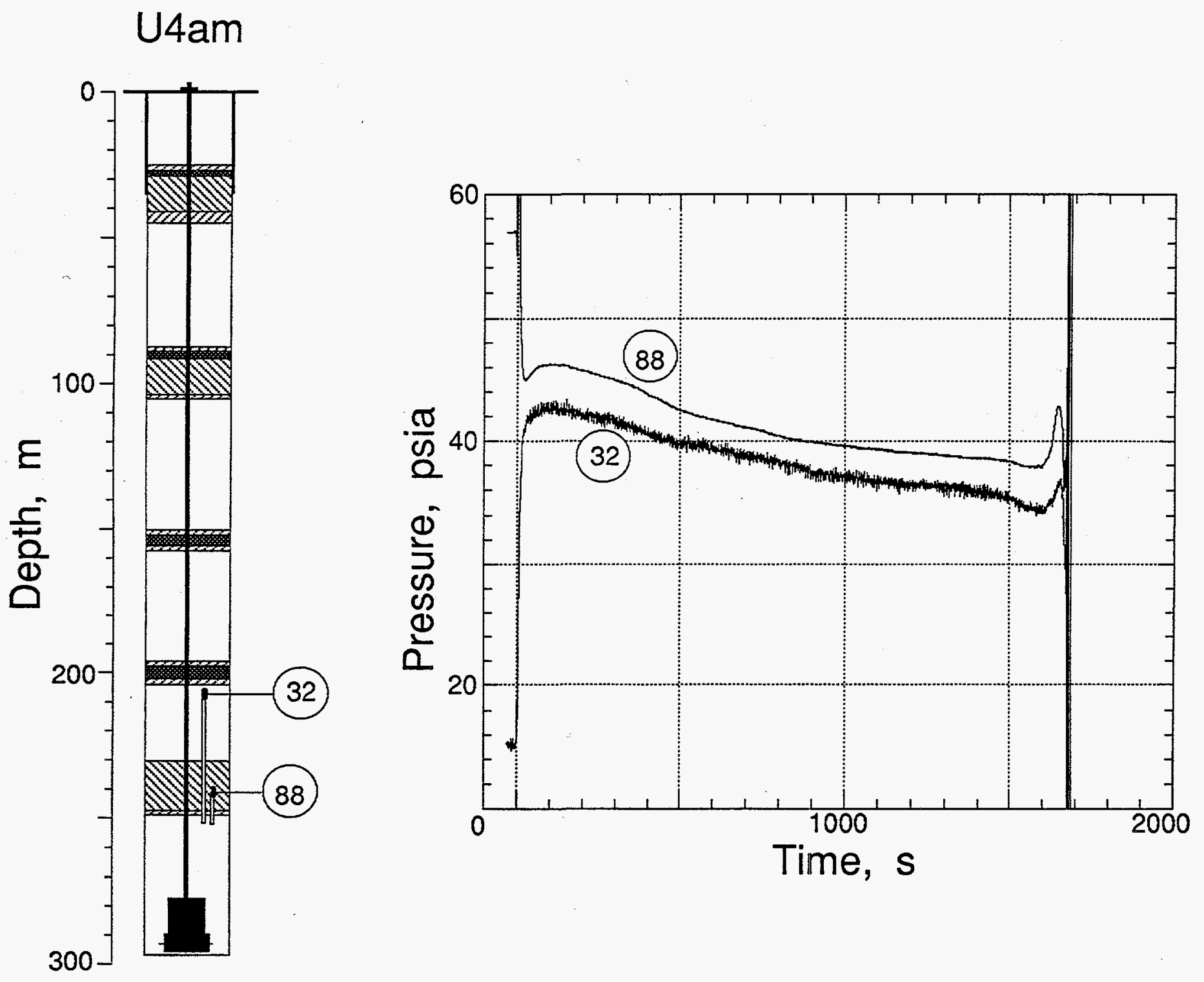

Figure 3.10 Comparison of challenge pressure wave forms sensed at stations 88 and 32 . 


\subsection{Explosion-Induced Motion}

Explosion-induced motion histories obtained from the VILLE experiment are shown in figures 3.11-3.24. Characteristics of the motion and of the motion transducers are given in tables 3.1-3.3.

The signal at station 4 near the bottom of the bottom GFA plug at a depth of 244.7 $\mathrm{m}$ (figure 3.11) exceeded the system dynamic range of $2500 \mathrm{~g}$ 's at about $66 \mathrm{~ms}$. Values quoted for this station in table 3.1 represent the motion occurring before this time.

Motion from all stemming stations below GFA plug $4(30,32,33,35$, and 36$)$ showed a large component of noise leading to uncertainty in the final derived displacement and, in some instances, the peak of the acceleration. A circuit breaker associated with the signal conditioning system for the accelerometers of stations 21 , $22,23,5,61$ and 71 failed at about $0.75 \mathrm{~s}$ invalidating the data at later times for these channels. 
Table 3.1 Summary of Motion

\begin{tabular}{|c|c|c|c|c|c|c|}
\hline Gauge & $\begin{array}{c}\text { Slant Range } \\
(\mathrm{m})\end{array}$ & $\begin{array}{l}\text { Arrival Time } \\
\text { (ms) }\end{array}$ & $\begin{array}{l}\text { Acceleration } \\
\text { Peak (g) }\end{array}$ & $\begin{array}{l}\text { Velocity Peak } \\
(\mathrm{m} / \mathrm{s})\end{array}$ & $\begin{array}{l}\text { Displacement } \\
\text { Peak (cm) }\end{array}$ & $\begin{array}{l}\text { Displacement } \\
\text { Residual }(\mathrm{cm})\end{array}$ \\
\hline $21 a v$ & 195.2 & 49,107 & 2.1 & 0.33 & 7 & (a) \\
\hline $21 u v$ & & - & - & $0.4^{(b)}$ & 6.5 & -5 \\
\hline $22 \mathrm{av}$ & 257.0 & 150 & 1.2 & 0.48 & 6.9 & (a) \\
\hline $22 u v$ & & - & - & 0.48 & 6.7 & -3 \\
\hline $23 a v$ & 292.4 & 114,178 & $1.7^{(b)}$ & 0.5 & 7.4 & (a) \\
\hline $23 u v$ & & - & - & 0.5 & 7.0 & -1 \\
\hline $30 a v$ & 82.1 & 50 & 33 & $8.1(c)$ & 93 & $20(d)$ \\
\hline $32 a v$ & 85.7 & 53 & 21 & $6.2^{(c)}$ & 72 & ${ }_{80}(d)$ \\
\hline $33 a v$ & 87.6 & 123 & 19 & $5.8(c)$ & 67 & (e) \\
\hline $34 a v$ & 92.8 & ${ }_{50}(\mathrm{~d})$ & 25 & $7.5^{(c)}$ & 94 & $73^{(d)}$ \\
\hline $35 a v$ & 97.9 & ${ }_{50}(\mathrm{~d})$ & 7 & $3.7^{(c)}$ & 42 & $50^{(d)}$ \\
\hline $36 a v$ & 184.2 & $46^{(f)}$ & 0.2 & 0.13 & 1.9 & -5 \\
\hline $38 a v$ & 247.4 & 68,150 & $0.2,0.4$ & $0.14,0.19$ & 2.8 & -0.5 \\
\hline $4 a v$ & 47.6 & 22,47 & 100,2600 & $7,133,(g)$ & (g) & (g) \\
\hline $5 a v$ & 293 & 143 & 135 & 10 & 15,63 & (a) \\
\hline $5 u v$ & & - & - & 9.6 & 74 & 62 \\
\hline $61 a v$ & 292.8 & 185 & 2.6 & 0.5 & 73 & (a) \\
\hline 61uv & & - & - & 0.5 & 6.3 & 1 \\
\hline $71 a v$ & $326.9^{(h)}$ & 218 & 1.4 & 0.52 & 6.7 & (a) \\
\hline 71uv & & - & - & 052 & 6.2 & -5 \\
\hline \multicolumn{7}{|c|}{$\begin{array}{l}\text { (a) Signal terminated at about } 0.75 \mathrm{~s} \text {. } \\
\text { (b) Noisy signal: peak may be in error. } \\
\text { (c) Maximum value. } \\
\text { (d) Approximate. } \\
\text { (e) Could not estimate. } \\
\text { (f) Early arrival. } \\
\text { (g) Signal out of band: integral in error. } \\
\text { (h) Station in recording trailer; range ap }\end{array}$} \\
\hline
\end{tabular}




\section{Table 3.2 Accelerometer Characteristics}

\begin{tabular}{|c|c|c|c|}
\hline Gauge & $\begin{array}{l}\text { Natural Frequency } \\
(\mathrm{Hz})\end{array}$ & Damping Ratio & $\begin{array}{c}\text { System Range } \\
\text { (g's) }\end{array}$ \\
\hline $21 a v$ & 174 & 0.85 & 8 \\
\hline $22 a v$ & 270 & 0.63 & 25 \\
\hline $23 a v$ & 310 & 0.7 & 25 \\
\hline $30 \mathrm{ac}$ & (a) & (b) & 500 \\
\hline $32 a v$ & (a) & (b) & 500 \\
\hline $33 a v$ & (a) & (b) & 500 \\
\hline $34 a v$ & (a) & (b) & 200 \\
\hline $35 a v$ & (a) & (b) & 150 \\
\hline $36 a v$ & (a) & (b) & 10 \\
\hline $38 a v$ & (a) & (b) & 50 \\
\hline $4 a v$ & (c) & & 2500 \\
\hline $5 a v$ & 940 & 0.75 & 150 \\
\hline $61 a v$ & 428 & 0.75 & 30 \\
\hline $71 a v$ & 250 & 0.7 & 8 \\
\hline
\end{tabular}
(a) Piezoresitive element: mounted resonance $\geq 2000 \mathrm{~Hz}$.
(b) Manufacturer's specification: damping ratio $=0.7$.
(c) Unknown characteristics: transducer supplied by Sandia. 


\section{Table 3.3 Velocimeter Characteristics}

\begin{tabular}{|c|c|c|c|c|c|}
\hline Gauge & $\begin{array}{c}\text { Natural } \\
\text { Frequency } \\
\left(\mathrm{H}_{2:}\right)\end{array}$ & $\begin{array}{l}\text { Time to } 0.5 \\
\text { Amplitude } \\
\text { (s) }\end{array}$ & $\begin{array}{c}\text { Calibration } \\
\text { Temperature } \\
\left({ }^{\circ} \mathrm{C}\right)\end{array}$ & $\begin{array}{c}\text { Operate } \\
\text { Temperature } \\
\left({ }^{\circ} \mathrm{C}\right)\end{array}$ & $\begin{array}{c}\text { System } \\
\text { Range } \\
(\mathrm{m} / \mathrm{s})\end{array}$ \\
\hline 5uv & 3.737 & 28.26 & 25.96 & 39.34 & 30 \\
\hline $21 u v$ & 3.597 & 8.27 & 26.23 & 37.77 & 6 \\
\hline $22 u v$ & 3.407 & 9.90 & 26.48 & 40.26 & 10 \\
\hline $23 u v$ & 3.534 & 9.24 & 25.93 & 36.26 & 10 \\
\hline 61uv & 3.434 & 10.38 & 26.18 & 22.93 & 10 \\
\hline $71 u v$ & 3.253 & 11.75 & 25.25 & 22.56 & 4 \\
\hline
\end{tabular}



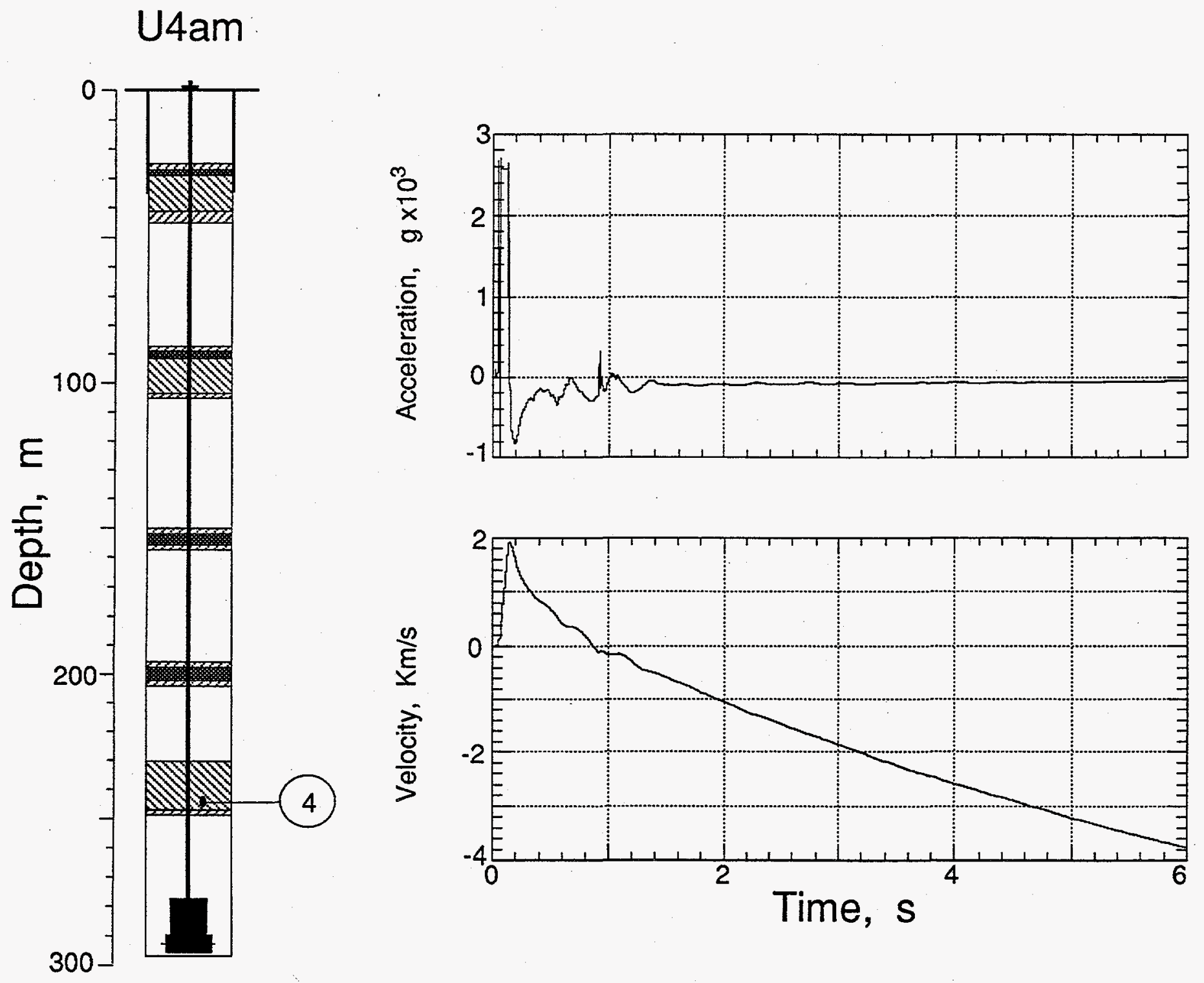

Figure 3.11 Vertical motion of the deepest GFA plug at a depth of $244.75 \mathrm{~m}$ (station 4). The peak of the signal at about $0.15 \mathrm{~s}$ exceeds the dynamic range of the system and the integral at times greater than this cannot be believed. This sensor was supplied by Sandia. 

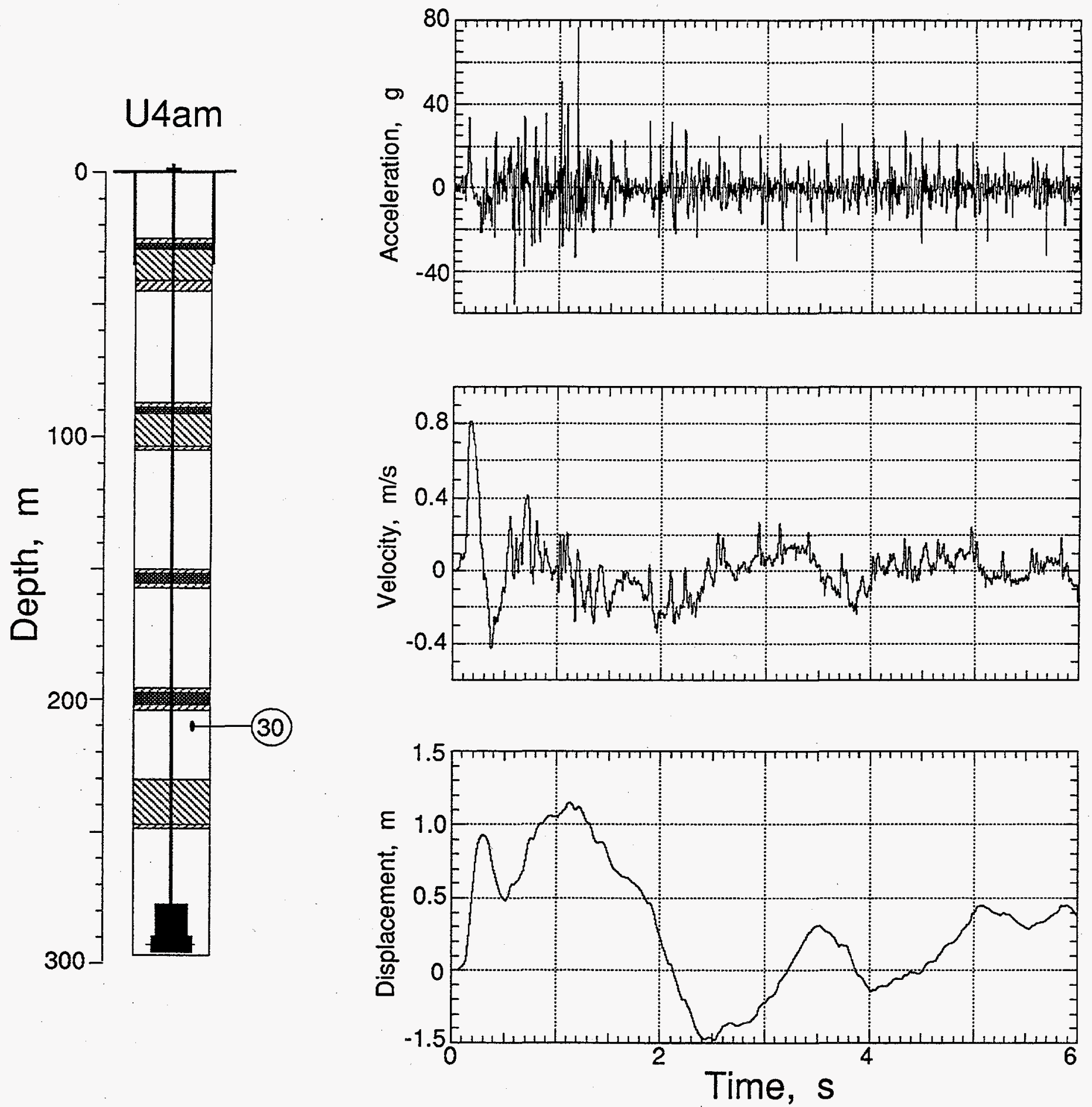

Figure 3.12 Vertical motion of the stemming between the deepest GFA plug 1 and the deepest gas seal plug 2 (station 30 at a depth of $210.3 \mathrm{~m}$ ). 

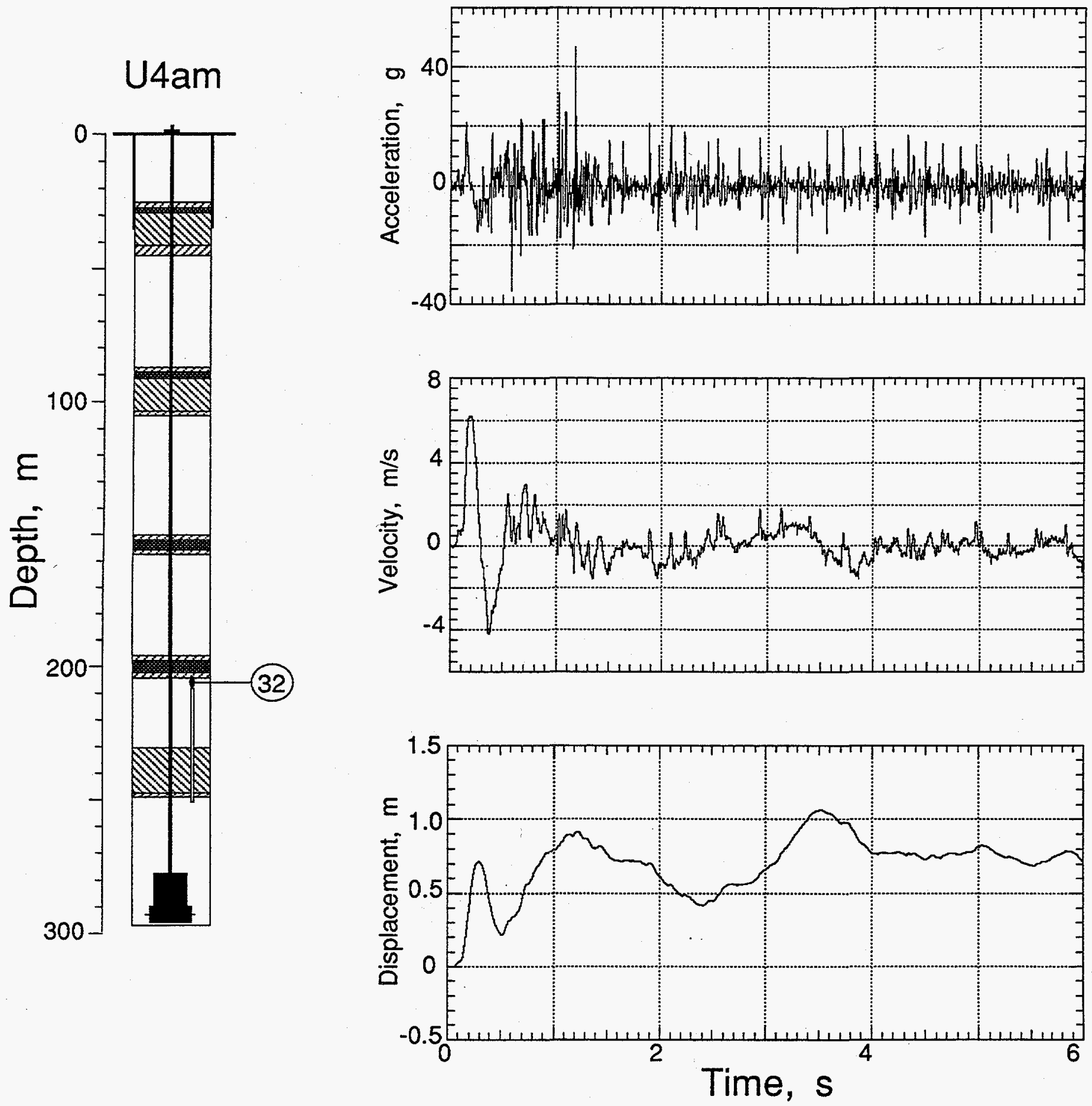

Figure 3.13 Vertical motion of the stemming below the deepest gas seal plug 2 (station 32 at a depth of $206.7 \mathrm{~m}$ ). This station was attached to a section of gas sample hose. 

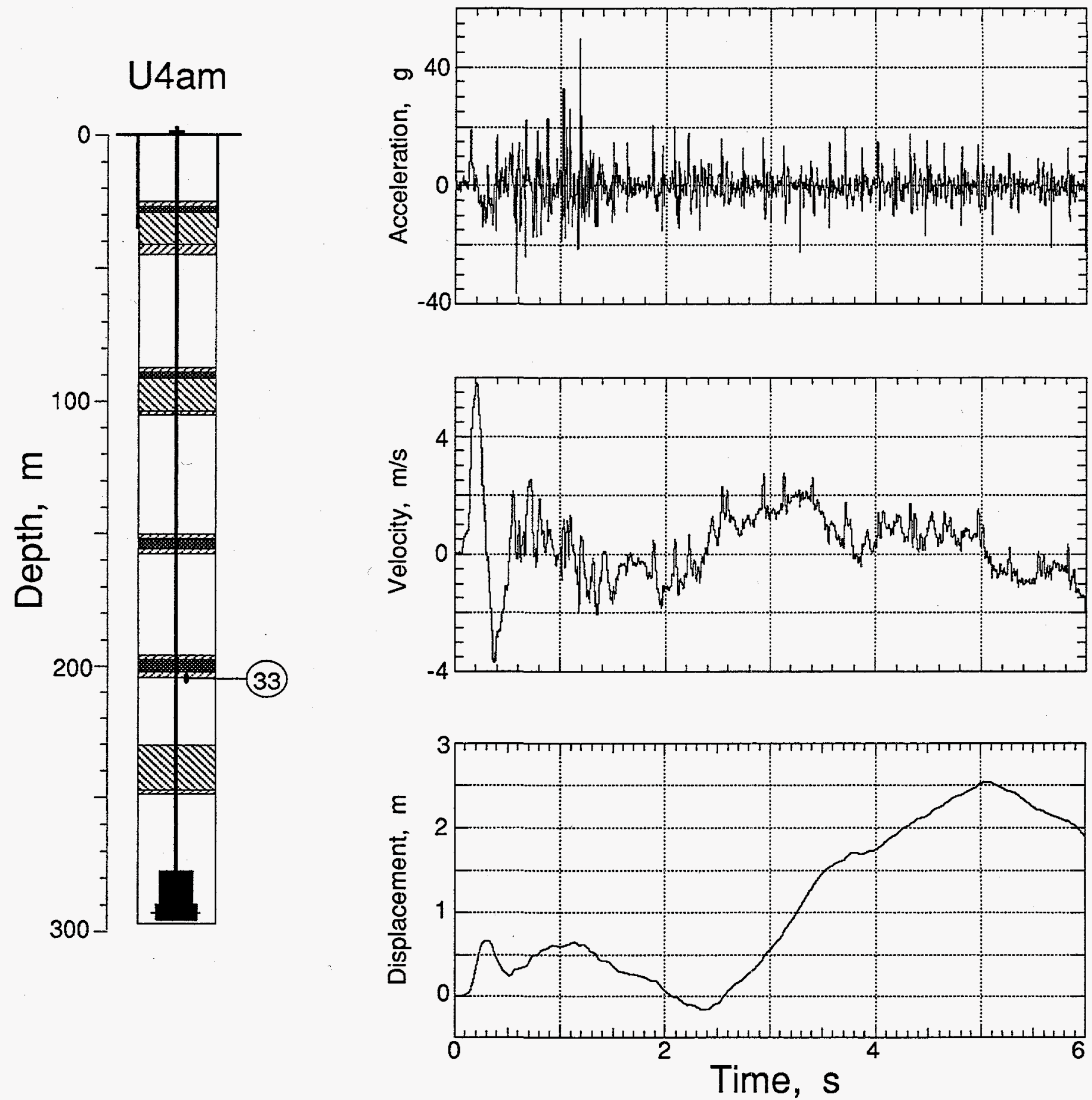

Figure 3.14 Vertical motion of the stemming below the deepest gas seal plug 2 (station 33 at a depth of $204.8 \mathrm{~m}$ ). 

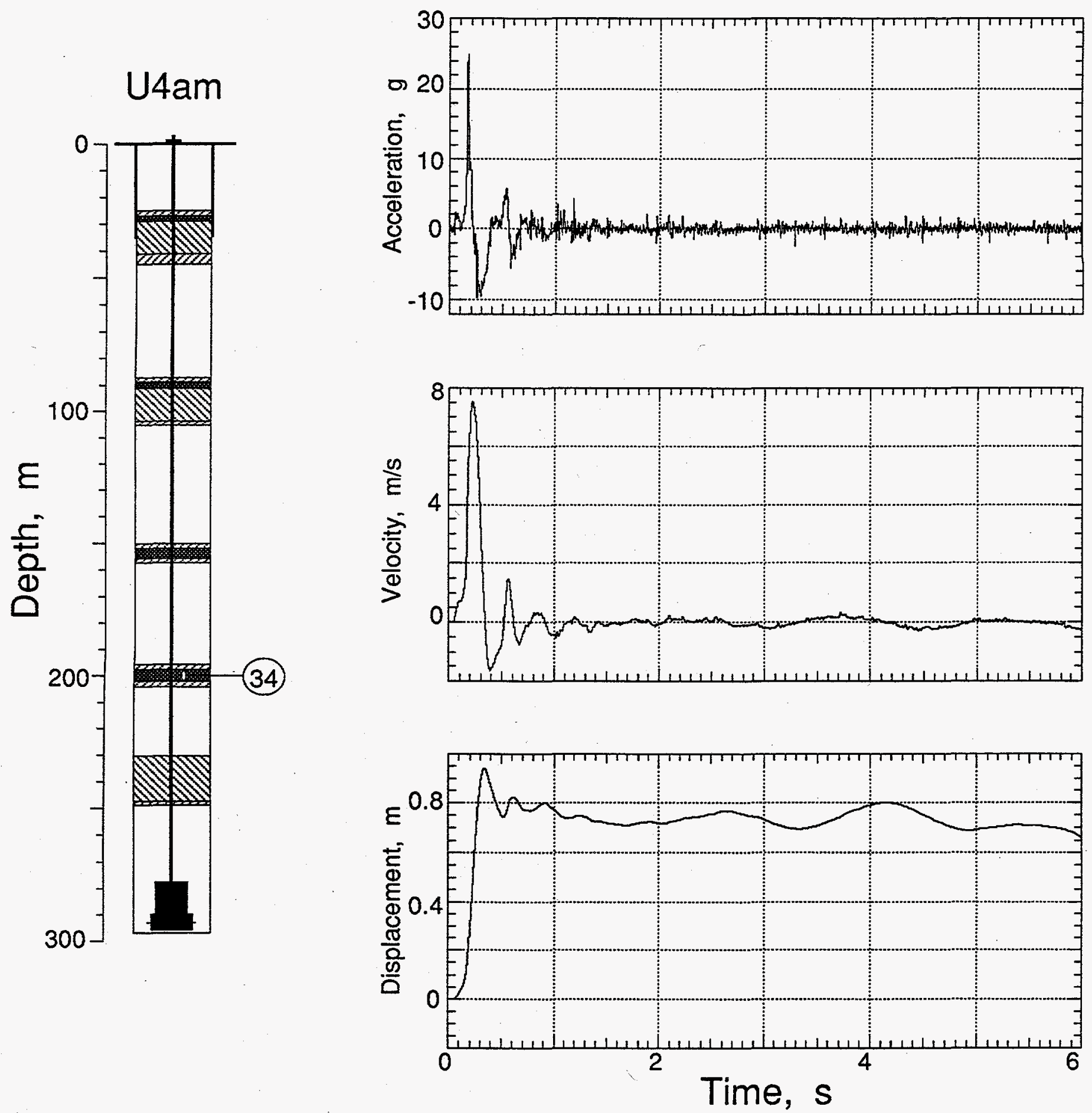

Figure 3.15 Vertical motion of the deepest gas seal plug 2 (station 34 at a depth of $199.6 \mathrm{~m}$ ). 

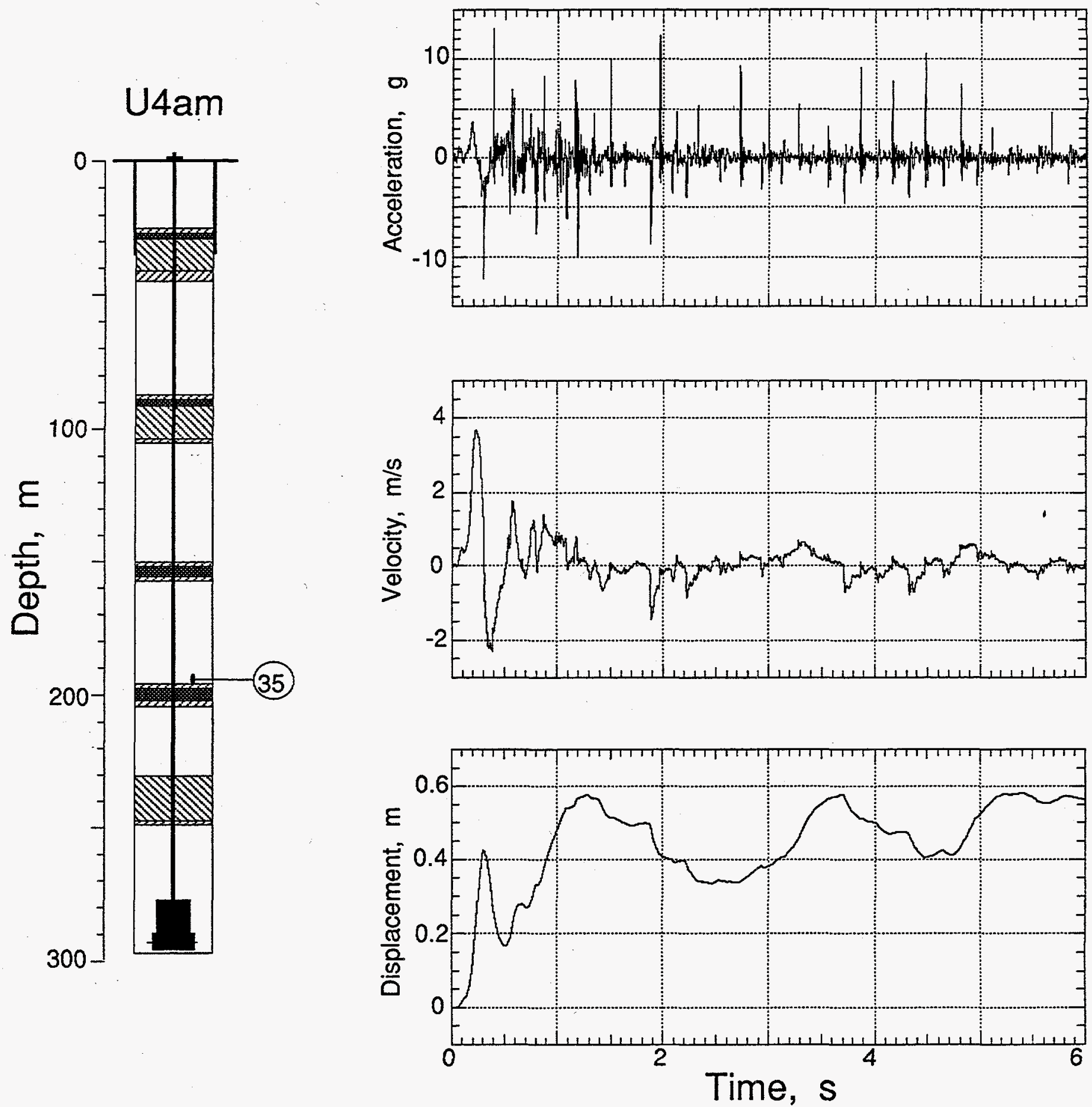

Figure 3.16 Vertical motion of the stemming above the deepest gas seal plug 2 (station 35 at a depth of $194.5 \mathrm{~m})$. 

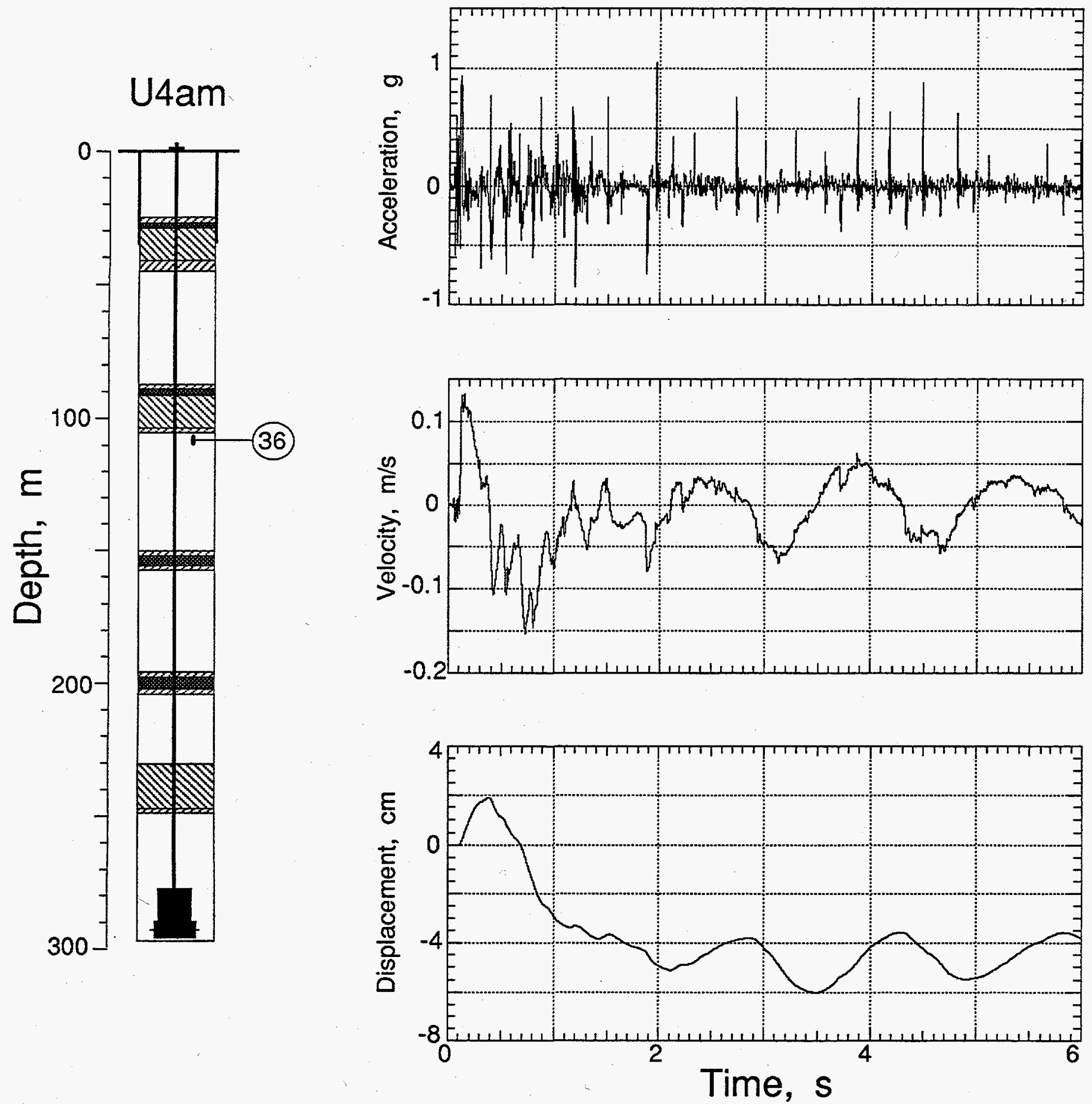

Figure 3.17 Vertical motion of the stemming below GFA plug 4 (station 36 at a depth of $108.2 \mathrm{~m}$ ). 


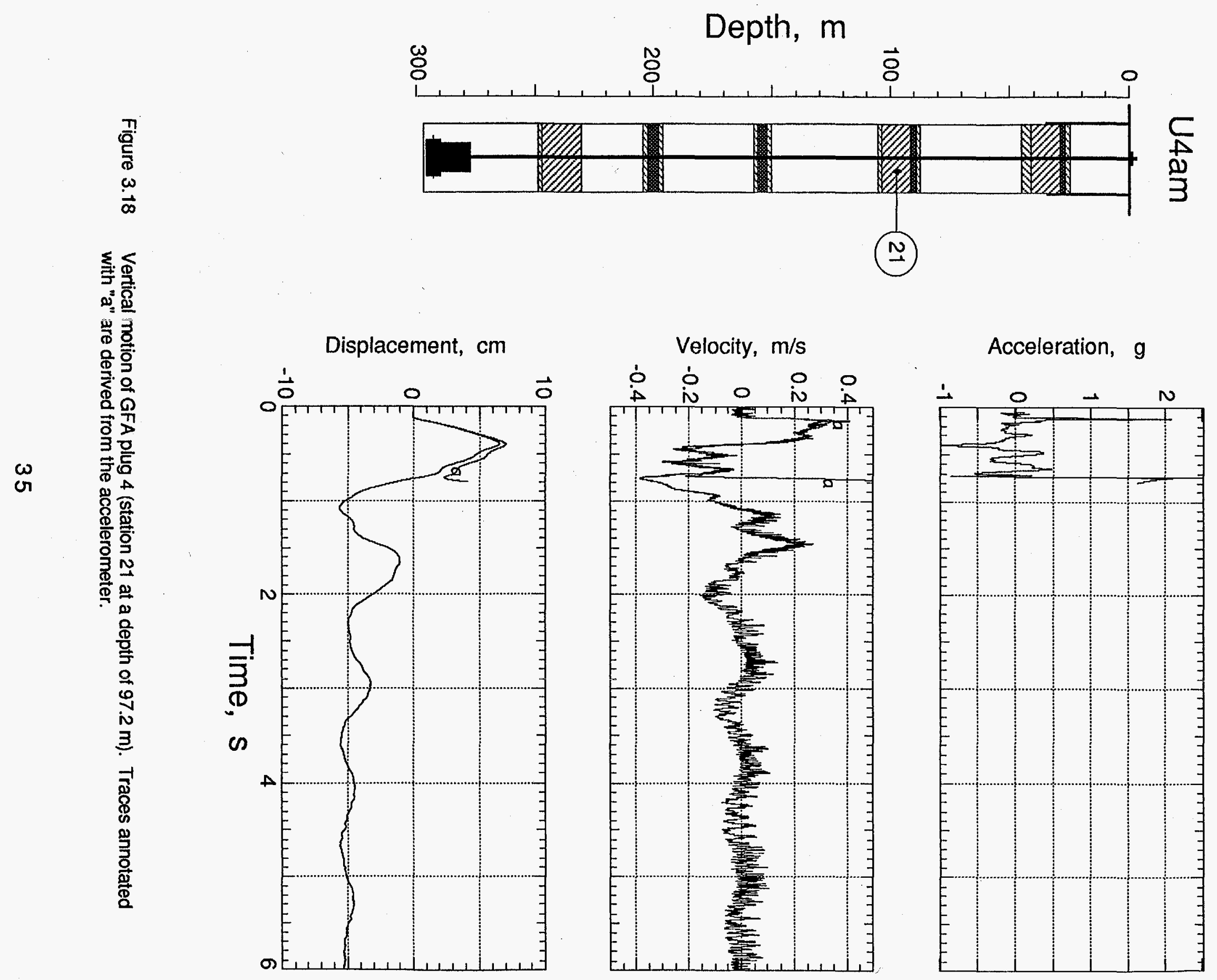



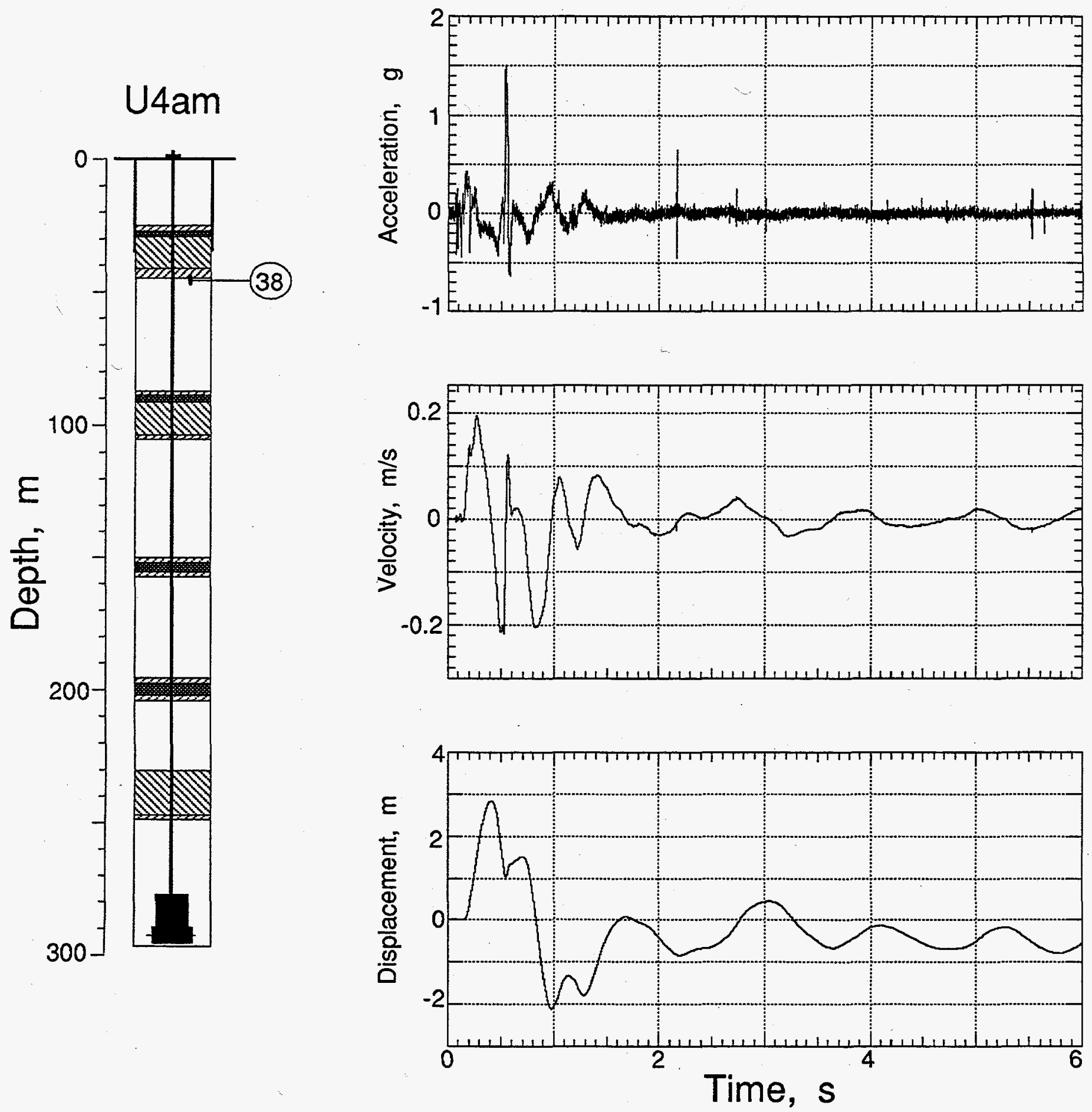

Figure 3.19 Vertical motion of the stemming below the top GFA plug 5 (station 38 at a depth of $45.0 \mathrm{~m}$ ). 


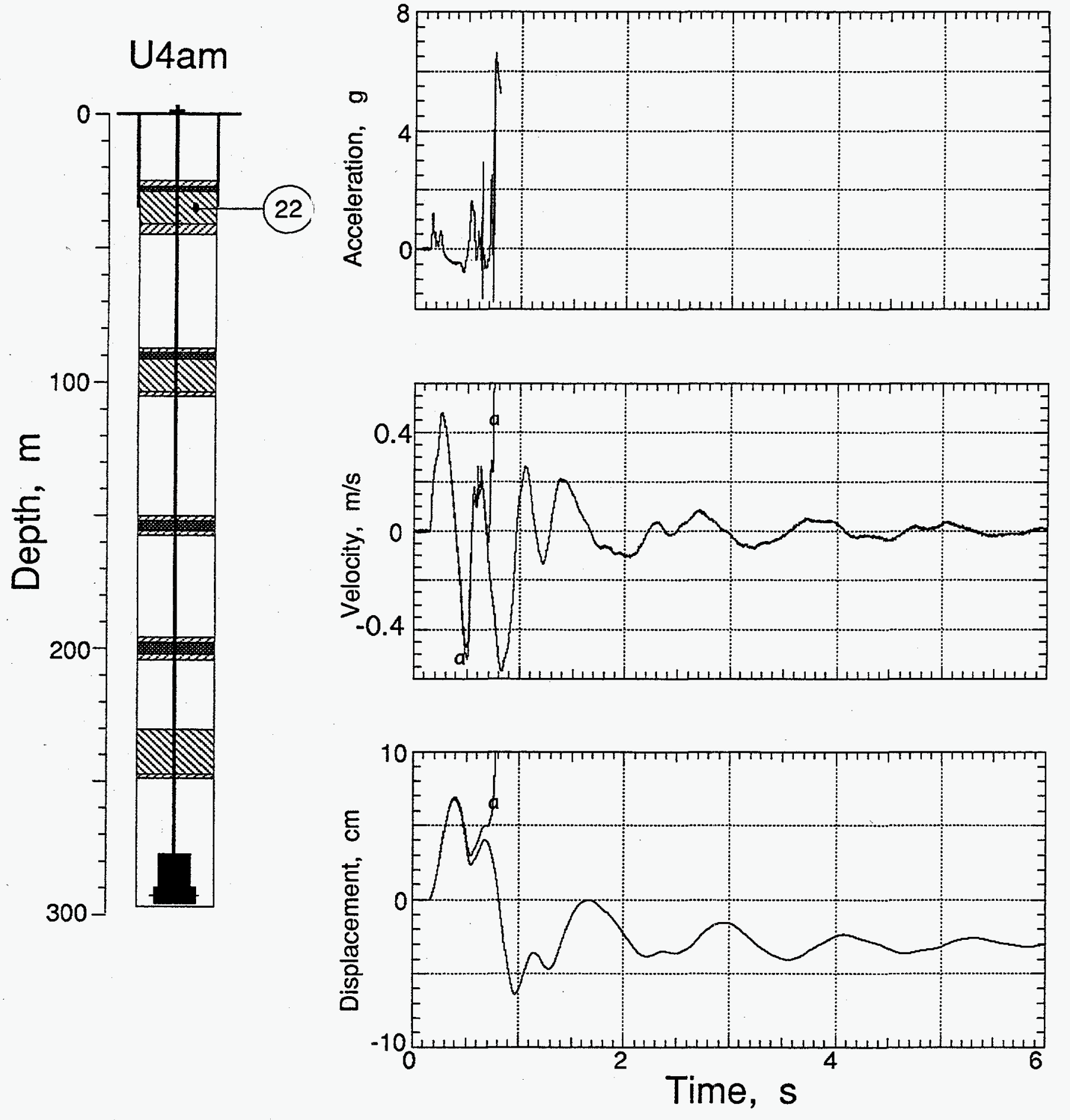

Figure 3.20 Vertical motion of the top GFA plug 5 (station 22 at a depth of $35.4 \mathrm{~m}$ ). Traces annotated with "a" are derived from the accelerometer. 

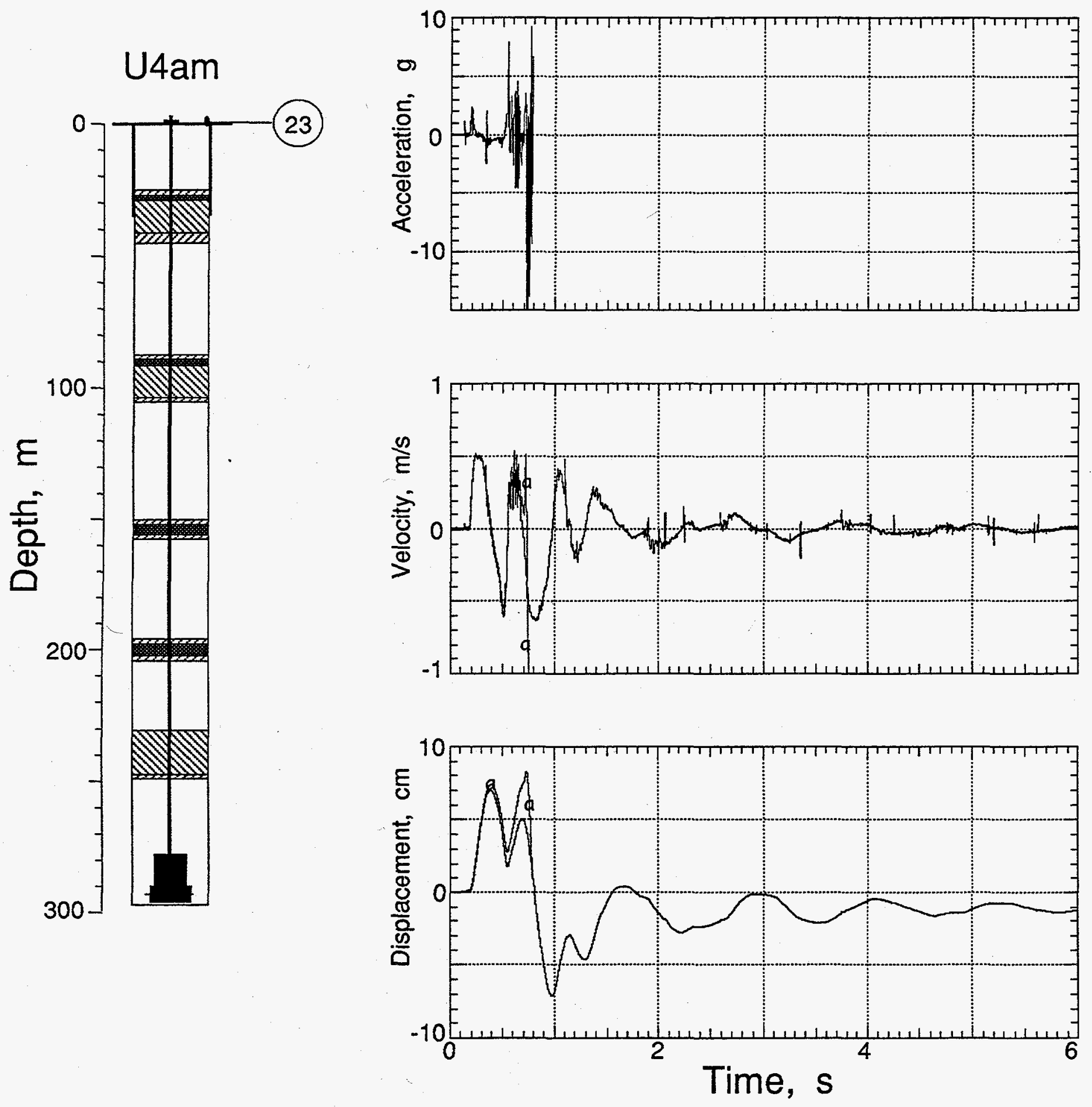

Figure 3.21 Vertical motion of the surface conductor (station 23). Traces annotated with "a" are derived from the accelerometer. 


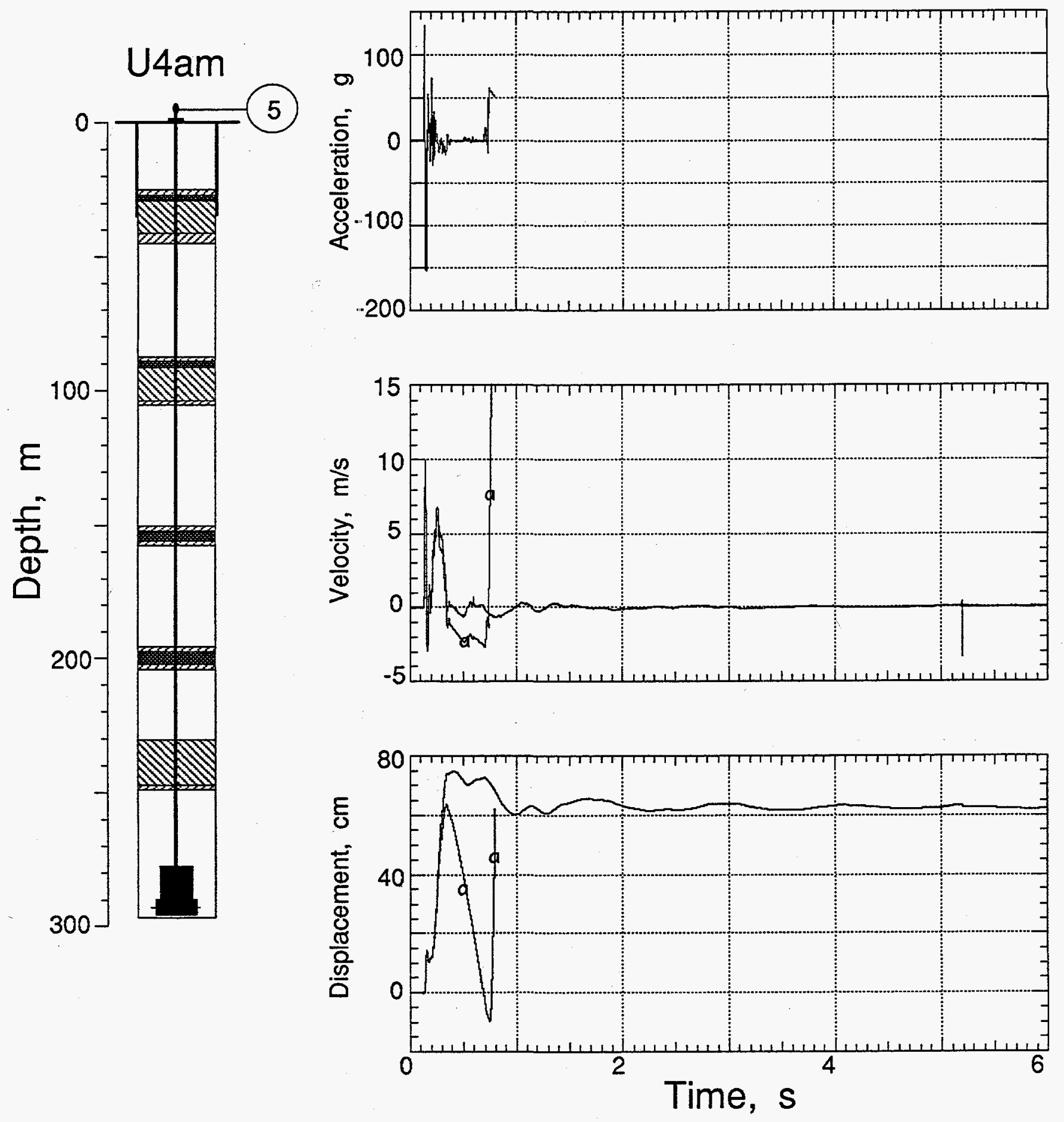

Figure 3.22 Vertical motion of the top of the emplacement pipe (station 5). Traces annotated with "a" are derived from the accelerometer. 

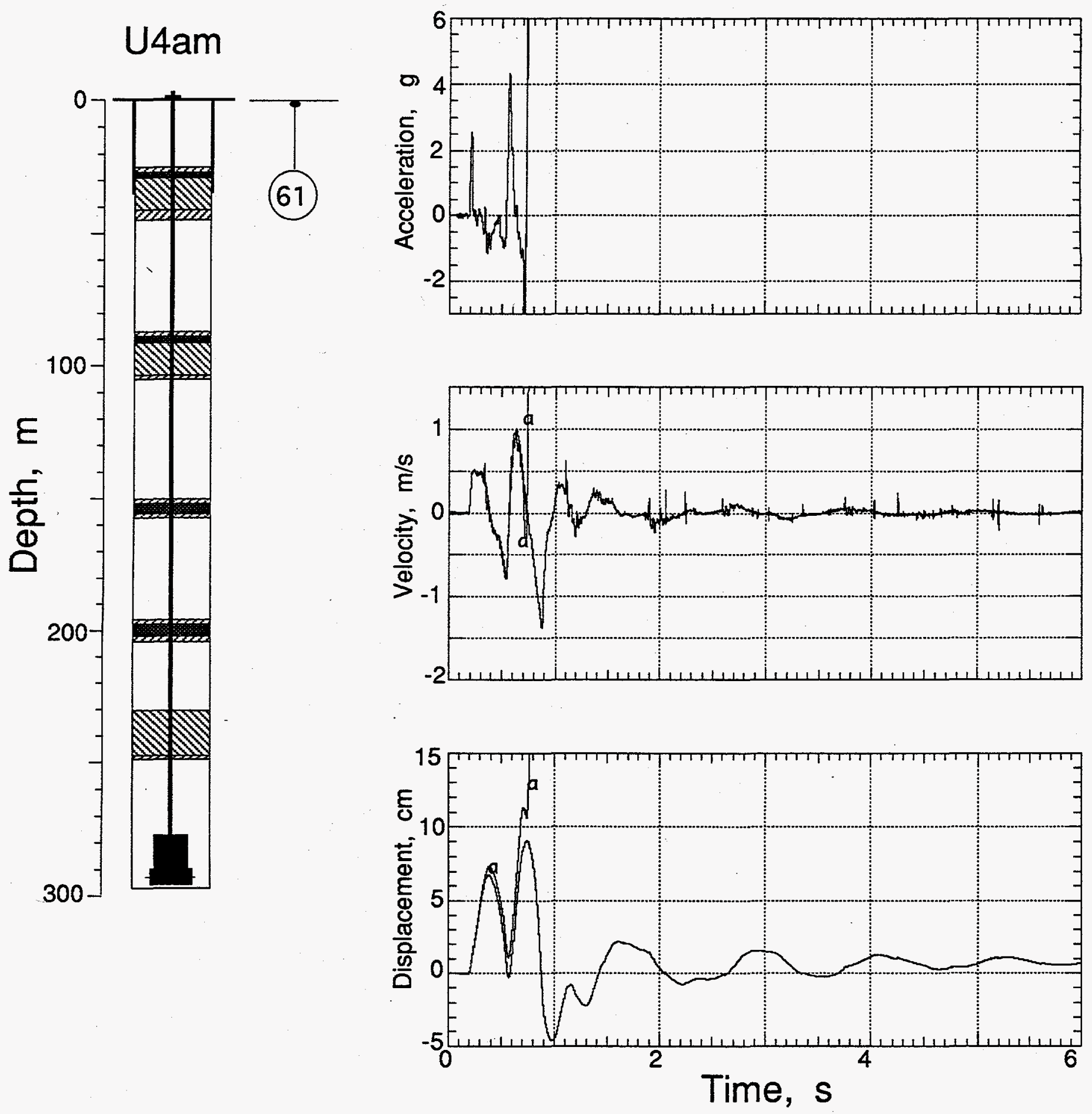

Figure 3.23 Vertical motion of the ground surface (station 61 at a horizontal range of $15.24 \mathrm{~m}$ and a depth of $0.9 \mathrm{~m}$ ). Traces annotated with "a" are derived from the accelerometer. 


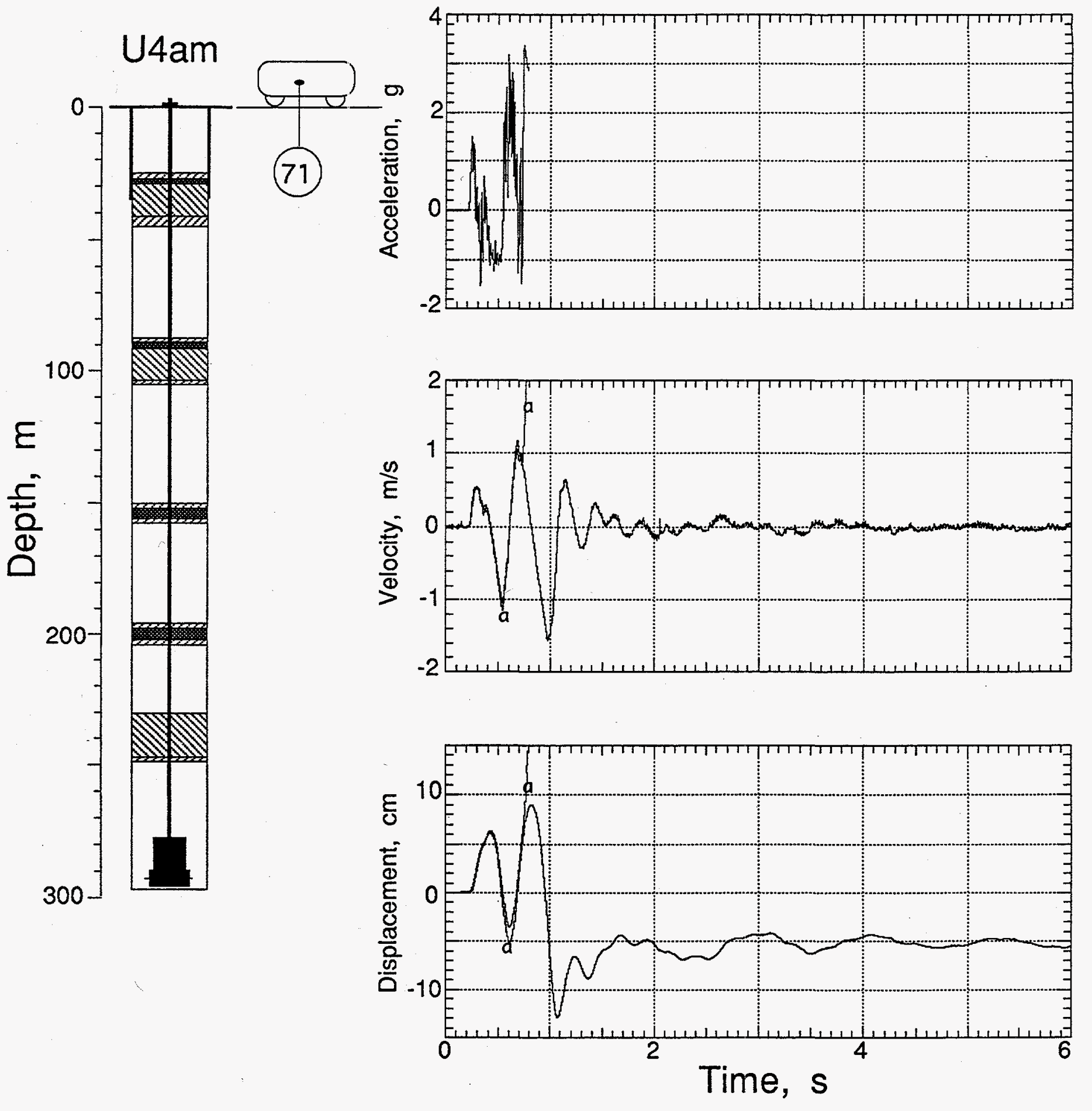

Figure 3.24 Vertical notion of the recording trailer (station 71 at a horizontal range of about $327 \mathrm{~m}$ ). Traces annotated with "a" are derived from the accelerometer. 


\subsection{Collapse phenomena}

Collapse motion histories are shown in figures 3.25-3.37. All stations below the top plug were lost at collapse between 1675 and $1681 \mathrm{~s}$. All stations in and above the top plug survived collapse. Station 22 (figure 3.33) was mounted in the concrete of the GFA plug, $0.3 \mathrm{~m}$ above the bottom of the surface casing.

Both CLIPER cables (station 91 and 92) performed as expected, giving the lower position of each cable end as a function of time during the cavity collapse. These data are shown in figure 3.38 along with selected displacement wave forms (not to vertical scale). The CLIPER history suggest that there was a final failure in the top plug near the bottom of the surface casing. The displacement histories from stations 22 and 61 shown in figure 3.38 suggest that all material fell as a unit after the collapse front reached the surface casing. Figure 3.39 displays the displacement histories of the top plug (station 22), the surface casing (station 23), and the emplacement pipe (station 5). There does not seem to be any separation between the surface casing and the plug, at least until the sensor at station 23 exceeds its dynamic range and the histories of station 22 and 23 cease to track. The emplacement pipe begins its motion at about $1679 \mathrm{~s}$, the time the collapse reaches GFA plug 4 as shown in figure 3.38 .

A vertical, linear array of seven proximity switches was mounted in the top SGC plug next to the bottom of the surface casing. Switch states labeled "on" imply the nearby presence of ferrous metal (surface casing) and "off"; its absence. No change of switch state was noted until the time of surface collapse and then switches "a", "b", "c" and "d" registered a change of state (switch "c" was lost at collapse time). Figure 3.40 shows the switch closure history around collapse time. Correlation of the proximity switch data and the collapse slap-down peak suggests that the collapse drove the switch array $15 \pm 5 \mathrm{~cm}$ into the casing. (The switches had a vertical separation of $5.08 \mathrm{~cm}$.) 

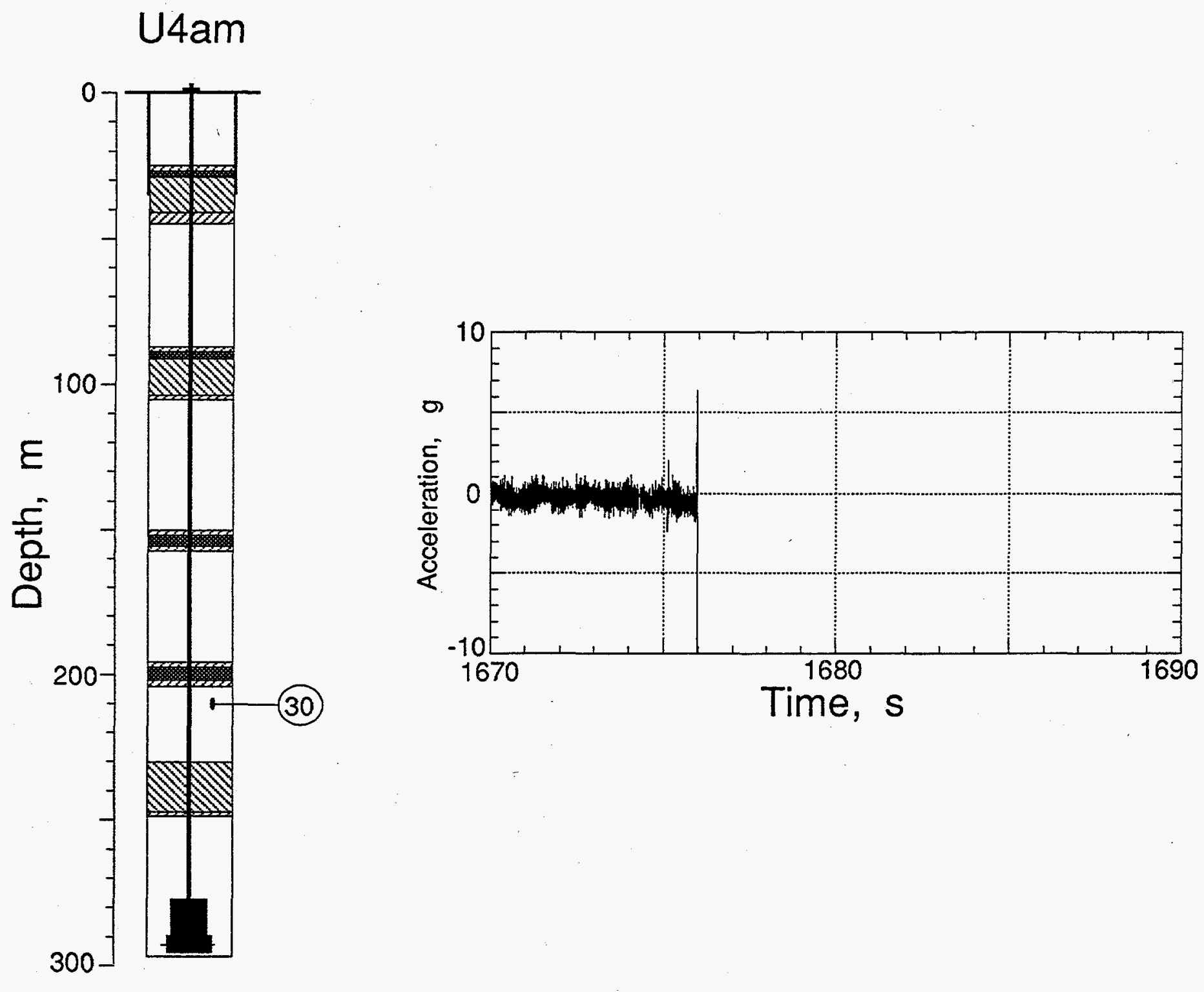

Figure 3.25 Collapse motion of the stemming between the deepest GFA plug 1 and the deepest gas seal plug 2 (station 30 at a depth of $210.3 \mathrm{~m}$ ). Signal was lost at about $1676 \mathrm{~s}$. 

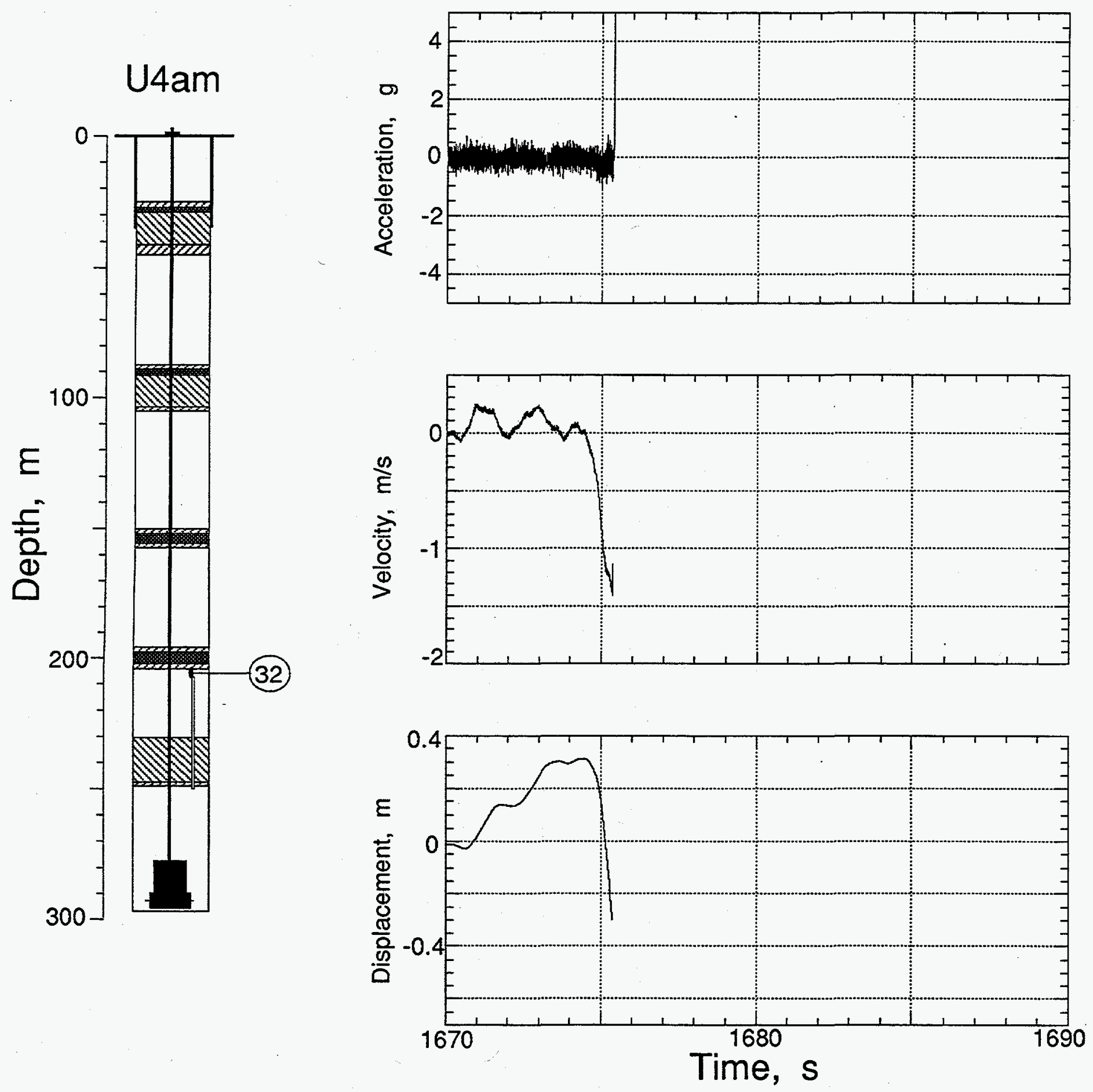

Figure 3.26 Collapse motion of the stemming below the deepest gas seal plug 2 (station 32 at a depth of $206.7 \mathrm{~m}$ ). This station was attached to a section of gas sample hose. Signal was lost at about $1675.5 \mathrm{~s}$. 

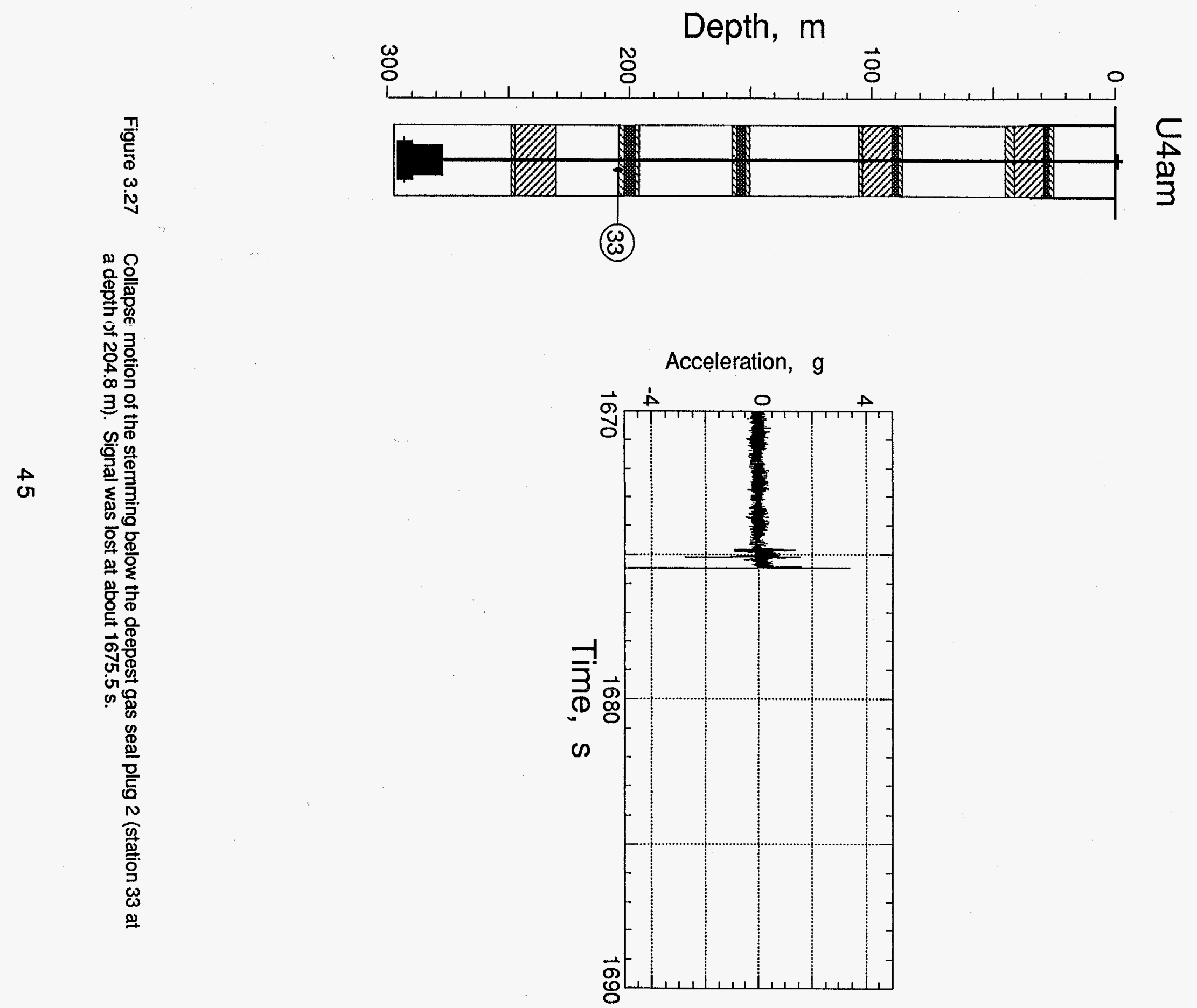

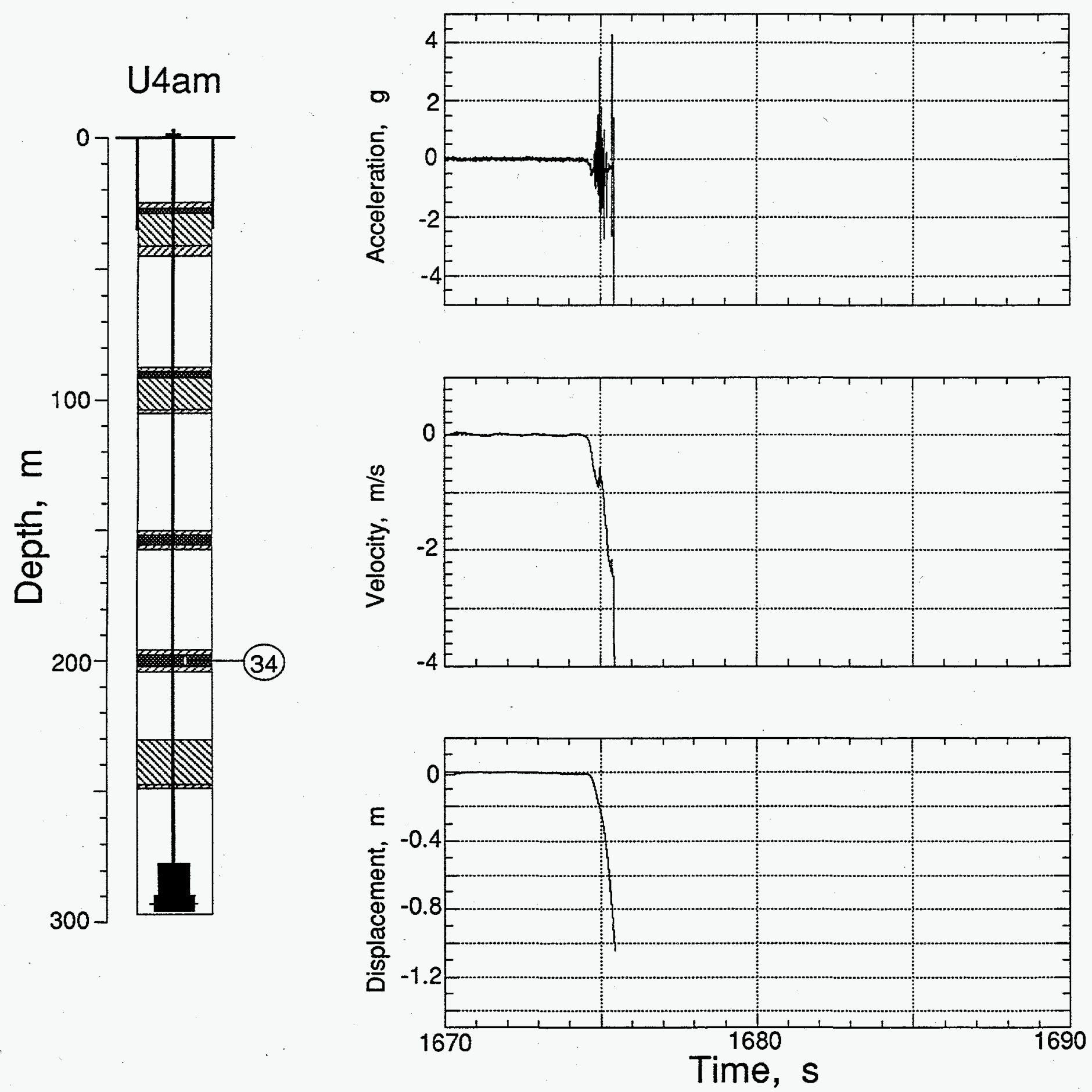

Figure 3.28 Collapse motion of the deepest gas seal plug 2 (station 34 at a depth of $199.6 \mathrm{~m}$ ). Signal was lost at about $1675.5 \mathrm{~s}$. 

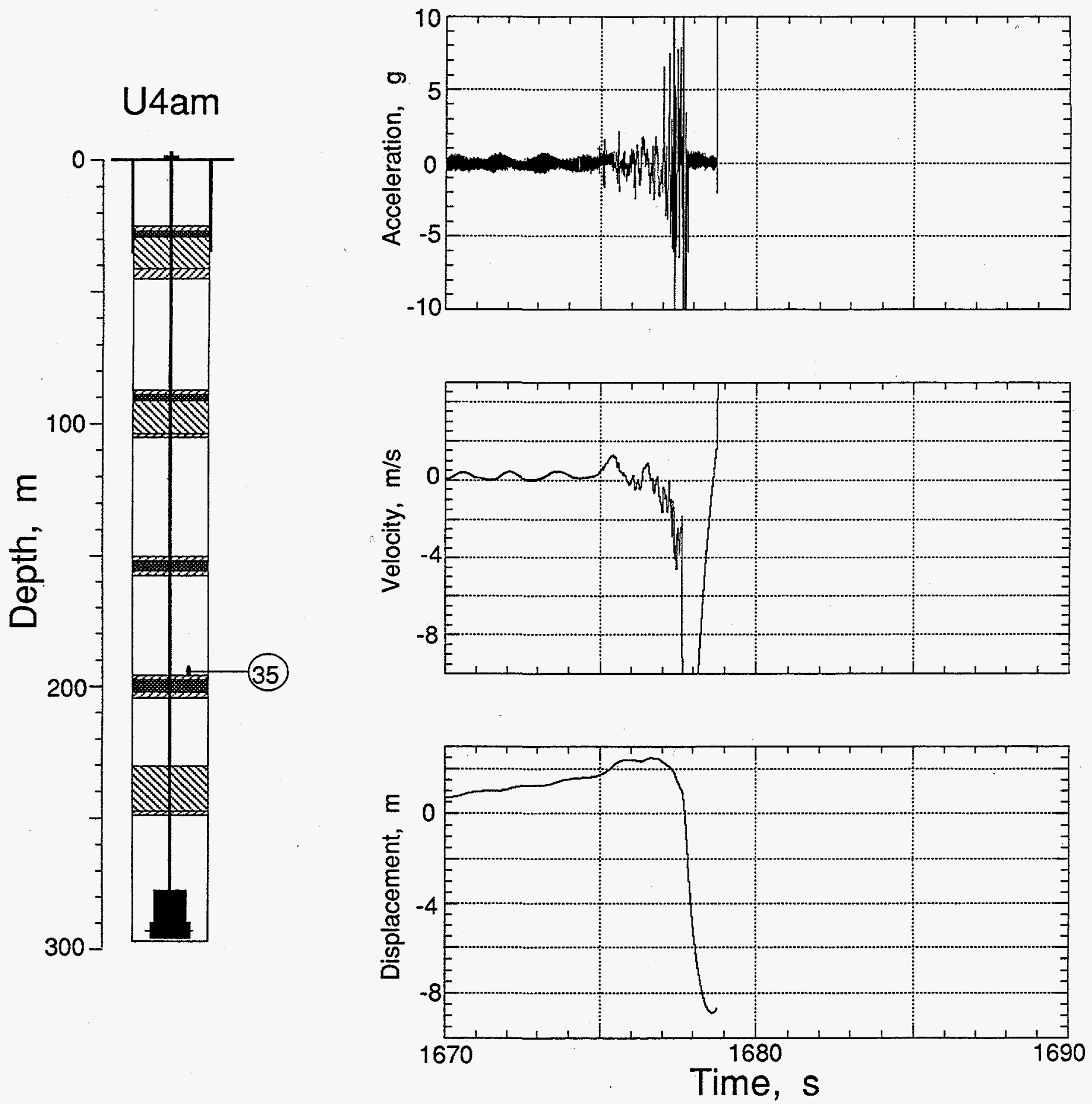

Figure 3.29 Collapse motion of the stemming above the deepest gas seal plug 2 (station 35 at a depth of $195.5 \mathrm{~m}$ ). Signal was lost at about $1677.5 \mathrm{~s}$. 

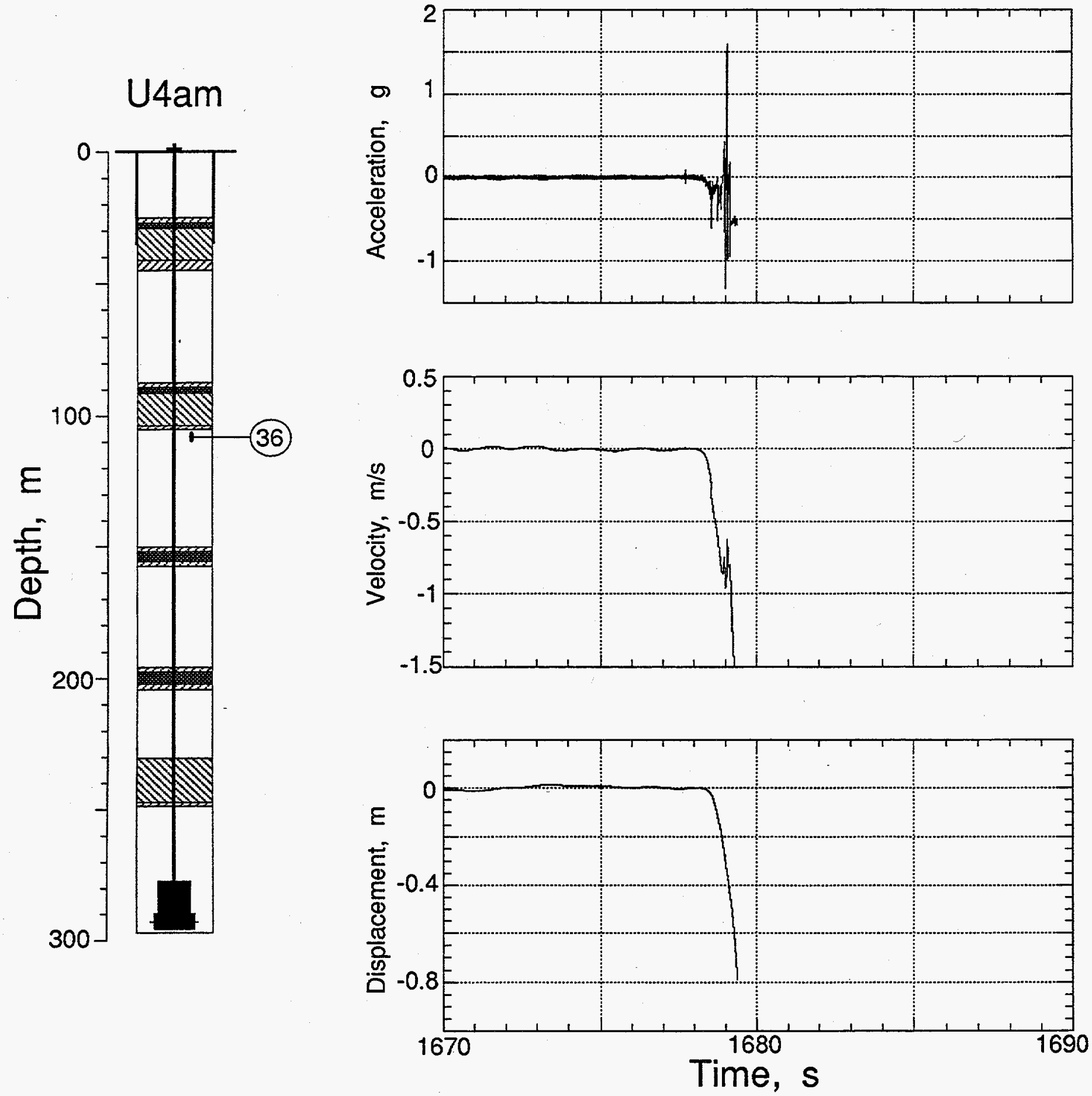

Figure 3.30

Collapse motion of the stemming below GFA plug 4 (station 36 at a depth of $108.2 \mathrm{~m}$ ). Signal was lost at about $1679 \mathrm{~s}$. 


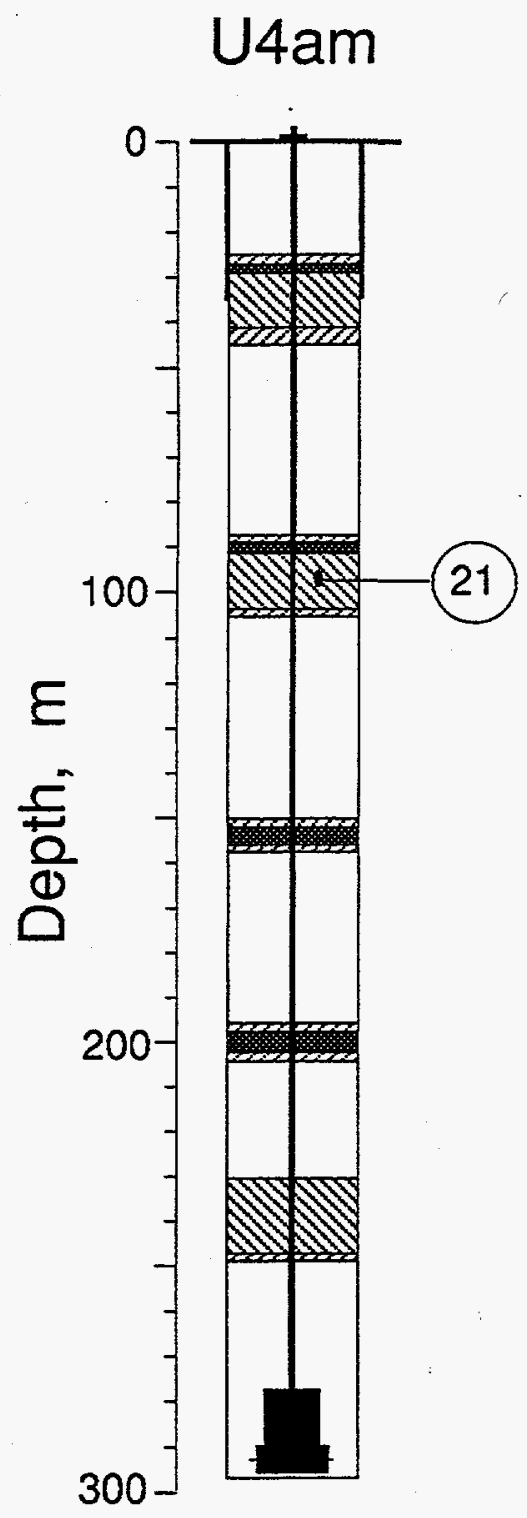

accelerometer signal lost at about $+0.75 \mathrm{~s}$
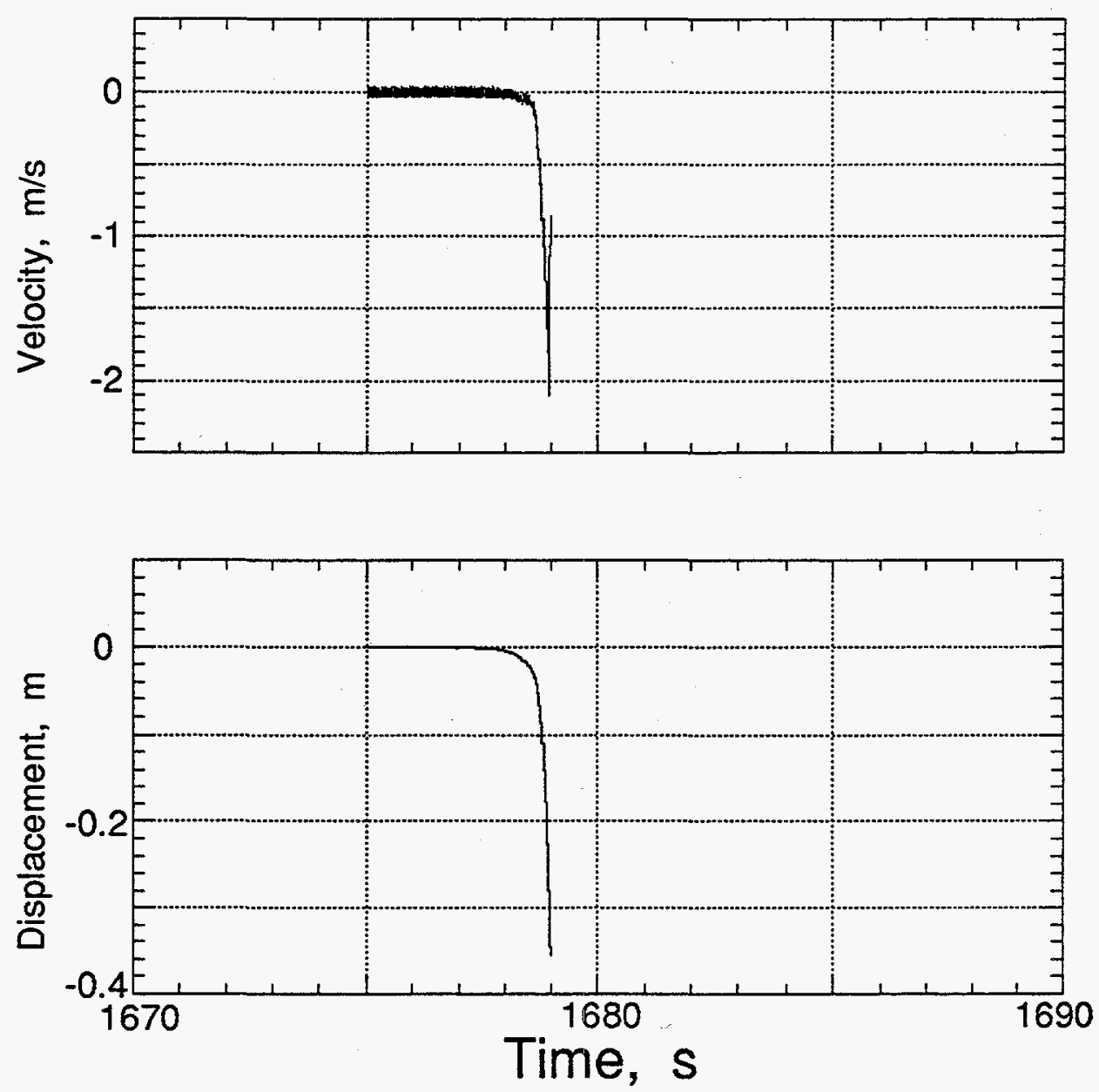

Figure 3.31 Collapse motion of GFA plug 4 (station 21 at a depth of $97.2 \mathrm{~m}$ ). Signal was lost at about $1679 \mathrm{~s}$. 

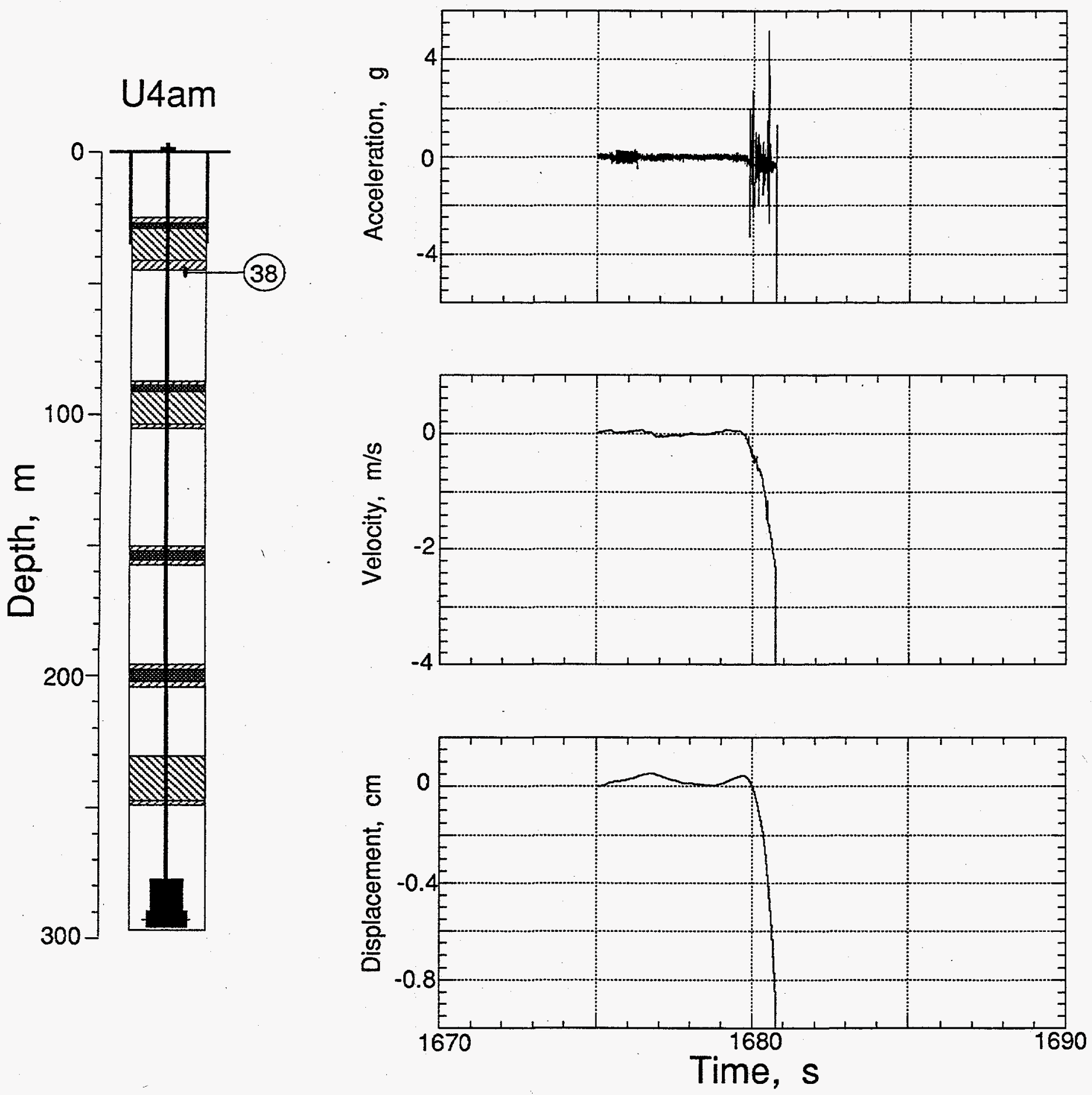

Figure 3.32 Collapse motion of the stemming below the top GFA plug 5 (station 38 at a depth of $45.0 \mathrm{~m}$ ). Signal was lost at about $1671 \mathrm{~s}$. 


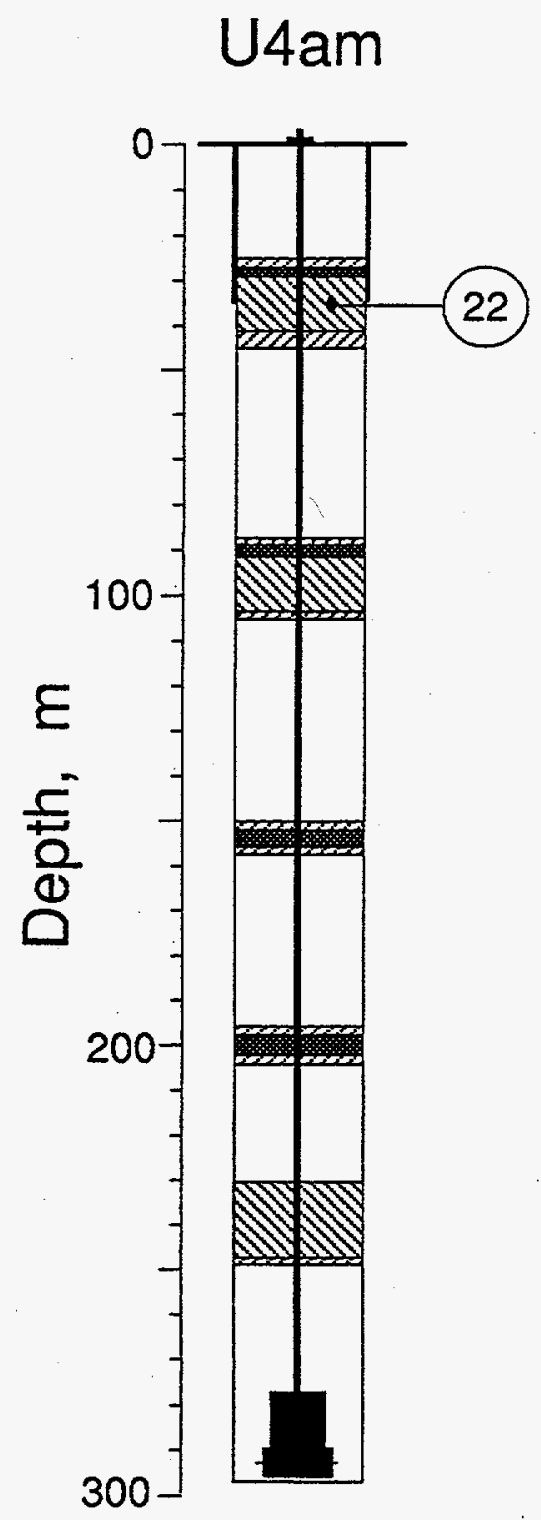

accelerometer signal lost at about $+0.75 \mathrm{~s}$
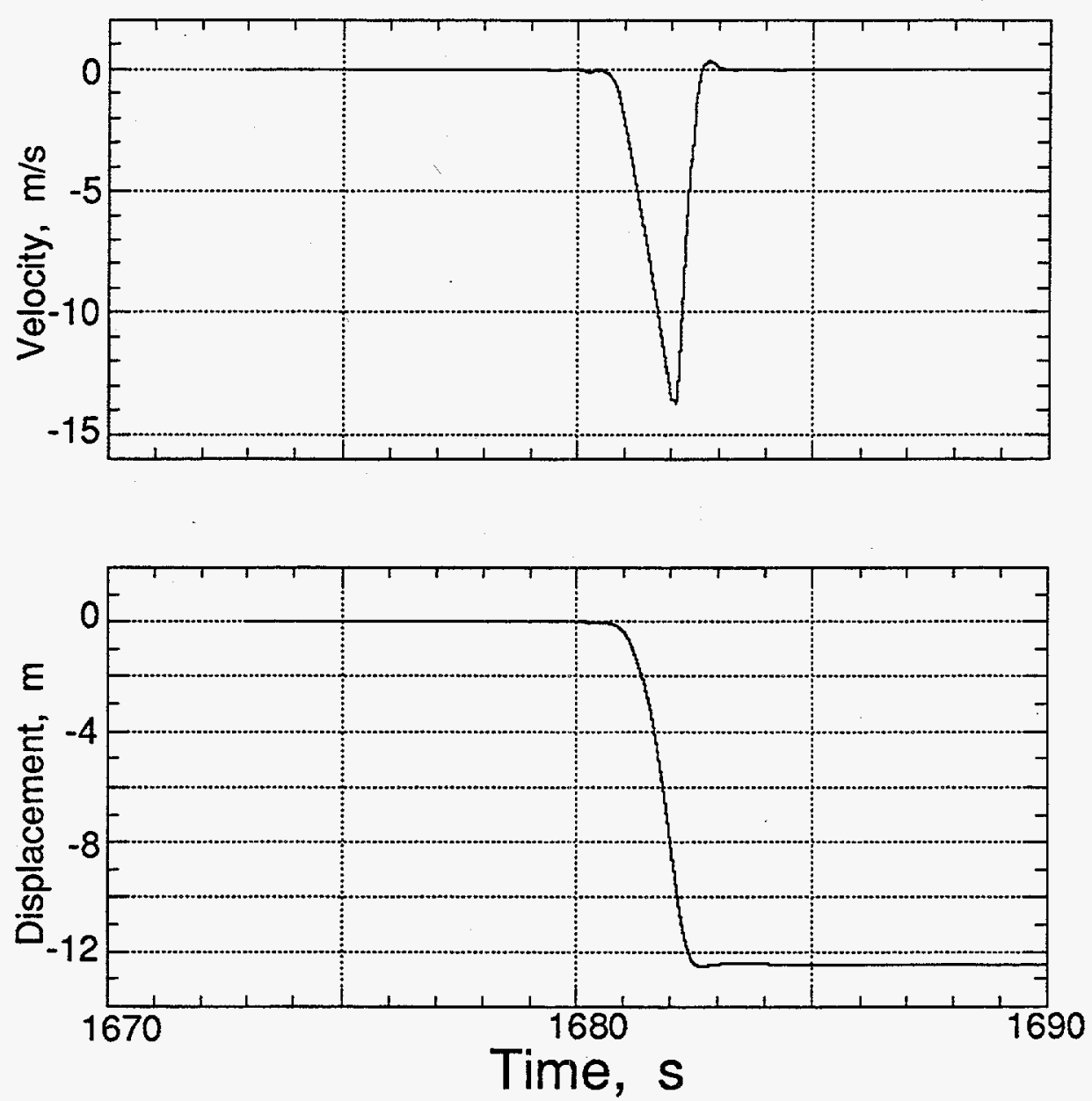

Figure 3.33 Collapse motion of the top GFA plug 5 (station 22 at a depth of $35.4 \mathrm{~m}$ ). 


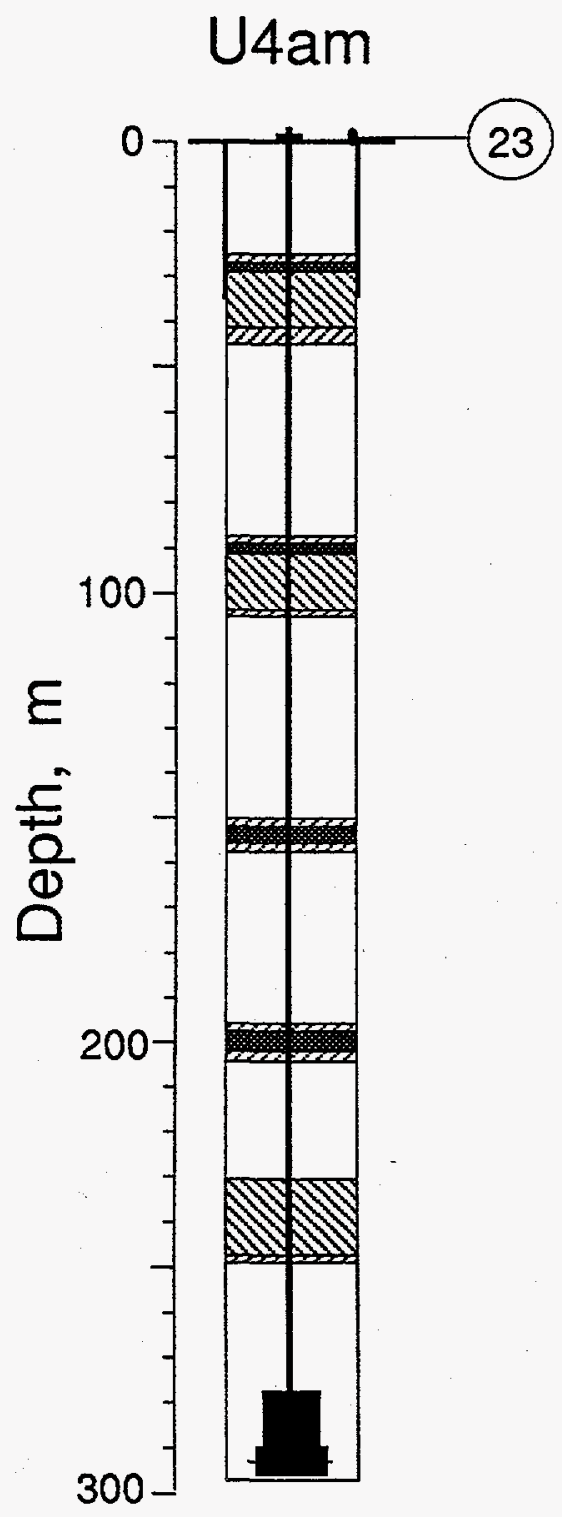

accelerometer signal lost at about $+0.75 \mathrm{~s}$
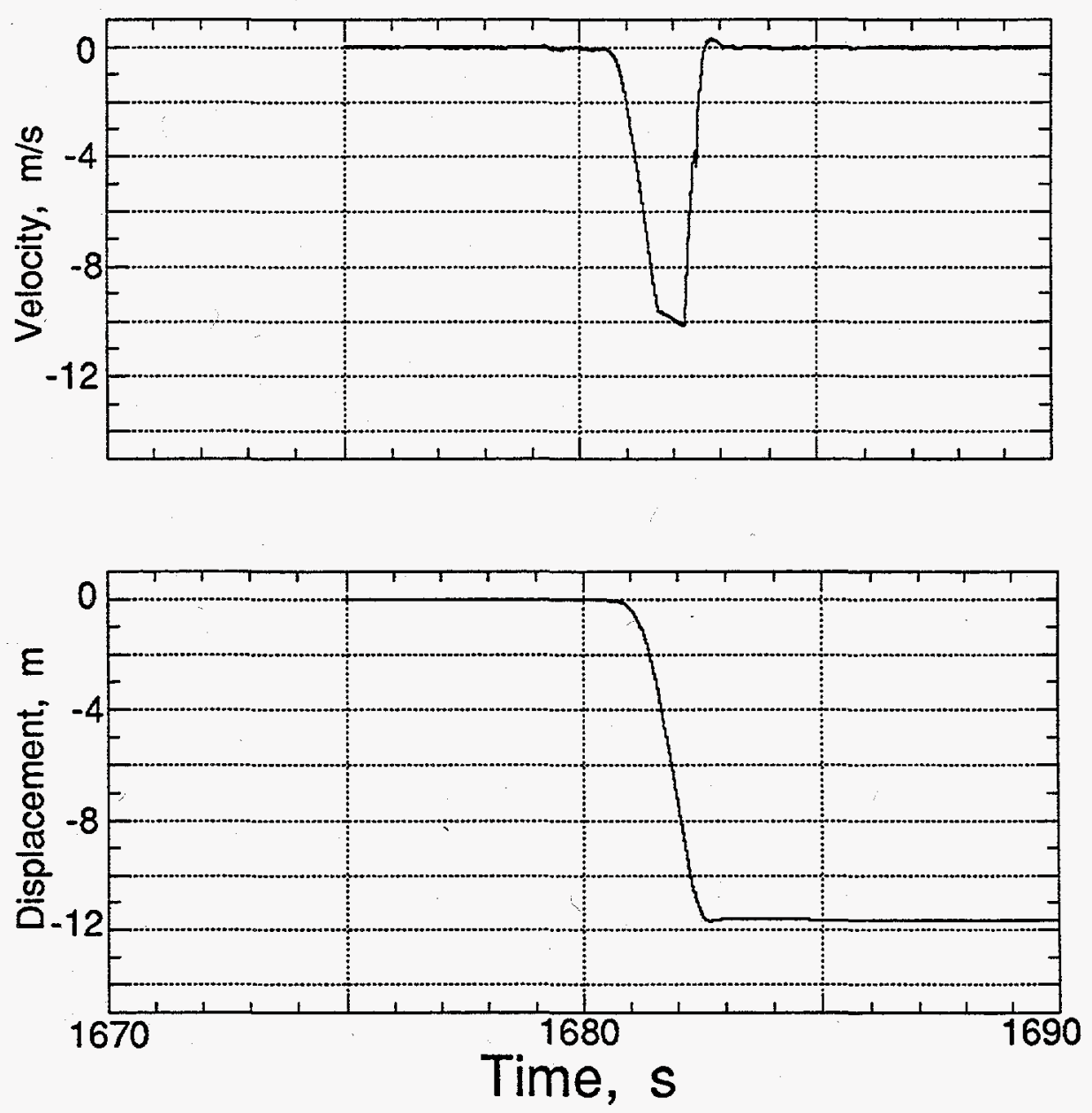

Figure 3.34 Collapse motion of the surface conductor (station 23). The velocity signal exceeded the dynamic range of the system so the final displacement is greater than that shown. 


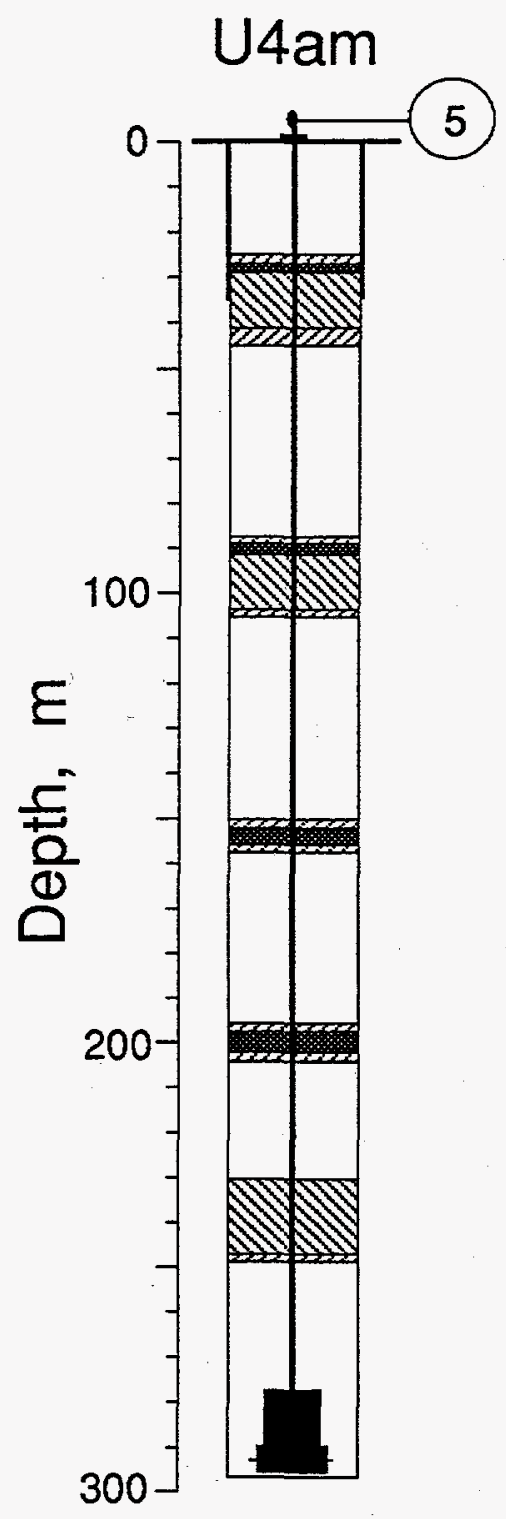

accelerometer signal lost at about $+0.75 \mathrm{~s}$
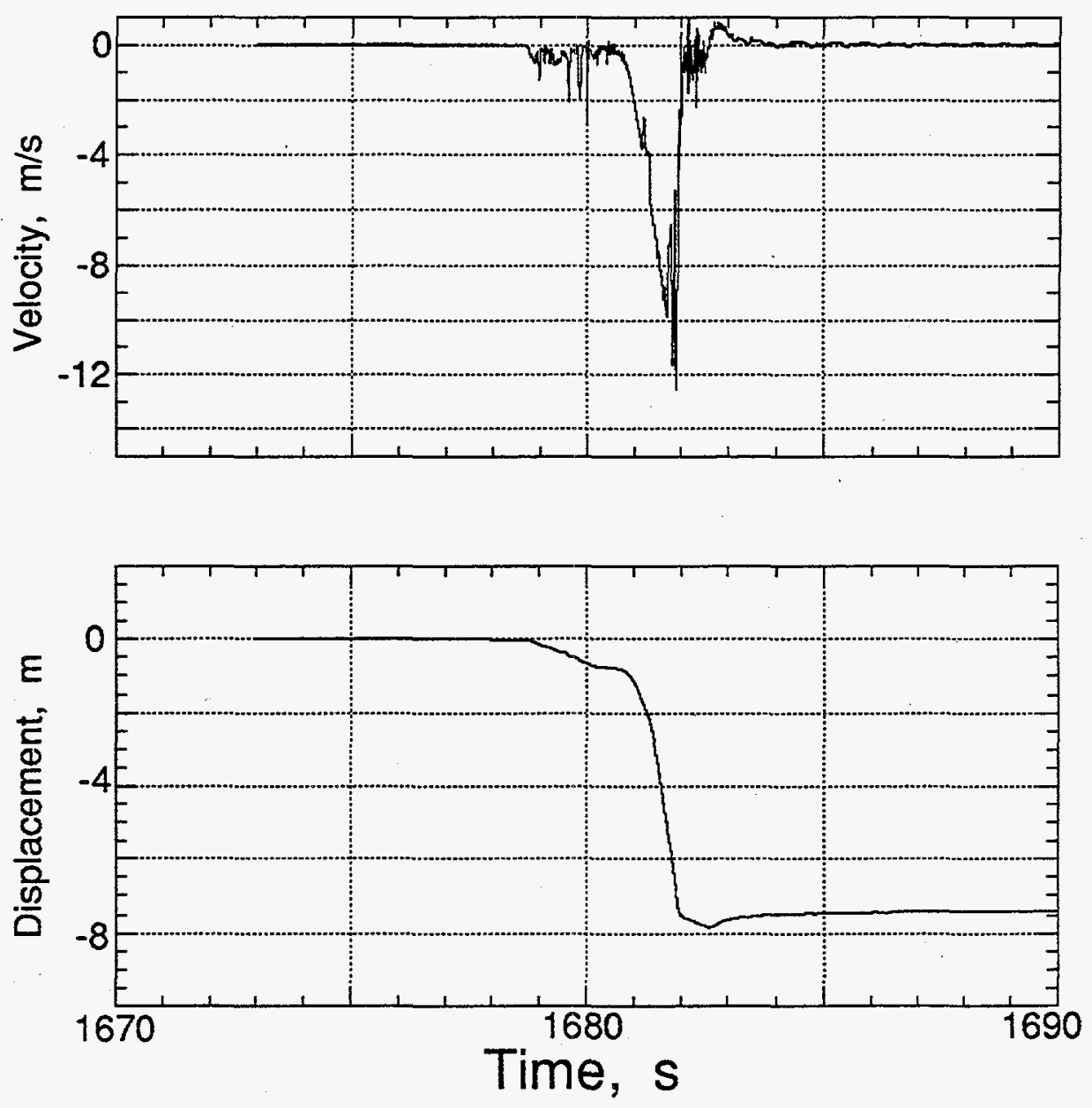

Figure 3.35 Collapse motion of the top of the emplacement pipe (station 5). 


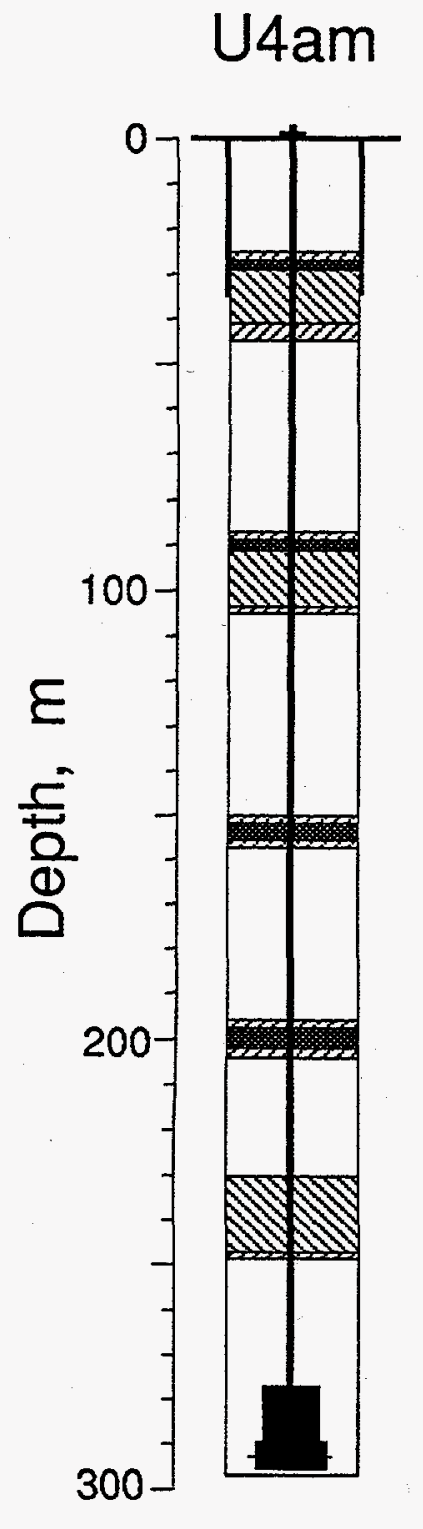

accelerometer signal lost at about $+0.75 \mathrm{~s}$

(61)
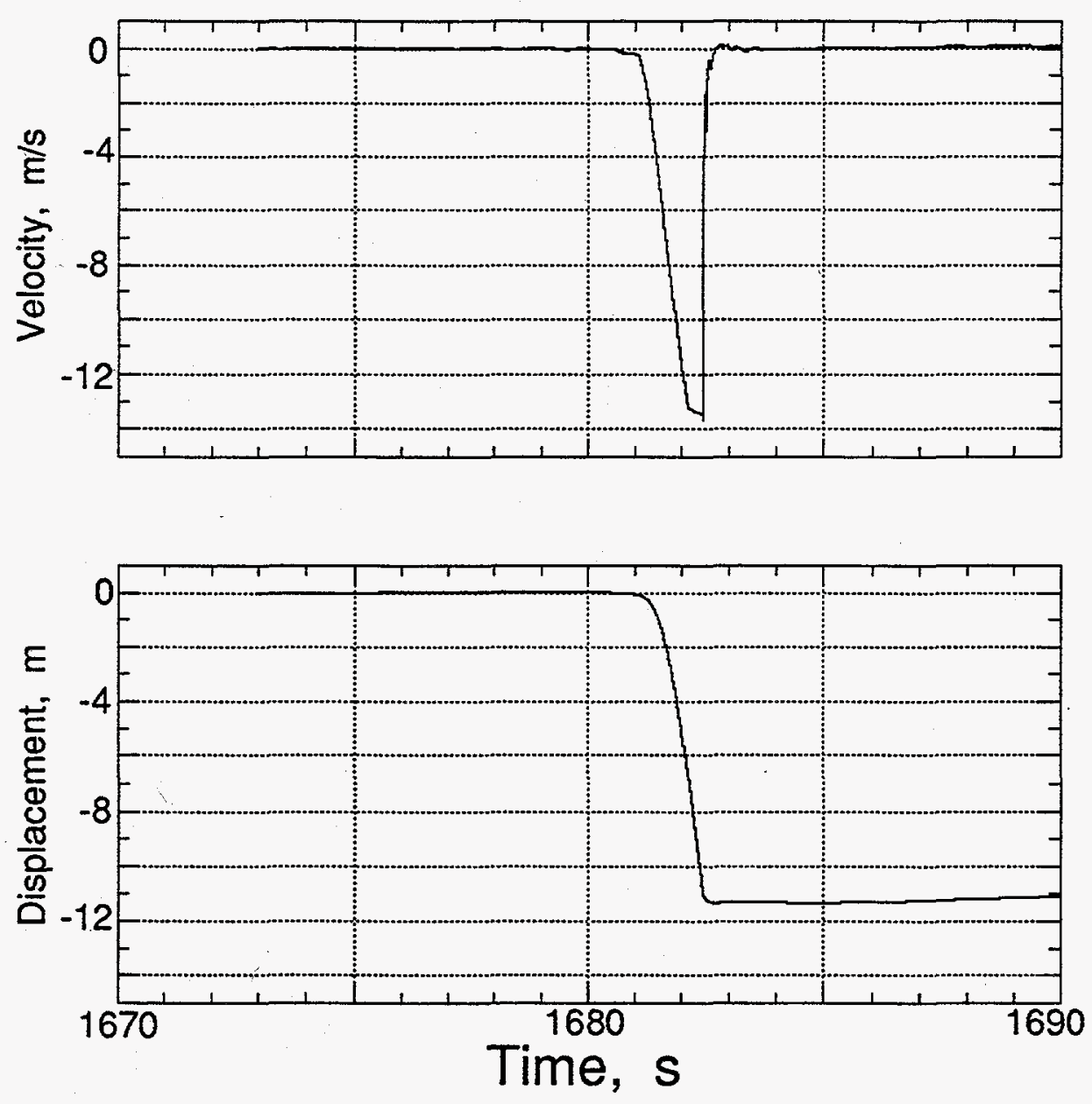

Figure 3.36 Collapse motion of the ground surface (station 61 at a horizontal range of $15.24 \mathrm{~m}$ and $a$ depth of $0.9 \mathrm{~m}$ ). Velocity amplitude was greater than system range so final displacement is greater than that shown. 


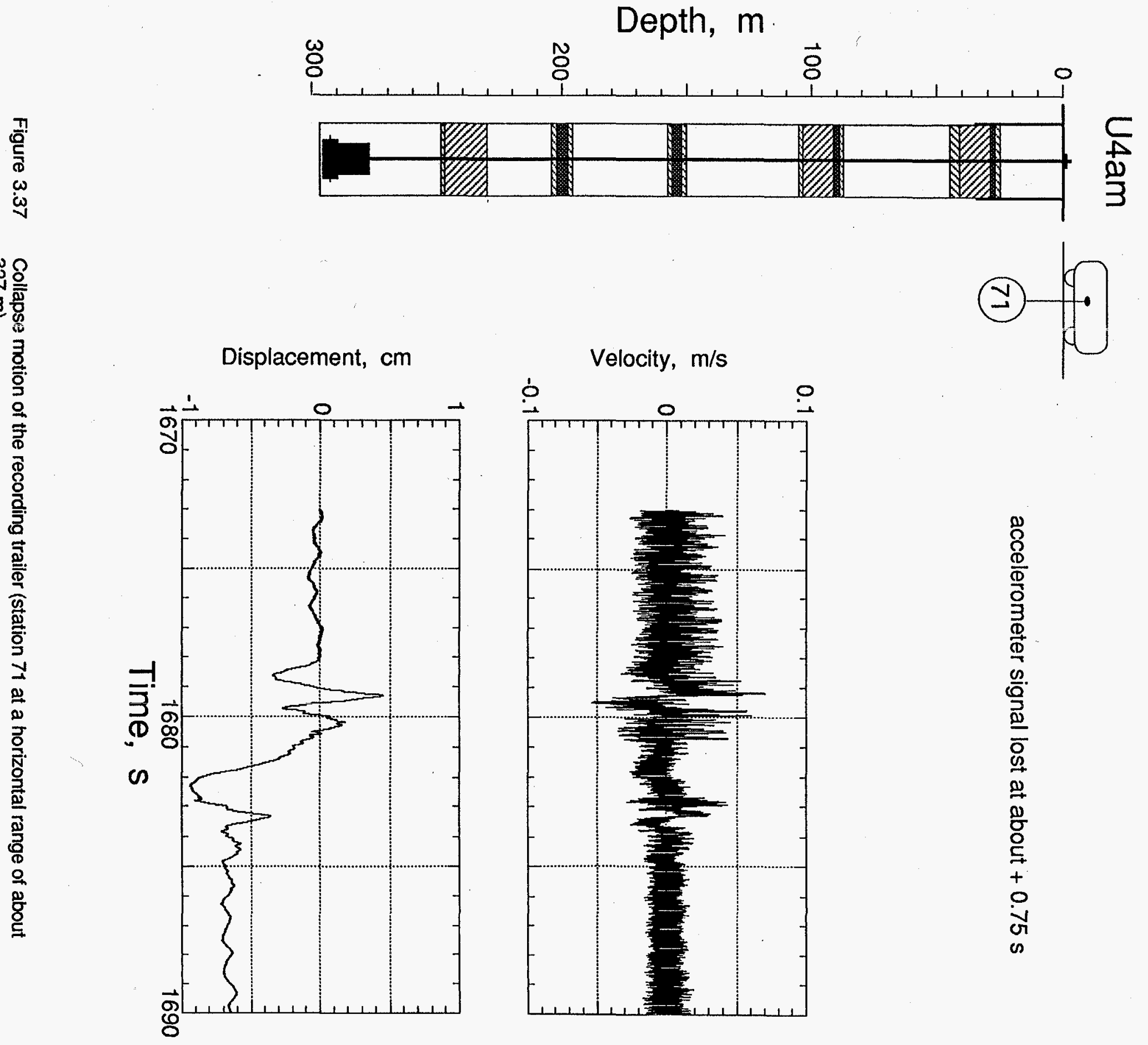



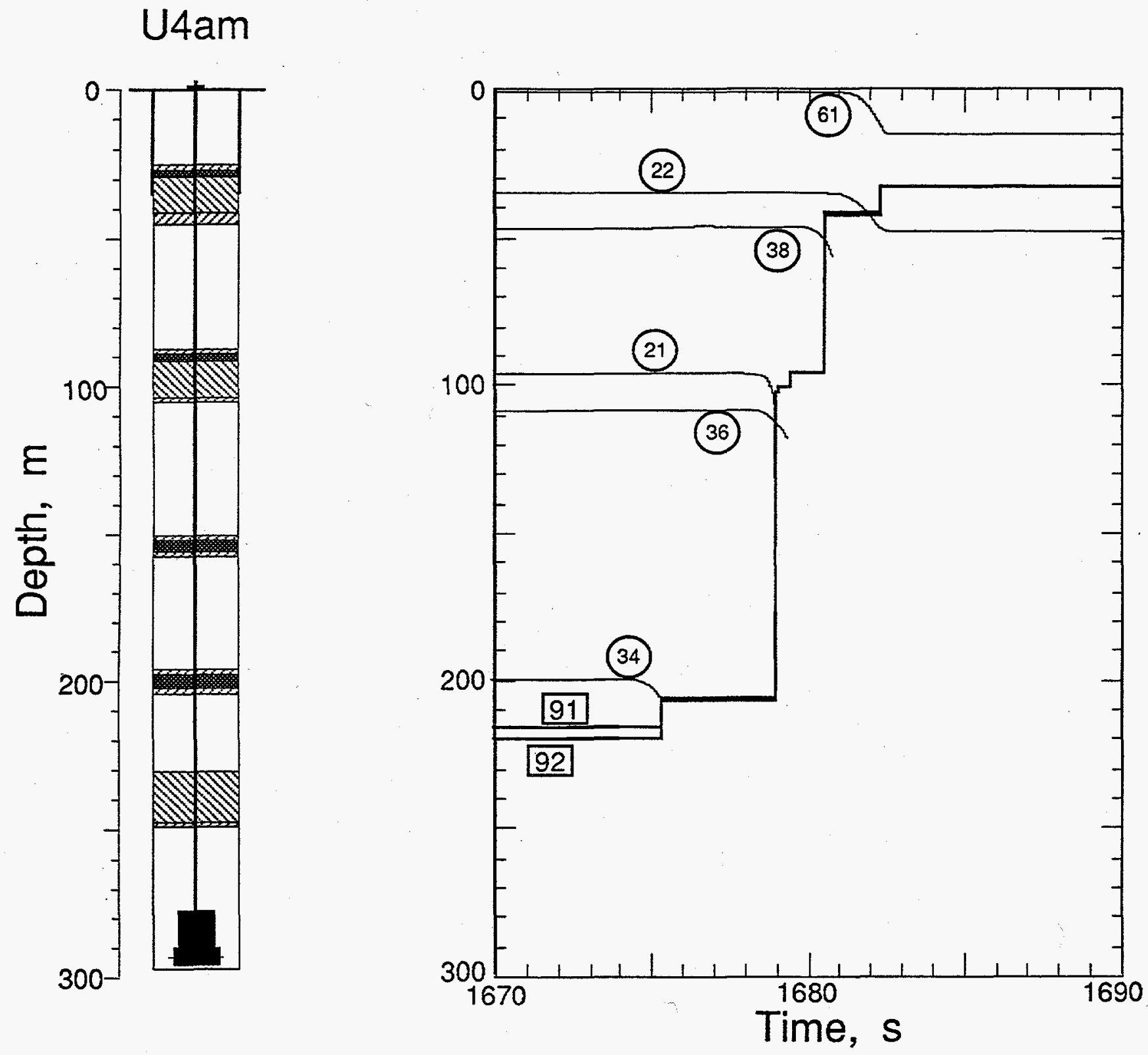

Figure 3.38 Progression of collapse in stemming column as indicated by CLIPER data (stations 91 and 92). Also shown are selected displacement wave forms (not to vertical scale) from five stations in the emplacement hole and one station on the ground surface. 


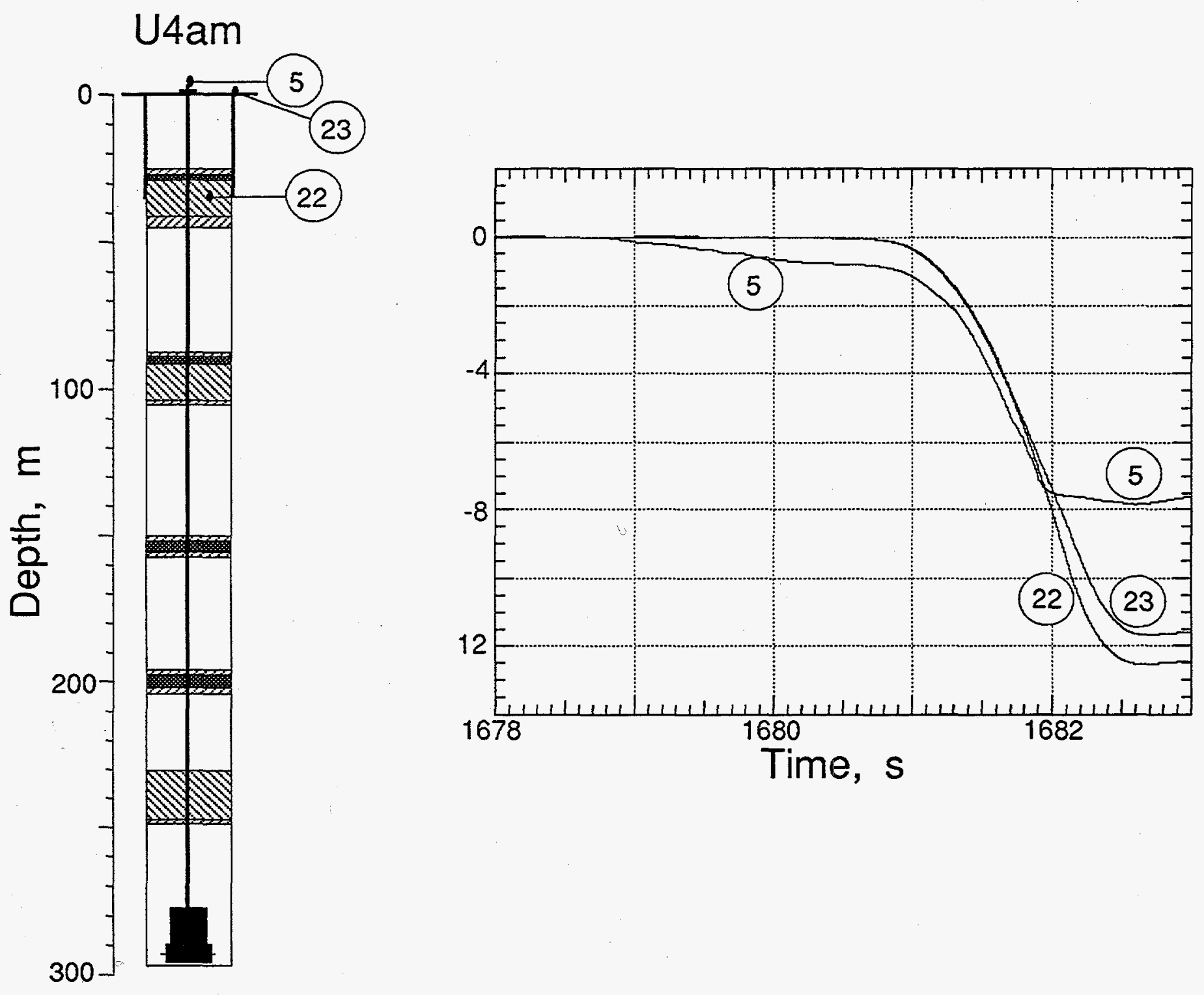

Figure 3.39 Comparison of the displacement histories of the top GFA plug, surface casing and emplacement pipe. 


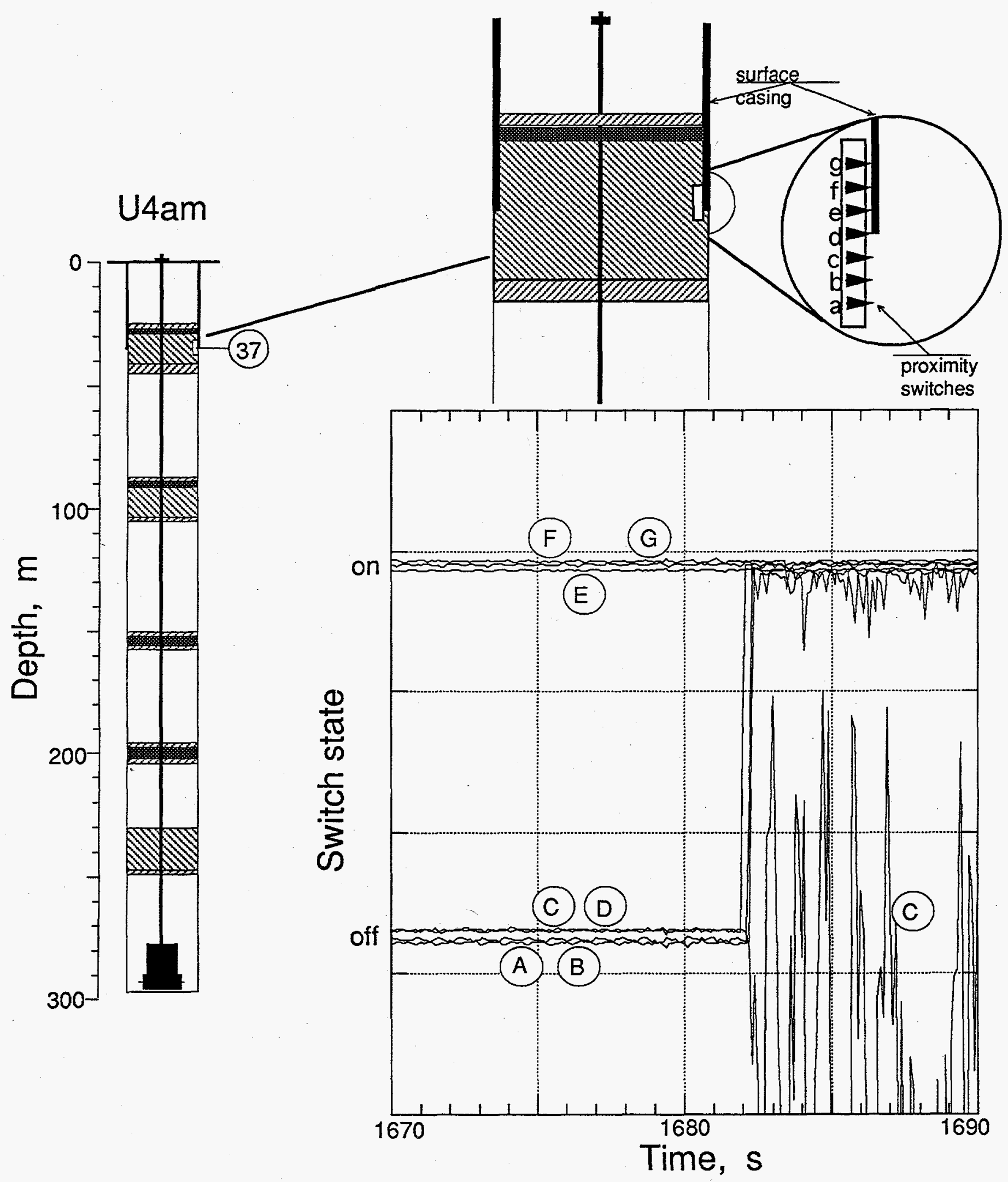

Figure 3.40 Proximity switch array behavior during collapse. No switch state change was observed prior to this time. 


\section{Other Measurements}

\subsection{Gas temperature in the challenge pressure hose}

Temperature of the gas within the section of gas sample hose connecting station 32 with the coarse stemming below the first GFA plug was monitored at station 32. The temperature history thus obtained is shown in figure 4.1. The data at times later than $100 \mathrm{~s}$ are suspect.

\subsection{Stress and strain in the deepest plugs}

Stress measurements were made in the bottom GFA plug and in the bottom CT/A gas seal plug. The resulting wave forms are shown in figures 4.2-4.8. Amplitudes of these records are given in percent change of initial gauge resistance.

The sensor of station 4 (at 244.7 m depth in the GFA plug, figure 4.2) was a fluidcoupled disk supplied by Sandia Corporation.

Bi-axial stress arid strain transducers ${ }^{(6)}$ were mounted at two elevations in the bottom GFA plug and at one location in the bottom CT/A. The active elements for stress were Ytterbium while the strain elements were composed of Constantan. Figures 4.3, 4.5, and 4.7 show the raw transducer outputs while figures $4.4, .4 .6$, and 4.8 show the "corrected" stress derived from these records. The polarity of the sensors is such that the strain component of the Ytierbium is removed by a simple addition of the Constantan output multiplied by the ratic of the strain gage factors ( 1.57 in this case).

The stress wave should arrive at these stations no earlier than $\mathbf{4 0}$ ms suggesting that the wave form seen on stations 1,2 , and 3 starting at detonation time is probably due to coupling of the EMP into the transducer system. Due to its magnitude and duration, this common signal appears to interfere with the stress and strain data in an irremovable manner. 


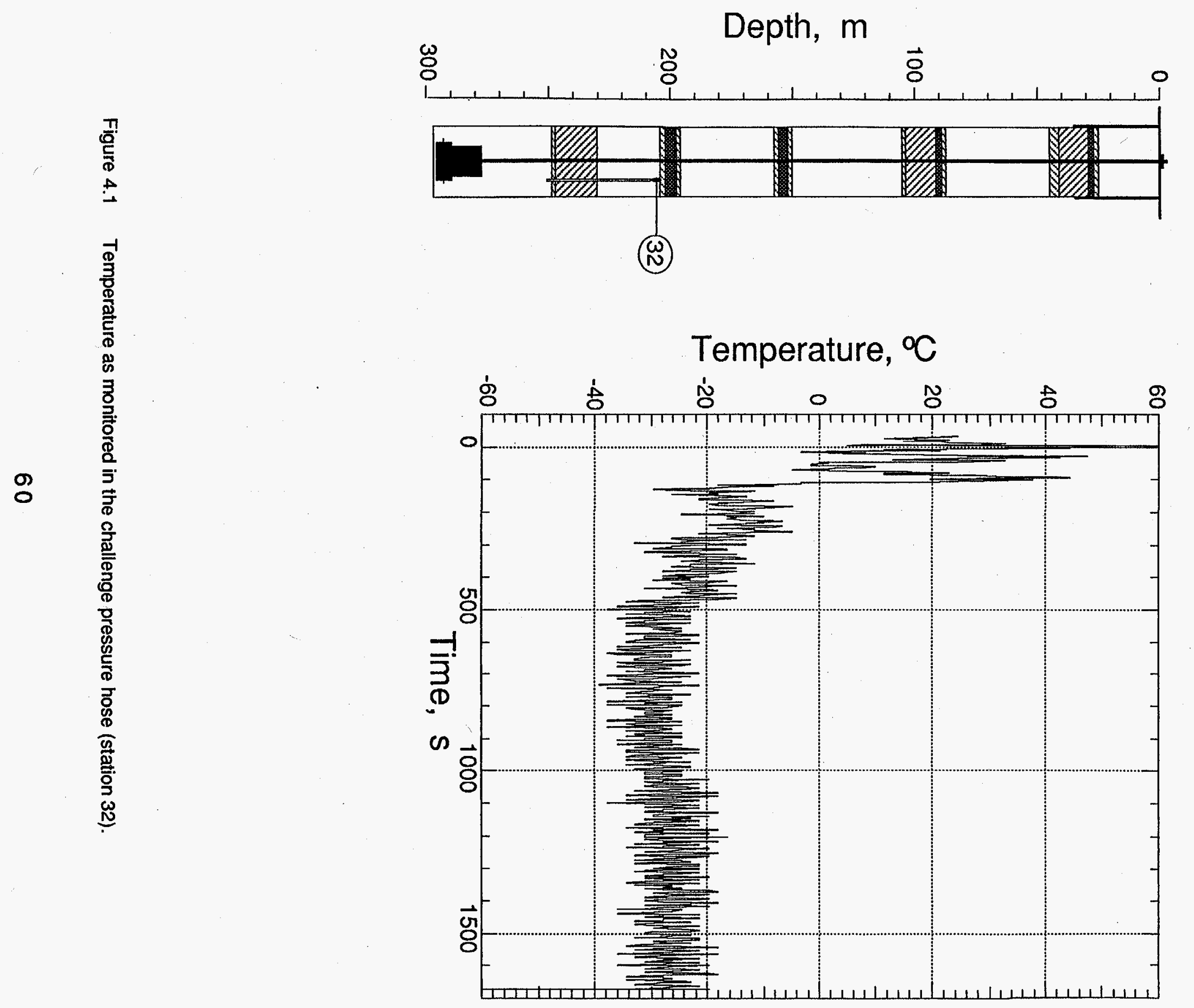



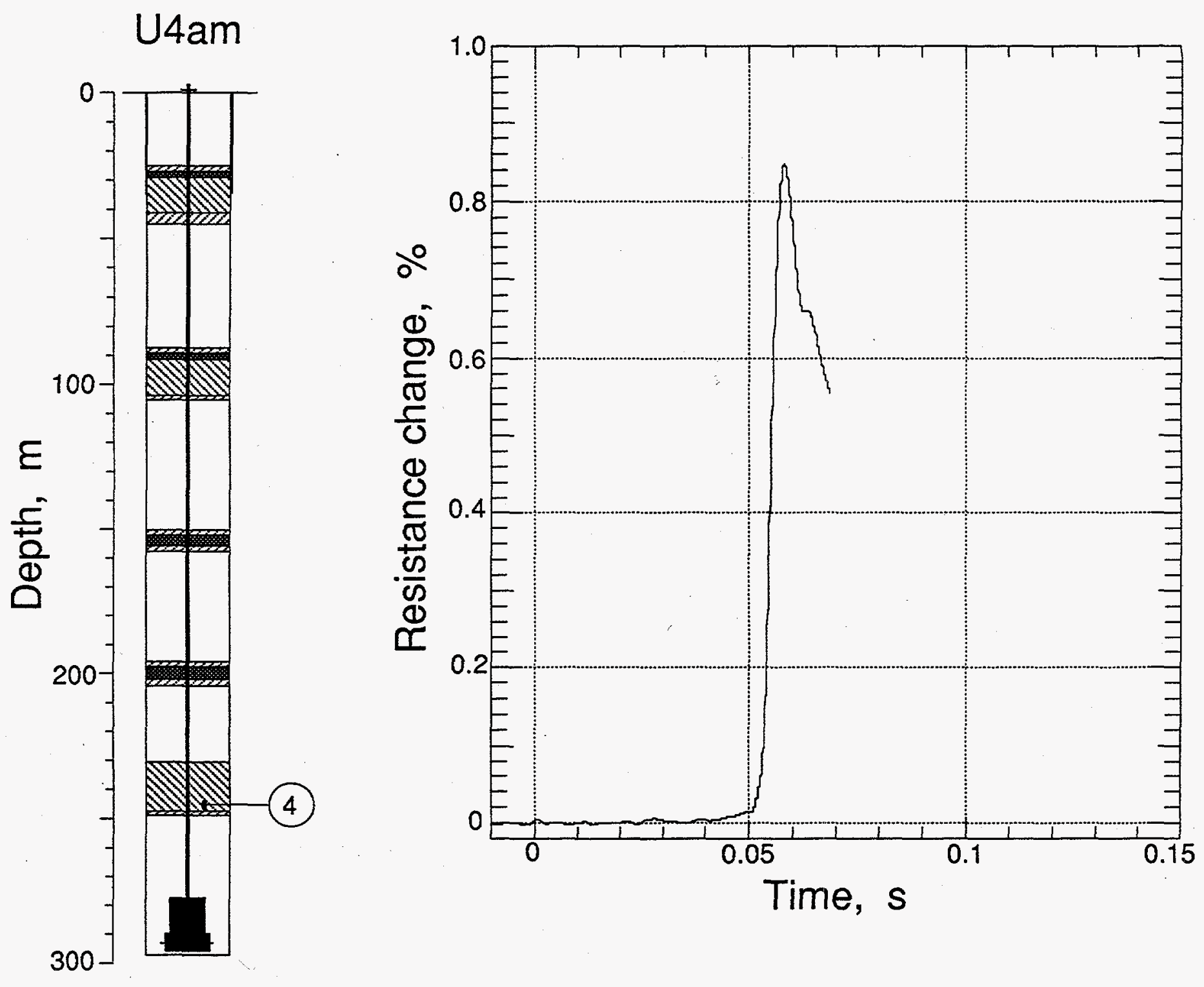

Figure 4.2 Stress in the deepest GFA plug as monitored by a Sandia fluid-coupled disk transducer at a depth of $244.7 \mathrm{~m}$ (station 4). 

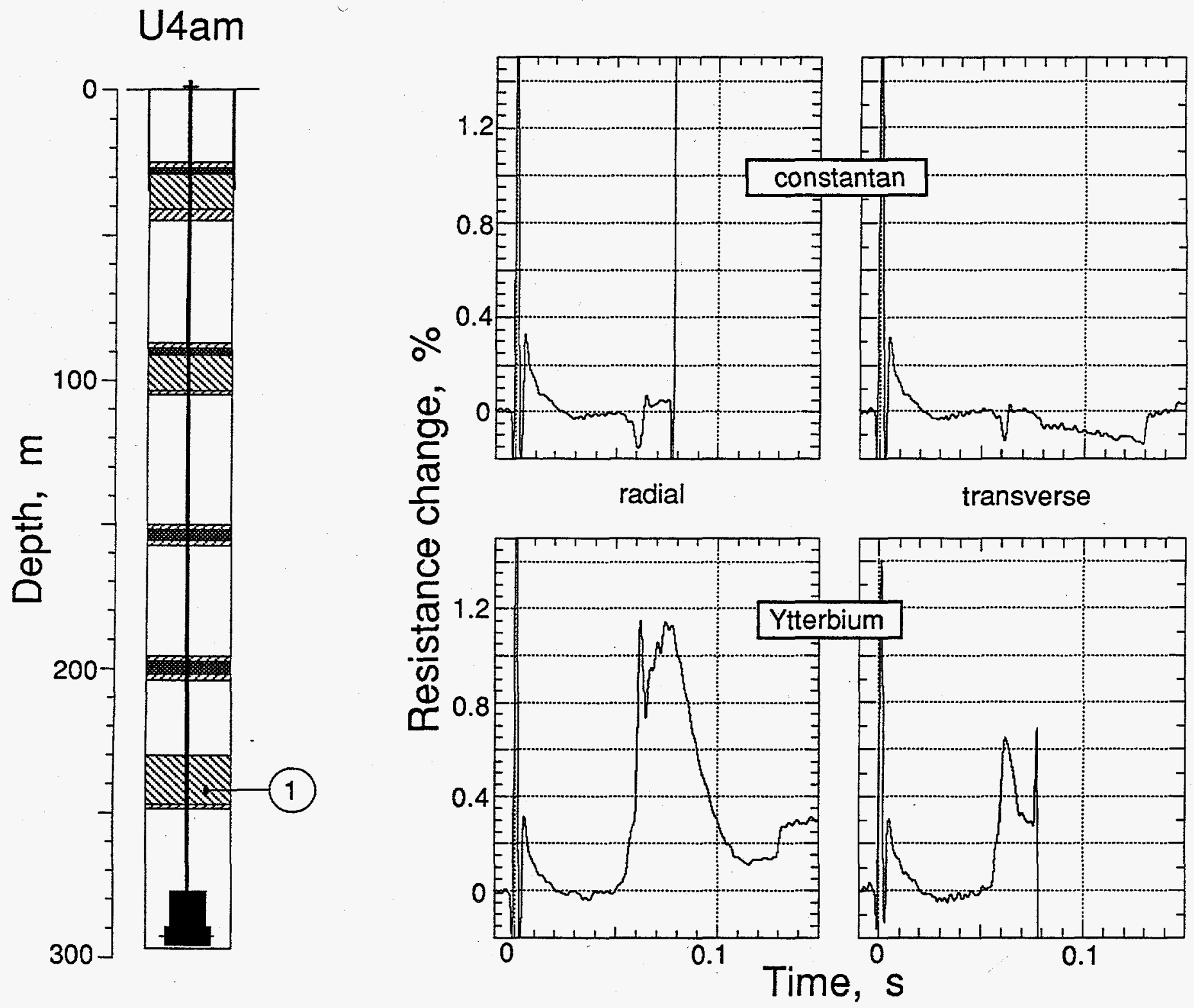

Figure 4.3 Bi-axial stress and strain in the deepest GFA plug at a depth of $242.3 \mathrm{~m}$ (station 1). Ytterbium data are NOT corrected for strain. 

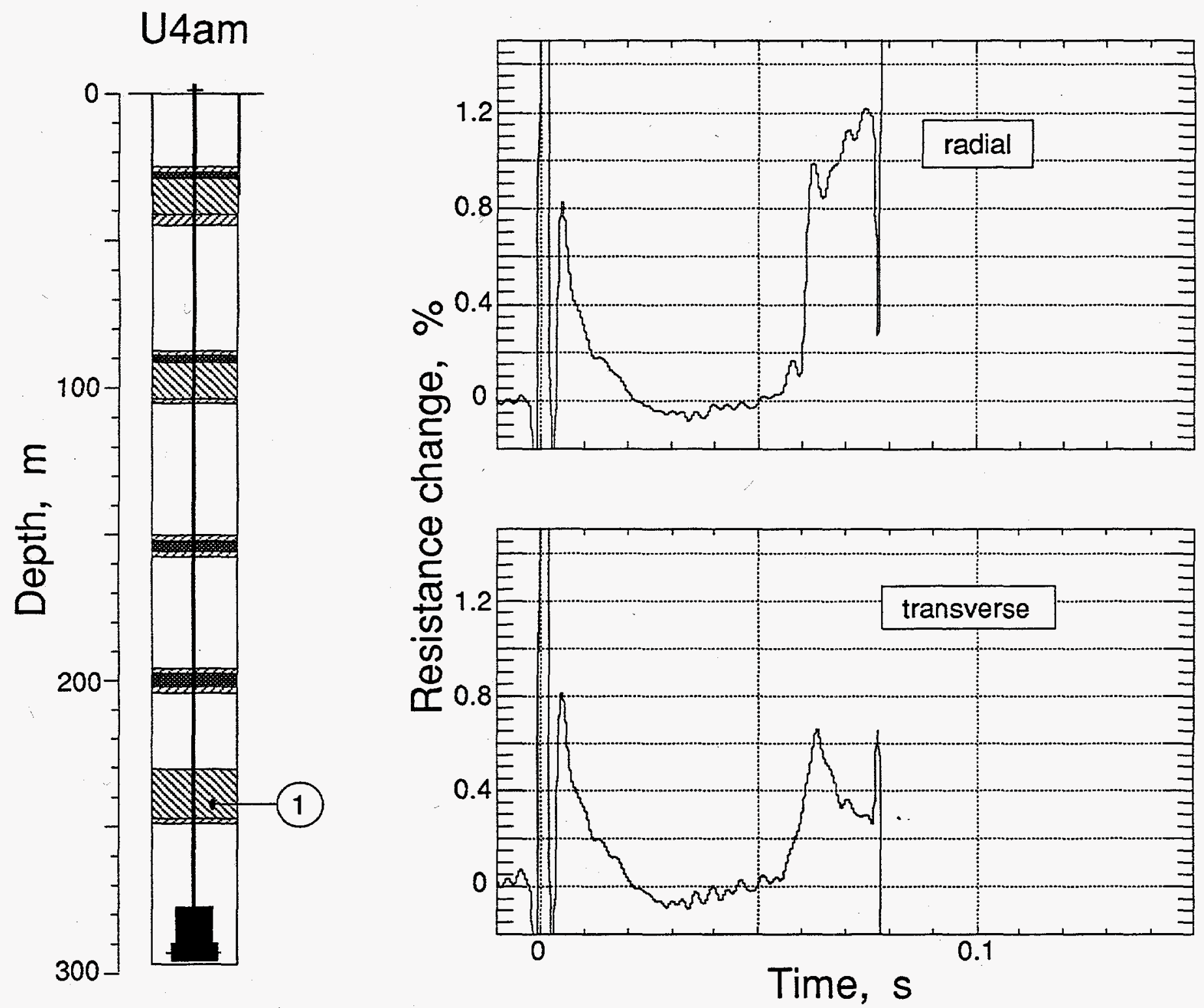

Figure 4.4 Bi-axial stress and strain in the deepest GFA plug at a depth of $242.3 \mathrm{~m}$ (station 1). Stress data are corrected for strain. 

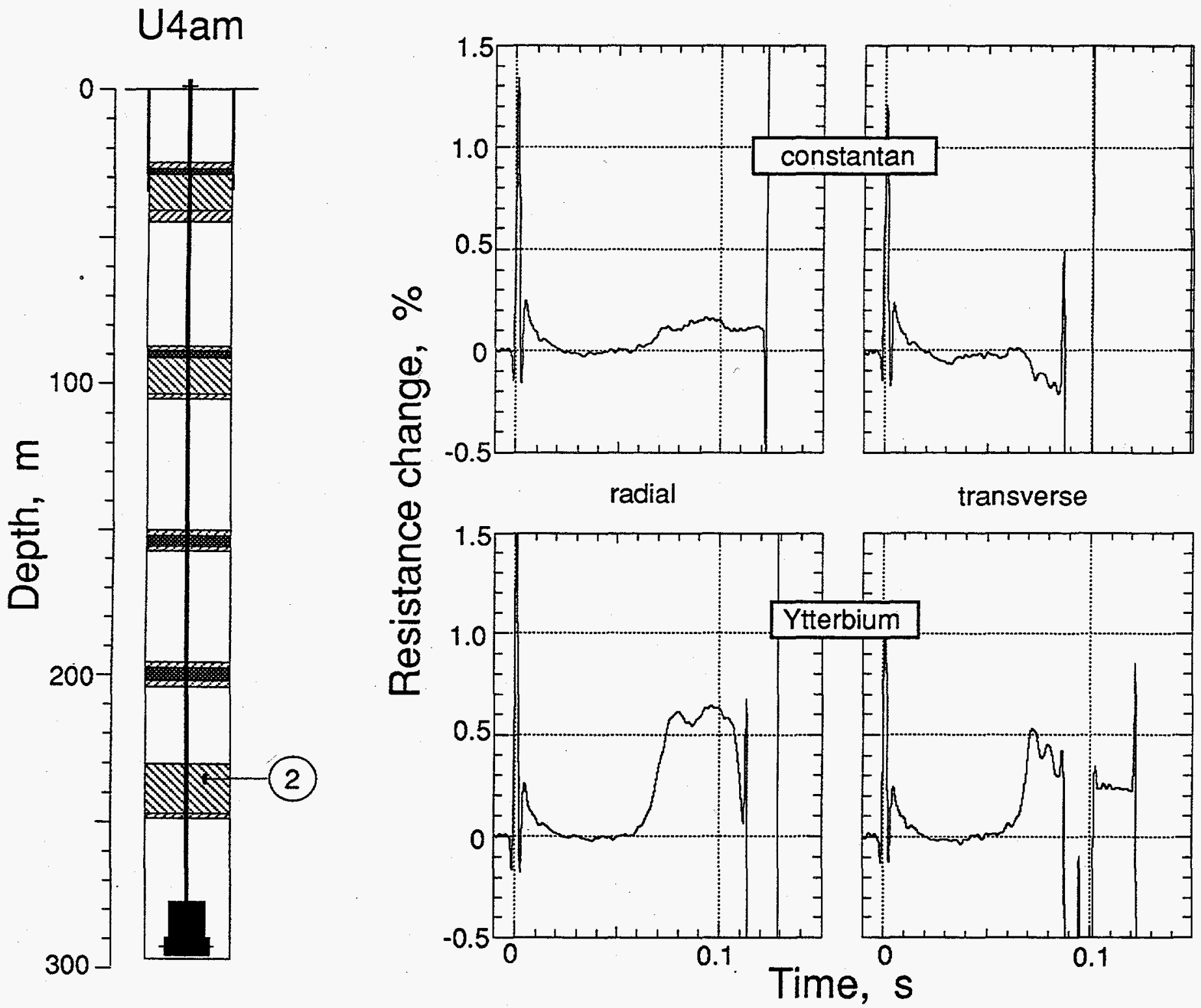

Figure 4.5 Bi-axial stress and strain in the deepest GFA plug at a depth of $236.2 \mathrm{~m}$ (station 2). Ytterbium data are NOT corrected for strain 

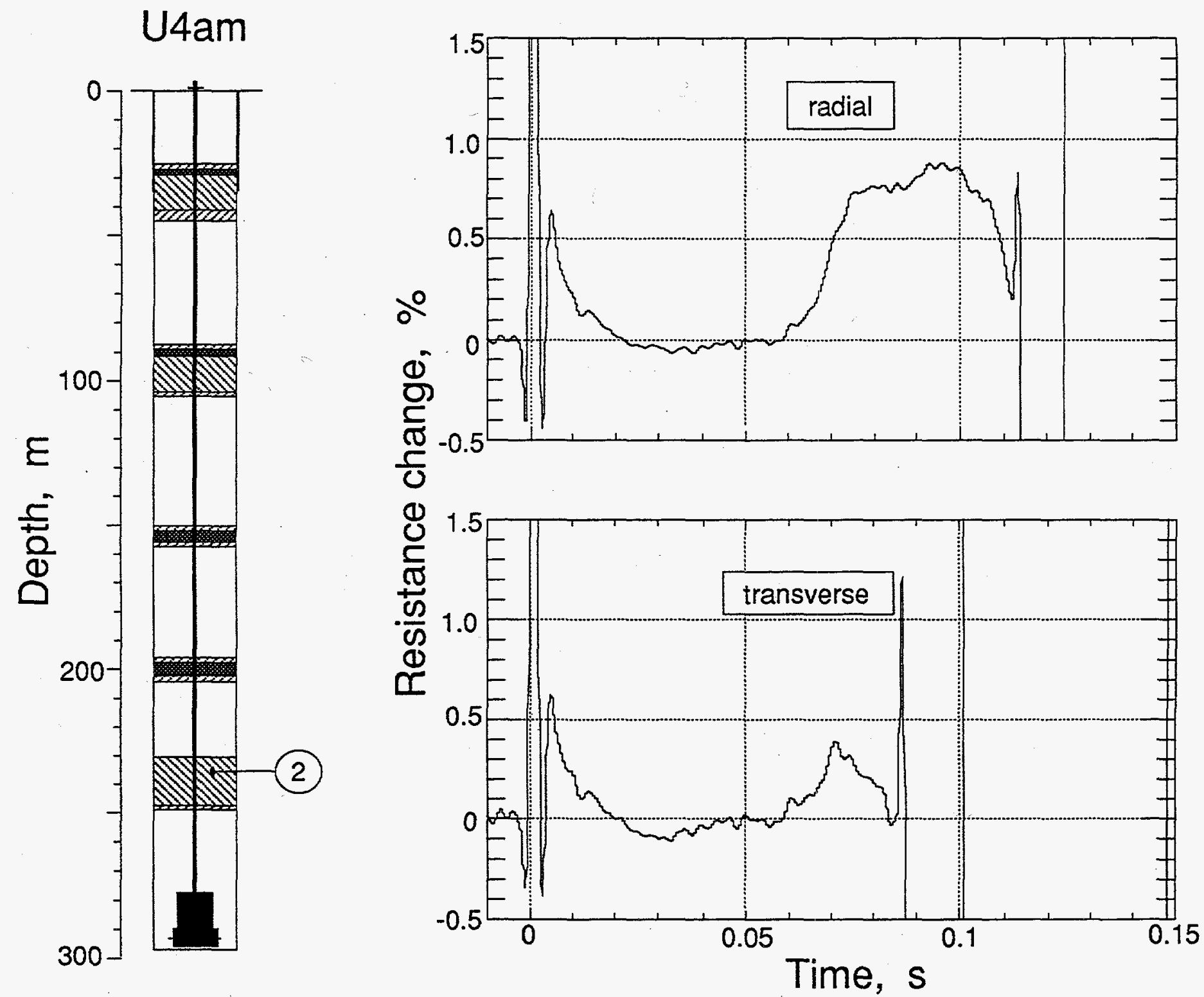

Figure 4.6 Bi-axial stress and strain in the deepest GFA plug at a depth of $236.2 \mathrm{~m}$ (station 2). Stress data are corrected for strain. 


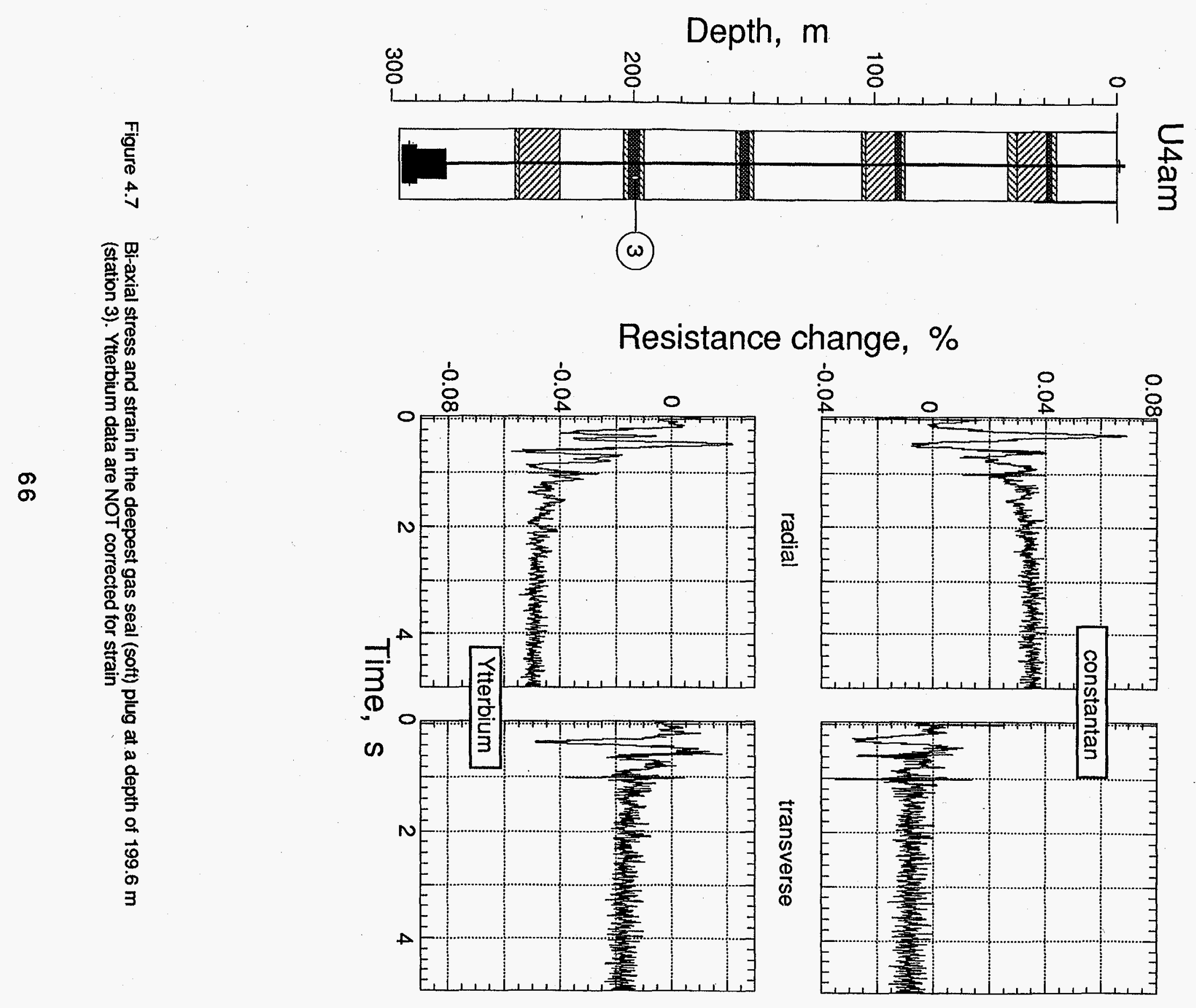



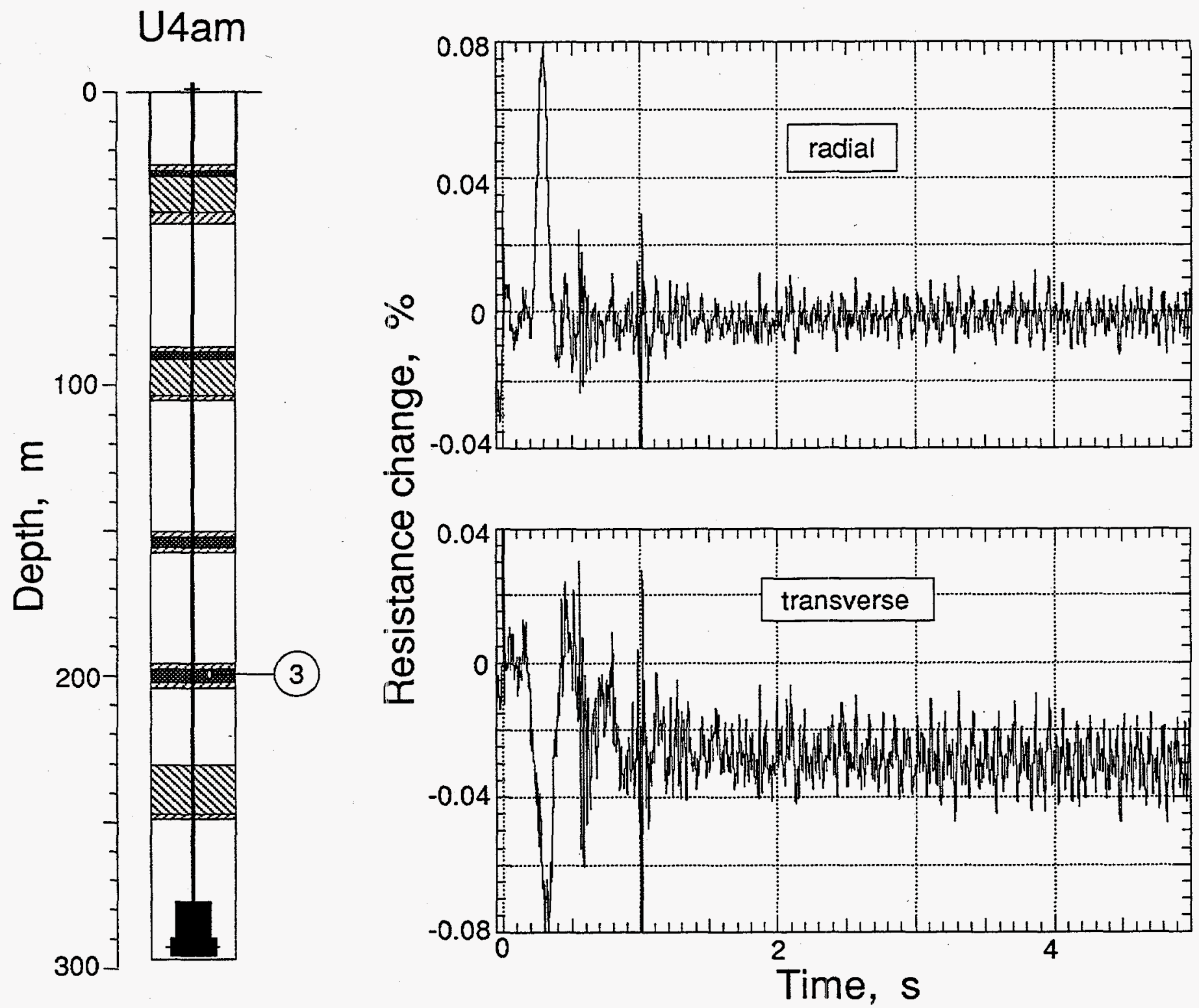

Figure 4.8 Bi-axial stress and strain in the deepest gas seal (soft) plug at a depth of $199.6 \mathrm{~m}$ (station 3). Stress data are corrected for strain. 


\section{References}

1. Stephen R. Clark, "U4am Site Characteristics Report," CP 84-99, Lawrence Livermore National Laboratory, Livermore, CA, September 26, 1984.

2. Alfred E. Burer, "Emplacement and Containment Report for VILLE U4am," Holmes \& Narver, NTS:A2:85-35, June 10, 1985.

3. LLNL contacts for additional information: H. Goldwire and R. E. Heinle (CORTEX and SLIFER data)

4. William G. Webb, "Special Measurements Final Engineering Report VILLE, U4am", EG\&G, Energy Measurements, Las Vegas, NV, SM:85E-124-31, 30 September, 1985.

5. William G. Webb, "Special Measurements Physics/Instrumentation for VILLE, U4am", EG\&G, Energy Measurements, Las Vegas, NV, SM:84E-124-30, 8 August, 1985.

6. J. Kalinowski, T. Stubbs, L. Davies, and B. Hudson, "Recent stress gage developments", Range Commanders Council, Telemetry Group, 4-6 July, 1985, Monterey, California. 
Distribution:

LLNL

TID (11)

Test Program Library

Containment Vault

Burkhard, N.

Cooper, W

Denny, $M$.

Goldwire, $H$.

Heinle, R. (5)

Mara, G.

Moran, M. T.

Moss, W.

Patton, $\mathrm{H}$,

Pawloski, G.

Rambo, J.

Roland, $\mathrm{K}$.

Roth, B.

Valk, $T$.

Younker, L.

LANL

App, F.

Brunish, W.

Kunkle, T.

Trent, B.

\section{Sandia}

Chabai, A.

Smith, Carl W.
L-053

L-045

L-221

L-221

L-049

L-205

L-221

L-221

L-049

L-777

L-200

L-205

L-221

L-200

L-221

L-049

L-154

L-203

F-659

F-659

F-665

F-664

MS-1159

MS-1159
EG\&G/AVO

Brown, $T$.

Gilmore, L.

A-5

Hatch, $M$.

A-1

Still, G.

Stubbs, T.

A-5

A-5

A-5

EG\&G/NVO

Bellow, B.

N 13-20

Davies, L.

N 13-20

Moeller, A.

N 13-20

Robinson, R.

N 13-20

Webb, W.

$N$ 13-20

\section{DNA}

Ristvet, B.

\section{S-Cubed}

Peterson, E.

Eastman Cherrington Environment

1640 Old Pecos Trail, Suite H

Santa Fe, NM 87504

Keller, C. 